\title{
33. GEOCHEMISTRY OF TETRAPYRROLE, CAROTENOID, AND PERYLENE PIGMENTS IN SEDIMENTS FROM THE SAN MIGUEL GAP (SITE 467) AND BAJA CALIFORNIA BORDERLAND (SITE 471), DEEP SEA DRILLING PROJECT LEG 631
}

\author{
J. William Louda and Earl W. Baker, Organic Geochemistry Group, College of Science, \\ Florida Atlantic University, Boca Raton, Florida
}

\section{INTRODUCTION}

Twenty-one core samples from DSDP/IPOD Leg 63 were analyzed for products of chlorophyll diagenesis. In addition to the tetrapyrrole pigments, perylene and carotenoid pigments were isolated and identified.

The 16 core samples from the San Miguel Gap site (467) and the five from the Baja California borderland location (471) afforded the unique opportunity of examining tetrapyrrole diagenesis in clay-rich marine sediments that are very high in total organic matter.

The chelation reaction, whereby free-base porphyrins give rise to metalloporphyrins (viz., nickel), is well documented within the downhole sequence of sediments from the San Miguel Gap (Site 467). Recognition of unique arrays of highly dealkylated copper and nickel ETIO-porphyrins, exhibiting nearly identical carbonnumber homologies (viz., C-23 to C-30; mode $=\mathrm{C}-26$ ), enabled subtraction of this component (thought to be derived from an allochthonous source) and thus permitted description of the actual in situ diagenesis of autochthonous chlorophyll derivatives.

Pigment-yield data, as a function of organic carbon, coupled with the unique arrays of copper and nickel ETIO-porphyrins, have further substantiated the likelihood of a pre-oxidized terrestrial source (cf., Palmer and Baker, 1978) for these pigments.

Sediments from the Baja California borderland (Site 471) yielded nickel porphyrin assemblages that had undergone losses of the keto and carboxylic acid moieties with increased sediment depth.

Vanadyl porphyrins were found to be present, in an extractable form, only in deepest sediments from the San Miguel Gap suite (1,035 m sub-bottom depth: Section 467-110-3).

Perylene, quite abundant in Leg 63 samples, was investigated in order to ascertain the usefulness of this $\mathrm{PAH}$ (polyaromatic hydrocarbon) compound as a source indicator parameter (cf., Aizenshtat, 1973; Simoneit, 1978). A direct correlation between possible terrestrial sources of dealkylated $\mathrm{Cu} / \mathrm{Ni}$ ETIO-porphyrins (cf., Palmer and Baker, 1978) and perylene (cf., Aizenshtat, 1973) - as indicated by the presence or absence and concentration of the latter-was not found. As a result of these studies, however, a potentially more useful role

\footnotetext{
${ }^{1}$ Initial Reports of the Deep Sea Drilling Project, Volume 63.
}

for perylene, and homologues, is proposed: the role of diagenetic-geothermal history indicator. That is, as depth of burial and in situ sediment temperature increased, the proportion of C-21, C-22, and C-23 alkylated derivatives of perylene (C-20) increased. On the basis of sediment depth and thermal profiles, the alkylperylenes were found to be generated prior to the appearance of nickel porphyrin homologues above C-32 and the release or formation of the vanadyl pigments. Alkylation of perylene within DSDP/IPOD sample suites has previously been mentioned (Brassell et al., 1980).

$\beta$-Carotene was found to be present in Site 467 upper Pliocene and Quaternary sections (viz., 467-18-5 and 467-8-5, respectively). The presence of intact carotenoids correlates precisely with a large increase in the yield of tetrapyrrole pigments per organic carbon unit and suggests favorable (viz., anoxic) depositional conditions for the preservation of autochthonously produced organics during the period.

Throughout our continued studies of tetrapyrrole diagenesis in DSDP and IPOD core samples, attempts are made to relate the diagenesis of chlorophyll to the geochemical histories of these pigments. Primarily because of in situ thermal measurements obtained onboard by DSDP scientists, we are now able to correlate these processes directly to geothermal histories. Comparison of Leg 63 results to various past studies is included herein.

\section{MATERIALS AND METHODS}

Recently, slight modifications and a few major additions in the analyses of the various pigments have been made; an updated scheme is presented in Figure 1.

Previously core samples were extracted repeatedly with acetone: methanol $(9: 1$, volume to volume, $v / v)$ until no further pigment was extracted. Because of the organic richness of these samples, after 12 extractions (see Fig. 2) the extracting solvent was then changed to benzene. Extraction with benzene appeared to release larger quantities of porphyrins that were in some manner passively bound and not extracted with the acetone: methanol mixture. Benzene or benezene:acetone $(1: 1, v / v)$ extraction following dehydration and extraction with the usual acetone:methanol mixture has now become routine in our studies.

Following extraction, pooled extracts were evaporated in vacuo, dissolved in minimal benzene, diluted with ethyl ether, and washed successively with brine and distilled water (Fig. 1). The ethereal organic layer from liquid:liquid separation was evaporated, the residue dissolved in a known volume of deperoxided tetrahydrofuran (THF), and the electronic spectrum of the "crude" extract recorded. Gel-permeation chromatography (GPC), over Sephadex LH-20 ${ }^{R}$ with 


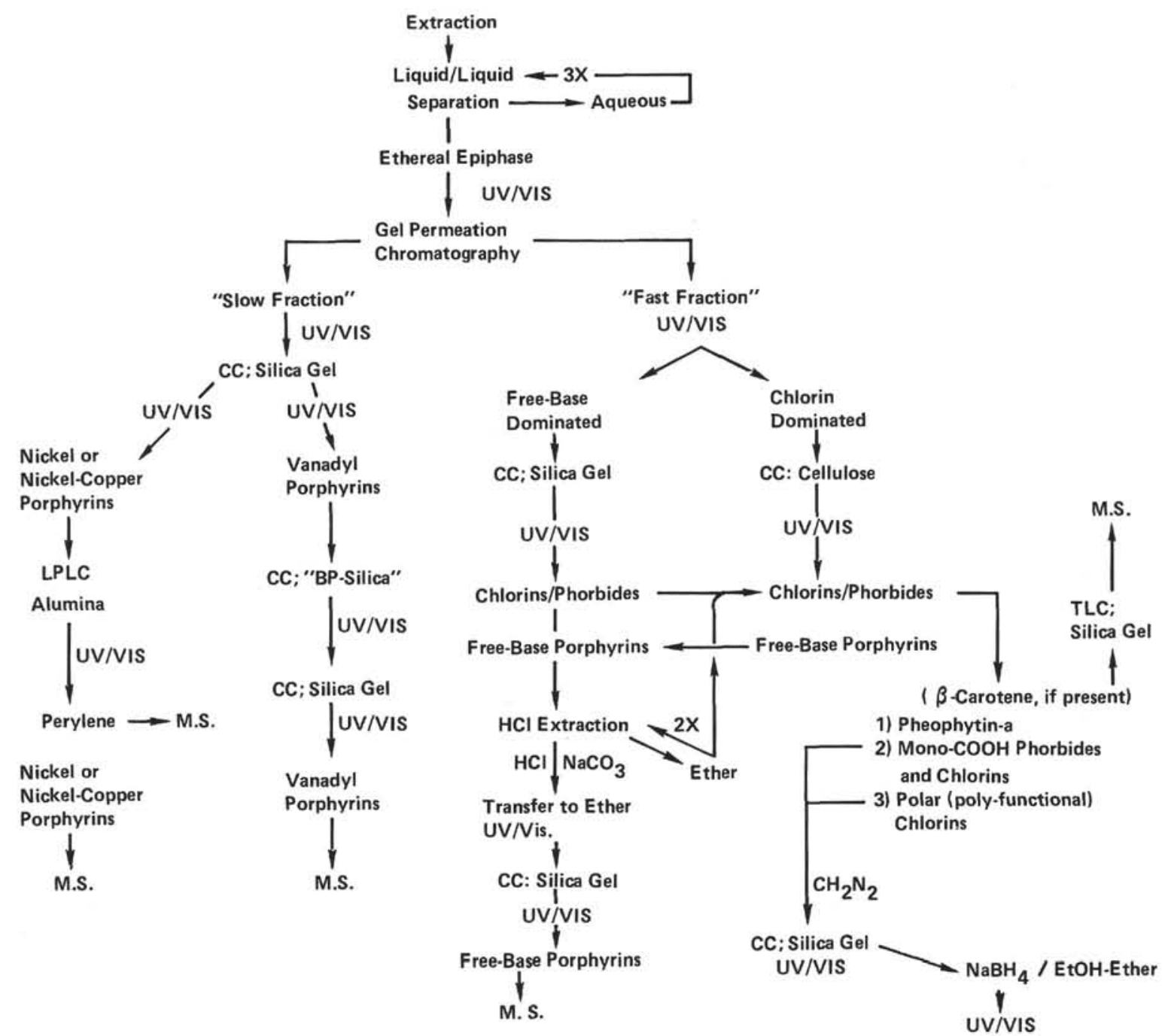

Figure 1. Separation and identification scheme utilized in studies of DSDP/IPOD Leg 63 samples (analyses of tetrapyrrole, perylene, and carotenoid pigments). $(C C=$ column chromatography, UV/VIS $=$ electronic spectroscopy, LPLC $=$ lowpressure, high-performance liquid chromatography, TLC = thin-layer chromatography.)

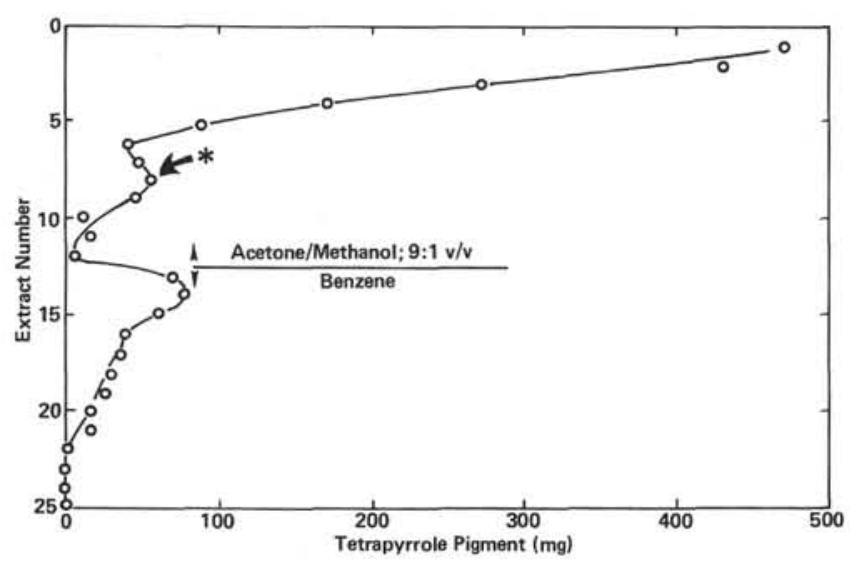

Figure 2. Plot of tetrapyrrole pigment yield as a function of extraction 8-5 number and solvent ${ }^{*}$ indicates an overnight period during which sediment was in the solvent of extract number seven).
THF as the mobile phase, served to remove large molecular-weight compounds above the exclusion limit (ca. 4,000 daltons) of the gel while retarding remaining salts and lower (ca. $<150$ daltons) molecular-weight organics. Most often tetrapyrrole pigments are collected as two or three fractions, representing "slow" or "fast" moving fractions. Chlorins/phorbides and free-base porphyrins freely migrate ("fast") and thus become relatively well separated from the metalloporphyrins ("slow"). As discussed later, in mixtures containing highly dealkylated $\mathrm{Ni}$ and $\mathrm{Cu}$ ETIO-porphyrins, an increased retardation of these compounds, most likely due to open $\beta$-positions, was also found. Each GPC fraction was next assessed for quality and quantity of tetrapyrrole pigments via electronic spectroscopy (i.e., UV/VIS of Fig. 1). At this point, chlorin-dominated fractions were chromatographically separated over microcrystalline cellulose, free-base or metalloporphyrin isolates over silica gel, and in each case increasing percentages of acetone in petroleum ether $\left(30-60^{\circ} \mathrm{C}\right)$ were used for development. Polar chlorins, potentially containing carboxylic acid and hydroxyl groups, were esterified with diazomethane $\left(\mathrm{CH}_{2} \mathrm{~N}_{2}\right)$ and rechromatographed over silica gel.

Hydrocarbon carotenoids, such as $\beta$-carotene, eluted prior to pheophytin-a from the initial cellulose chromatography, were purified via thin-layer chromatography (TLC) on silica gel and identified via electronic and mass-spectrometric determination. 
Free-base porphyrins, acid and nonacid types, were semipurified via extraction of an ethereal solution with $1.5 \% \mathrm{HCl}(\mathrm{W} / \mathrm{V}) . \mathrm{HCl}$ extraction was repeated until no further porphyrin dication fluorescence was detectable in the hypophase (minimally three times). Partially purified free-base porphyrins were then transferred to diethyl ether via neutralization of the aqueous acid with sodium carbonate. The freebase porphyrin isolate was then purified by silica gel chromatography, acid fractions esterified, and the pigments identified via electronic and mass-spectral characteristics.

Metalloporphyrins, present in the "slow" GPC fraction(s), were separated into $\mathrm{Ni}$ or $\mathrm{Ni}-\mathrm{Cu}$ and vanadyl fractions via liquid chromatography over silica gel. Vanadyl porphyrins, in toluene, were next passed through a column of "BP functionalized Silica" (Reg. U.K. Patent Office \#2030-564), which served to remove interfering nitrogenous bases and thus lowered the subsequent mass spectral background (see Barwise and Whitehead, 1980; in press). Rechromatography over standard silica gel, if required, provided a vanadyl porphyrin isolate sufficiently pure for characterization via electronic and mass spectrometry.

Metalloporphyrin arrays consisting of nickel or nickel plus copper chelates, initially isolated by conventional silica gel column chromatography, were purified by low-pressure liquid chromatography (LPLC; see Fig. 1) over aluminum oxide (Grade II-III). The LPLC system consists of a 6-position solvent selection switch (Rheodyne \#5011; Ranin Instrument Co., Woburn, Mass.), a 0-300 psig explosion-proof 72 -pulse/min sinusoidal-delivery laboratory pump (Fluid Metering Inc., Ace Glass Inc., Vineland, New Jersey), a 0-400 psig pressure gauge, an $8-\times-85-\mathrm{mm}$ solvent pre-column packed with silica gel and glass wool, and an $8-\times-250-\mathrm{mm}$ chromatographic column with on-column injection (Michel-Miller system; Ace Glass, Vineland, New Jersey). Detection of pigments was via a variablewavelength (200-700 nm) monitor (Spectro-Monitor II, Laboratory Data Control, Riviera Beach, Florida), which had been preset to the position of maximal Soret absorption, in the case of porphyrin analyses. Metalloporphyrins were first dissolved in 1 to 2 drops benzene, diluted with ca. $0.5 \mathrm{ml}$ petroleum ether $\left(30-60^{\circ} \mathrm{C}\right)$ or cyclohexane, and injected onto the column at low pressure and flow (ca. $20 \mathrm{psig}, 2 \mathrm{ml}$ $\mathrm{min}^{-1}$ ) of $1.5 \%$ acetone in petroleum ether. Development, possible to follow visually through the glass column, and elution are manually controlled with stepwise gradients at higher pressures and flow rates (e.g., 100-175 psig, 10-15 ml min ${ }^{-1}$ ). Nickel or nickel-copper porphyrin arrays were eluted with $3.5 \%$ or $5.0 \%$ acetone in petroleum ether, depending upon the completeness of separation achieved from the less polar hydrocarbons and PAH compounds (e.g., perylene, Fig. 3 ). The resultant chromatogram (see Fig. 3), allowed collection of the entire metalloporphyrin eluate and enabled precise determination of the extent of fraction tailing, rather than obtaining merely "heartcuts." The collection of the "tail" of metalloporphyrin fractions was extremely important, because a large amount of the C-22 to C-26 ETIO-porphyrin chelates were found to exhibit relatively higher chromatographic polarities, as compared to the more fully alkylated DPEP and ETIO-series. Comparison of the elution profiles of a geologic nickel DPEF/ETIO array (Section 467-58-3) and authentic C-32 Ni DPEP is presented as part of Figure 3

The purified $\mathrm{Ni}$ or $\mathrm{Ni}-\mathrm{Cu}$ porphyrin isolates were then characterized by electronic and mass spectrometry, as was perylene, which was isolated via the same analytical route.

Chlorins, phorbides, and porphyrins thought to contain conjugated carbonyl-groups (e.g., 9-keto) were treated with sodium borohydride in ethyl ether containing $1 \%$ ethanol (cf., Baker and Louda, 1980; Holt, 1959).

Methyl esterification of suspected carboxylic tetrapyrrole pigments was performed by treating the isolate with diazomethane in base-free ethyl ether as described previously (Louda et al., 1980).

Electronic absorption spectra were recorded on a Perkin-Elmer model 575 instrument coupled to a Perkin-Elmer model C570-0729 derivative function accessory utilized in the precise location of absorption maxima of both resolved and unresolved mixtures.

Mass spectra were recorded with a DuPont 491-B instrument as described previously (Baker et al., 1978a). Volatilization of perylene and free-base or metalloporphyrins was accomplished by carefully raising the probe temperature until any and all interfering contaminants (i.e., lower molecular weight) were distilled. Spectra were then recorded at $12 \mathrm{eV}(50 \mu \mathrm{A}$ filament current) over the entire volatilization range of

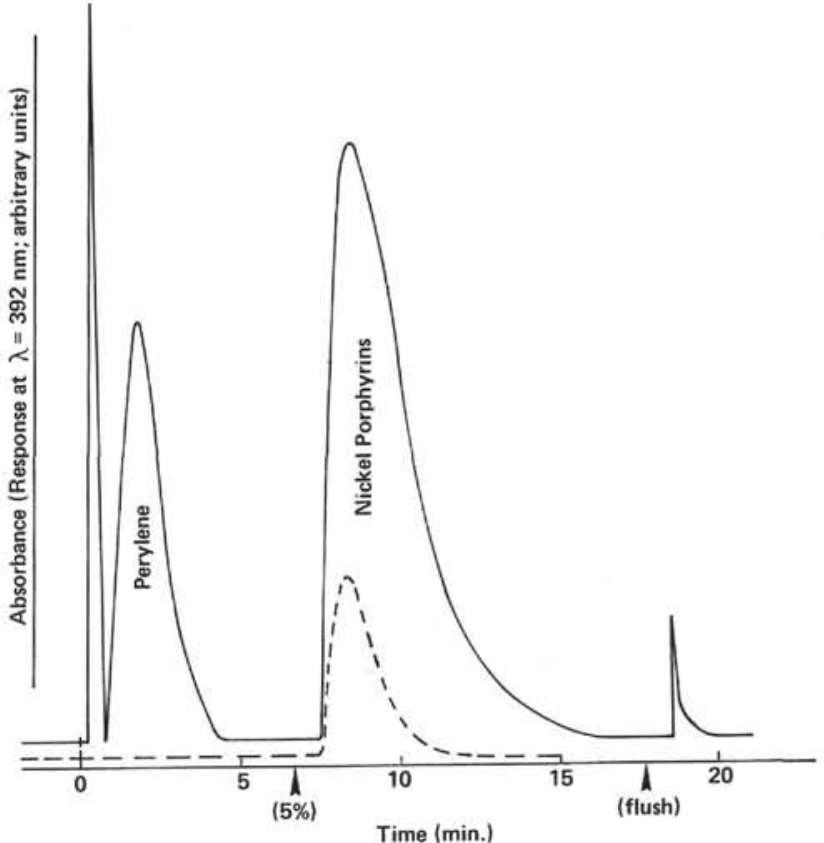

Figure 3. Low-pressure liquid chromatogram of nickel porphyrins isolated from Section 467-58-3 (solid trace); authentic nickel DPEP (C-32) is presented for comparison (dashed trace). (Column and conditions are given in Fig. 13;5\% refers to the time of stepped gradient from petroleum ether [PE] to $5 \%$ acetone in $\mathrm{PE}$.)

the sample. All scans yielding molecular ions were then compiled, normalized, and corrected for overlapping isotopic contributions due to $\mathrm{C}^{13}, \mathrm{H}^{2}$, and the isotopes of nickel or copper (cf., Tables 3 and 4 , footnotes). Mass spectra of carotenoids (viz., $\beta$-carotene) were determined by initially slow distillation of contaminant at probe temperatures less than $100^{\circ} \mathrm{C}$ (e.g., ca. $1 \mathrm{~min}$ ) followed by rapid volatilization of the thermally labile polyene pigments at ca. $250^{\circ} \mathrm{C}$ to $265^{\circ} \mathrm{C}$. Source $(S)$ and probe $(P)$ temperatures $\left({ }^{\circ} \mathrm{C}\right)$ utilized during the mass spectrometric characterization of the various compounds isolated from Leg 63 core samples were: perylene $\left(S=110-160^{\circ} \mathrm{C} P=\right.$ $\left.100-150^{\circ} \mathrm{C}\right), \beta$-carotene $\left(S=275^{\circ} \mathrm{C} ; P=250-265^{\circ} \mathrm{C}\right)$, free-base porphyrins $\left(S=265-310^{\circ} \mathrm{C} ; P=245-290^{\circ} \mathrm{C}\right)$, nickel porphyrins $(S=$ 290-350 $\left.{ }^{\circ} \mathrm{C} ; P=275-325^{\circ} \mathrm{C}\right)$, nickel-copper porphyrin mixtures $(S=$ $\left.270-325^{\circ} \mathrm{C} ; P=260-305^{\circ} \mathrm{C}\right)$, and vanadyl porphyrins $(S=$ $290-350^{\circ} \mathrm{C} ; P=270-320^{\circ} \mathrm{C}$ ). In each case, following the disappearance of the sample, the probe temperature was rapidly raised an additional $100^{\circ} \mathrm{C}$ to $150^{\circ} \mathrm{C}$ in order to assure complete volatilization of each isolate class.

Quantitation of pigments was based upon electronic absorption spectroscopy in ethyl ether using the following extinction coefficients: chlorins, $\alpha=63.71 \cdot \mathrm{g}^{-1} \cdot \mathrm{cm}^{-1}$ at $667 \mathrm{~nm}$ (pheophytin-a); free-base porphyrins, $\Sigma \mathrm{m} M=6.54$ at $619 \mathrm{~nm}(\mathrm{DPE} \cdot \mathrm{ME})$; nickel and nickelcopper porphyrins, $\Sigma \mathrm{m} M=34.82$ at $550 \mathrm{~nm}$ (NiMeso-IX DME); vanadyl porphyrins, $\Sigma \mathrm{m} M=26.14$ at $570 \mathrm{~nm}$ (V $=0$ Meso-IX DME); perylene, $\log \Sigma=4.56$ at $434 \mathrm{~nm} ; \beta$-carotene, $\mathrm{E}_{\mathrm{lcm}}^{1 \%}=2505$ at $450 \mathrm{~nm}$.

During isolation of the free-base porphyrins from Section 467 $41-4$, a unique artifact was formed. The entire free-base isolate from this sample was found to have been converted to a zinc chelate. The chelation of zinc appears to have taken place following exposure to trace zinc salts in the sodium carbonate used for neutralization of the aqueous acid solution. Evaluation of laboratory notes showed that this sample was exposed to fresh dilute $\mathrm{HCl}$ in the presence of sodium carbonate. This was necessary, because the aqueous pigment solution was found to be basic following the addition of more sodium carbonate than required to titrate to neutrality. The mass spectral distribution of the original free-base porphyrins isolated from Section 467 41-4 was therefore calculated utilizing the known abundances of zinc isotopes (cf., Table 3). 


\section{RESULTS}

\section{Tetrapyrrole Pigments}

Table 1 describes samples analyzed from Leg 63 and the yields of tetrapyrrole pigments obtained. Total yield of tetrapyrrole pigments is presented on a sediment dry weight basis, which allows more valid comparison to other studies, such as the highly compacted sediments reported from the Japan Trench transect (DSDP/IPOD Leg 57; Baker and Louda, 1980).

\section{Pigment Yield}

The relation of intact chlorophyll derivatives to sedimentary organic carbon has been proposed as a method of determining the relative retention or removal of tetrapyrrole pigments from the fossil record (Louda et al., 1980). In our studies this has been quantitated by definition of the pigment yield index, PYI (PYI equals the value obtained by dividing the total yield of tetrapyrrole pigment [in $\mu \mathrm{g} / \mathrm{g}$ sediment] by the per cent organic carbon of the sediment, both values having been corrected to the dry weight of sediment), and plotting the values obtained versus the depth of burial (cf., Baker and Louda, 1980). Figure 4 is the plot of PYI versus subbottom depth obtained for the San Miguel Gap sediment sample suite.

Though we shall discuss Figure 4 later, two regions of relatively high tetrapyrrole pigment preservation (i.e., PYI > 4.0) can be noted as occurring at 70 to 165 meters (Quaternary-upper Pliocene) and 588 to 691 meters (upper Miocene). These zones of high pigment preservation are separated by an approximate 420 meter interval in which intact chlorophyll derivatives are much less prevalent in the organic matter. This intervening zone corresponds to the region of fastest sediment accumulation, presumed to have been caused by rapid influxes of terrestrial detritus (see Site 467 report, this volume), and to the occurrence of highly dealkylated copper and nickel ETIO porphyrins, suggested markers of reworked terrestrial organics in marine sediments (cf., Palmer and Baker, 1978). As discussed later, the lower PYI values obtained from the deeper Miocene sections of Site 467 appear more directly related to the thermal-thermocatalytic reactions of late chlorophyll diagenesis and catagenesis.

Table 2 summarizes the per cent composition of the tetrapyrrole pigment arrays isolated from IPOD Leg 63 sediment samples. Though we routinely consider three main classes of tetrapyrrole pigments (viz., chlorins/ phorbides, free-base porphyrins, and metalloporphyrins), chlorin-641, designated on the basis of the position (i.e., $641 \mathrm{~nm}$ ) of maximal band I electronic absorption, has been separated from other chlorins and phorbides. This has been done because of an apparent correlation with free-base porphyrins, discussed later.

\section{Phorbides, Chlorins}

On the basis of the pigment characteristics described in early studies (cf., Baker et.al., 1978a and b; Louda et al., 1980) and analyses performed during the present examination of Leg 63 core samples, it is imperative to reiterate the prima facie difference between phorbides

Table 1. Sample description and tetrapyrrole pigment yields for DSDP/IPOD Leg 63 samples.

\begin{tabular}{|c|c|c|c|c|c|c|c|c|}
\hline $\begin{array}{l}\text { Sample } \\
\text { (interval in } \mathrm{cm} \text { ) }\end{array}$ & $\begin{array}{l}\text { Sub-bottom } \\
\text { Depth } \\
\text { (m) }\end{array}$ & Chronostratigraphy $^{\mathrm{a}}$ & Lithologic Description ${ }^{\mathrm{a}}$ & $\begin{array}{l}\text { Organic } \\
\text { Carbonb } \\
\text { (\% dry wt.) }\end{array}$ & $\begin{array}{l}\text { Wet-Water } \\
\text { Content }{ }^{\mathrm{c}} \\
(\% \pm 1)\end{array}$ & $\begin{array}{l}\text { Tetra } \\
\text { Pigment } \\
\text { wet wt. }\end{array}$ & $\begin{array}{l}\text { yrrole } \\
(\mu \mathrm{g} / \mathrm{g})^{\mathrm{d}} \\
\text { dry wt. }\end{array}$ & $\begin{array}{l}\text { PYI, } \\
\text { drye }\end{array}$ \\
\hline $467-3-3,100-130$ & 19.5 & Quaternary & Olive gray diatomaceous silty clay & 1.2 & 45.9 & 1.08 & 2.00 & 1.66 \\
\hline $467-8-5,100-134$ & 70.0 & Quaternary & $\begin{array}{l}\text { Gray olive nanno-diatomaceous clay and } \\
\text { foraminiferal rich quartzose sand }\end{array}$ & 1.9 & 34.0 & 5.23 & 7.92 & 4.17 \\
\hline $467-13-4,100-132$ & 116.0 & Upper Pliocene & Olive gray calcareous clay & $2.9 \mathrm{x}$ & 54.4 & 6.65 & 14.58 & 5.03 \\
\hline $467-18-5,100-130$ & 165.0 & Upper Pliocene & Olive gray siliceous silty clay & 3.4 & 48.0 & 7.90 & 15.19 & 4.47 \\
\hline $467-25-6,100-131$ & 233.0 & Upper Pliocene & $\begin{array}{l}\text { Olive gray foraminiferous quartzose- } \\
\text { feldspathic sandy silt }\end{array}$ & 1.7 & 34.4 & 1.62 & 2.47 & 1.45 \\
\hline $467-32-2,100-135$ & 293.5 & Lower Pliocene & Olive gray nanno-clay & 2.9 & 34.2 & 1.85 & 2.81 & 0.97 \\
\hline $467-36-2,100-133$ & 340.5 & Lower Pliocene & Olive gray nanno-silty clay & 2.7 & 35.8 & 3.96 & 6.12 & 2.27 \\
\hline $467-41-4,100-135$ & 382.0 & Lower Pliocene & Olive gray nanno-claystone & $3.0 \mathrm{x}$ & 33.8 & 2.94 & 4.44 & 1.48 \\
\hline $467-48-2,100-132$ & 445.5 & Upper Miocene & Olive gray silty claystone & 4.6 & 40.7 & 6.96 & 11.74 & 2.55 \\
\hline $467-58-3,142-148$ & 542.0 & Upper Miocene & Olive gray (olive brown) calcareous claystone & $4.4 \mathrm{x}$ & 20.6 & 4.55 & 5.73 & 1.30 \\
\hline $467-63-2,118-125$ & 588.0 & Upper Miocene & $\begin{array}{l}\text { Mottled olive gray brown calcareous claystone } \\
\text { and quartzose-feldspathic sandstone }\end{array}$ & $5.2 \mathrm{x}$ & 20.8 & 30.35 & 38.32 & 7.37 \\
\hline $467-74-1,145-150$ & 691.0 & Upper Miocene & $\begin{array}{l}\text { Olive gray clayey nanno-chalk with } \\
\text { locally darker laminae }\end{array}$ & $2.9 \mathrm{x}$ & 25.4 & 29.19 & 39.13 & 13.49 \\
\hline $467-85-4,100-130$ & 800.0 & Middle Miocene & Gray calcareous claystone and lithic tuff & 0.7 & 25.2 & 0.36 & 0.48 & 0.69 \\
\hline $467-91-2,100-107$ & 854.0 & Middle Miocene & Olive gray clayey nanno-chalk & 2.3 & 12.2 & 5.33 & 6.07 & 2.64 \\
\hline $467-97-2,113-118$ & 911.0 & Middle Miocene & Olive gray calcareous claystone & 1.9 & 15.3 & 1.47 & 1.74 & 0.96 \\
\hline $467-110-3,9-14$ & $1,035.0$ & Middle Miocene & Olive gray calcareous silty claystone & 0.9 & 8.2 & 2.22 & 2.42 & 2.69 \\
\hline $471-3-2,100-130$ & 21.5 & Quaternary & Grayish olive nanno-silty clay & 0.8 & 59.4 & 0.24 & 0.59 & 0.74 \\
\hline $471-8-4,100-135$ & 72.0 & Upper Miocene & Greenish gray clayey diatomaceous ooze & $1.1 \mathrm{x}$ & 56.4 & 1.81 & 4.15 & 3.77 \\
\hline $471-34-2,107-115$ & 316.0 & Upper Middle Miocene & Grayish olive silty claystone & 0.7 & 26.4 & 0.27 & 0.37 & 0.53 \\
\hline $471-50-2,100-125$ & 468.0 & Middle Miocene & Olive gray silty claystone with silty sand & 0.9 & 20.2 & 0.13 & 0.16 & 0.18 \\
\hline $471-69-3,125-150$ & $\begin{array}{c}650.0 \\
\text { (basement } \\
741 \text { meters) }\end{array}$ & Middle Miocene & Olive gray silty claystone & 0.8 & 15.1 & 0.58 & 0.68 & 0.85 \\
\hline
\end{tabular}

a Sites 467 and 471 reports, this volume.

b DSDP grain size-Carbon/carbonate Lab, Scripps Institute of Oceanography, La Jolla, California. "x" refers to extrapolation from two adjacent samples.

c Determined by drying at $106^{\circ} \mathrm{C}$ for $18-24 \mathrm{hrs}$. and repeated to constant dry weight.

d Calculated by summing yields after initial Sephadex LH-20 and Silica Gel chromatographic separations. Amounts determined via electronic spectroscopy in ethyl ether solvent. Chlorins, $\alpha=63.7$ at $667 \mathrm{~nm}$ for pheophytin-a; free-base porphyrins $\Sigma \mathrm{m} M=6.54$ at $619 \mathrm{~nm}$ for deoxophylloerythrin; nickel and copper porphyrins, $\Sigma \mathrm{m} M$ $=34.82$ at $550 \mathrm{~nm}$ for NiDPEP; vanadyl porphyrins, $\Sigma \mathrm{mM}=26.14$ at $571 \mathrm{~nm}$ for $\mathrm{V}=\mathrm{O}$ DPEP.

e PYI, dry: pigment yield index defined as tetrapyrrole yield in $\mu \mathrm{g} / \mathrm{g}$ sediment, dry weight divided by $\%$ organic carbon, dry weight (cf., Baker and Louda, 1980). 


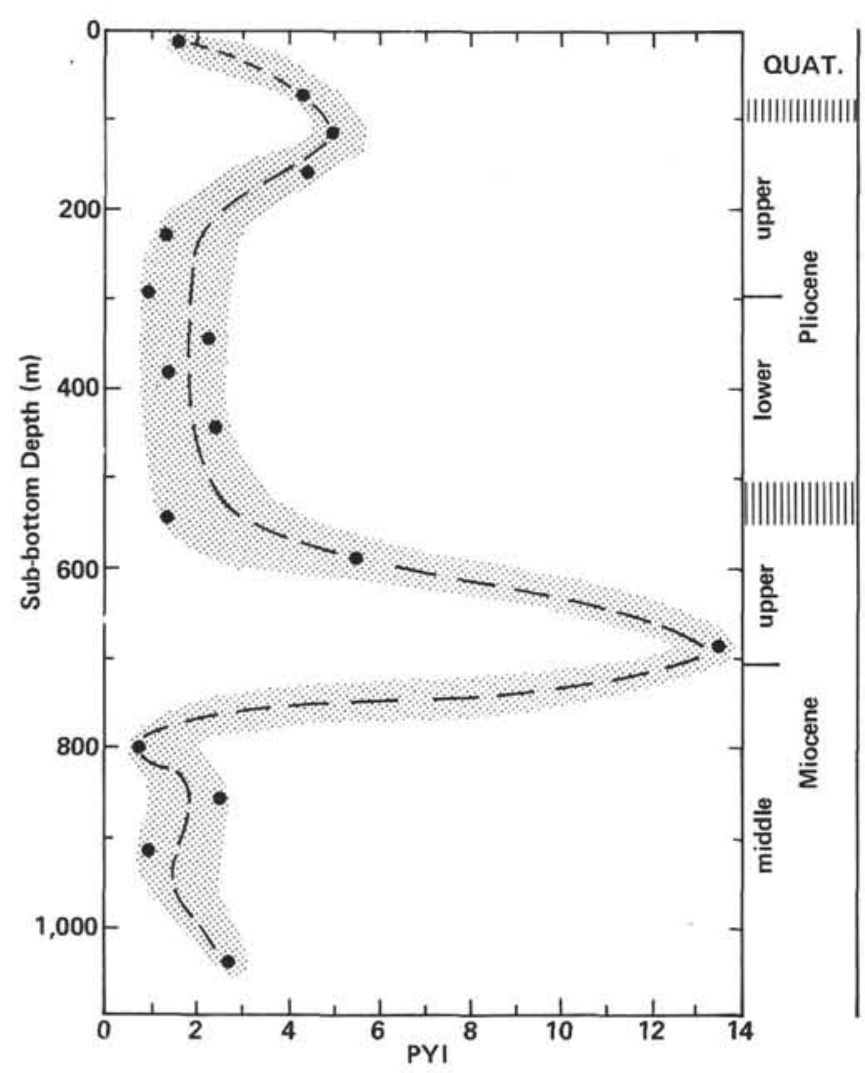

Figure 4. Plot of PYI (pigment yield index) versus sub-bottom depth for tetrapyrrole pigments isolated from sediments recovered at Site 467, San Miguel Gap. (PYI is defined as $\mu \mathrm{g}$ total tetrapyrrole pigments per $\mathrm{g}$ sediment divided by the percent organic carbon of that sediment, both taken on a dry weight basis.) and chlorins. In the past (cf., Baker and Palmer, 1978 and references therein) we, and others, routinely employed the term "chlorin" to describe any and all tetrapyrrole pigments of the dihydroporphyrin type that exhibit electronic spectra in which the red band (i.e., band I, $650-750 \mathrm{~nm}$ ) is of highest extinction, not including the Soret band. However, the application of the more sensitive techniques of mass-spectrometry (cf., Baker et al., 1978a) and improved electronic spectroscopy, coupled with specific functional analyses (cf., Baker and Louda, 1980, and herein), indicate that the presence or absence of the isocyclic ring (i.e., 6, $\gamma$-cycloethano) needs to be described. Thus the term "chlorin" is retained for dihydroporphyrins that lack the isocyclic ring or for pigments whose basic structure is unknown. Phorbide, on the other hand, is then used to describe dihydroporphyrin isolates for which the data suggest (or prove) the presence of an intact isocyclic ring. This is in line with accepted terminology (see Seely, 1966).

The diagenesis of chlorophyll, we feel, follows either an early oxidative route(s), generating chlorins and exhibiting rapid pigment loss rates, or a reductive pathway(s), yielding phorbides and eventually free-base and metalloporphyrins (cf., Baker and Louda, 1980).

Examination of the "chlorin/phorbide" fractions isolated from sediments obtained during Leg 63 has shown that the less deeply buried strata at Sites 467 and 471 are predominated by chlorins and a variety of more highly oxygenated chlorophyll derivatives believed to be purpurins.

Purpurins, by accepted nomenclature (cf., Bonnett, 1978; Seely, 1966), exhibit bathochromically shifted

Table 2. Percent composition of tetrapyrrole pigments isolated from DSDP/IPOD Leg 63 sections.

\begin{tabular}{|c|c|c|c|c|c|c|c|c|}
\hline \multirow[b]{2}{*}{ Section } & \multirow[b]{2}{*}{$\begin{array}{l}\text { Phorbides } \\
\text { Chlorins }^{\mathrm{a}}\end{array}$} & \multirow[b]{2}{*}{$\begin{array}{l}\text { Chlorin(s) } \\
641-643^{\mathrm{a}}\end{array}$} & \multirow[b]{2}{*}{$\begin{array}{l}\text { Free-Base } \\
\text { Porphyrins }{ }^{b}\end{array}$} & \multicolumn{5}{|c|}{ Metalloporphyrins } \\
\hline & & & & $\begin{array}{l}\text { Nickel Porphyrin } \\
\text { (phyllo-acid) }^{\mathrm{c}}\end{array}$ & $\begin{array}{l}\text { Nickel Porphyrin } \\
\text { (acid) }\end{array}$ & $\begin{array}{c}\text { Nickel } \\
\text { Porphyrins }\end{array}$ & $\begin{array}{c}\text { Copper-Nickel } \\
\text { Dealkylated ETIO's }\end{array}$ & $\begin{array}{l}\text { Vanadyl } \\
\text { Porphyrins }\end{array}$ \\
\hline $467-3-3$ & 98.0 & - & - & - & - & {$[1.0]$} & - & {$[1.0]$} \\
\hline $467-8-5$ & 19.5 & 24.4 & 55.5 & $(0.6)$ & - & - & - & - \\
\hline $467-13-4$ & 21.3 & 35.2 & 43.0 & $(0.5)$ & - & - & - & - \\
\hline $467-18-5$ & 30.7 & 5.5 & 63.5 & (0.3) & - & - & - & - \\
\hline $467-25-6$ & 58.6 & - & 29.8 & (2.3) & - & - & 9.2 & - \\
\hline $467-32-2$ & 19.8 & 19.7 & 32.1 & (2.5) & - & 2.0 & 23.9 & - \\
\hline $467-36-2$ & 11.6 & 32.6 & 32.8 & (1.3) & - & 3.7 & 18.0 & - \\
\hline $467-41-4$ & 7.1 & 14.9 & 48.9 & (1.3) & - & - & 27.8 & - \\
\hline $467-48-2$ & 9.7 & 18.2 & 44.3 & 4.4 & - & 4.6 & 18.9 & - \\
\hline $467-58-3$ & 7.7 & 12.9 & 48.0 & 2.9 & - & 9.5 & 18.9 & - \\
\hline $467-63-2$ & 2.0 & 14.6 & 65.5 & $(0.2)$ & - & 17.7 & - & - \\
\hline $467-74-1$ & - & 16.4 & 74.4 & - & - & 9.1 & - & - \\
\hline $467-85-4$ & - & 40.8 & 39.2 & - & - & 20.0 & - & - \\
\hline $467-91-2$ & - & - & - & - & - & 100.0 & - & - \\
\hline $467-97-2$ & - & - & - & - & - & 100.0 & - & - \\
\hline $467-110-3$ & - & - & - & - & - & 83.0 & - & 17.0 \\
\hline $471-3-2$ & 100.0 & - & - & - & - & - & - & - \\
\hline $471-8-4$ & 94.4 & 1.5 & 3.3 & - & - & 0.8 & - & - \\
\hline $471-34-2$ & - & - & - & 12.6 & 48.5 & 21.6 & 17.2 & - \\
\hline $471-50-2$ & - & - & - & - & 7.9 & 92.1 & - & - \\
\hline $471-69-3$ & - & - & - & - & - & 100.0 & - & - \\
\hline
\end{tabular}

${ }^{a}$ Determined via electronic spectroscopy using $\alpha=63.71 \cdot \mathrm{g}^{-1} \cdot \mathrm{cm}^{-1}$ for pheophytin-a, in ethyl ether solvent.

b As 1, using $\Sigma \mathrm{m} M=6.54$ at $619 \mathrm{~nm}$, with molecular weight of 476 amu for C-32 DPEP.

c As 1, using $\Sigma \mathrm{mM}=34.82$ at $583 \mathrm{~nm}$, with molecular weight of $590 \mathrm{amu}$ for C-32 Ni-phylloerythrin.

d As 1, using $\Sigma \mathrm{m} M=34.82$ at $550 \mathrm{~nm}$, with molecular weight of 576 amu for C-32 Ni-deoxophylloerythrin.

e As 1, using $\Sigma \mathrm{mM}=34.82$ at $550-557 \mathrm{~nm}$, with molecular weight of $532 \mathrm{amu}$ for C-32 Ni-DPEP.

f As 1, using $\Sigma \mathrm{mM}=26.14$ at $570 \mathrm{~nm}$, with molecular weight of $541 \mathrm{amu}$ for C-32 V=O-DPEP. 
band I absorption (i.e., red band to longer wavelengths) in electronic spectra due to additional auxochromic functional groups (e.g., conjugated carbonyl moieties). Figure 5, A is the electronic spectrum of a mixed isolate of monocarboxylic acid chlorins obtained from the Baja California borderland sediments originally at 21.5 meters sub-bottom depth (i.e., Sample 471-3-2, 100-130 $\mathrm{cm})$. Classification as monocarboxylic was based upon chromatographic behavior of these pigments on columns of microcrystalline cellulose, from which elution was achieved with $12 \%$ to $17 \%$ acetone in petroleum ether $\left(30-60^{\circ}\right)$ and by comparison to various known chlorin and phorbide free-acids.

The presence of a marked shoulder (ca., $690 \mathrm{~nm}$ ) on the low-energy side of the main band I absorption (i.e., $666 \mathrm{~nm}$ ) can be noted from examination of Figure 5, A. In the past (Louda et al., 1980) we have termed these pigments as "chlorins-690" or "altered chlorins." Recently we presented evidence that such pigments, isolated from Japan Trench sediments (DSDP/IPOD Legs 56-57; Baker and Louda, 1980; Louda et al., 1980), were, in fact, purpurin-18. In the present study we have applied second derivative electronic absorption spec- troscopy to such mixed chlorin isolates in order to establish the exact position of overlapping bands. Figure 5, B is the second derivative of the absorption spectrum presented in Figure 5, A. Through comparison to the known absorption of a holmium oxide standard, precise absorption maxima were then obtained. Indicated in Figure 5, B are two maxima, 538 and $696 \mathrm{~nm}$, which are highly indicative of purpurin-18. Purpurin-18 is a $6, \gamma$ diketo-lactone derivative of pheophorbide-a, and we believe this compound to be one of the major products of early oxidative chlorophyll diagenesis.

In general, the less deeply buried sediments from both the San Miguel Gap and Baja California borderland sites (i.e., Sections 467-3-3, 471-3-2, and 471-8-4) yielded tetrapyrrole pigment arrays dominated by chlorins and purpurins rather than by phorbides. Only traces of intact pheophytin-a could be isolated from these sediments.

Section 471-8-4 was found to contain an extremely complex array of chlorins and phorbides and is thought to represent the remnants of interacting oxic and anoxic early diagenesis. That is, it most likely contained an initial complement of diatom pigments, which, though

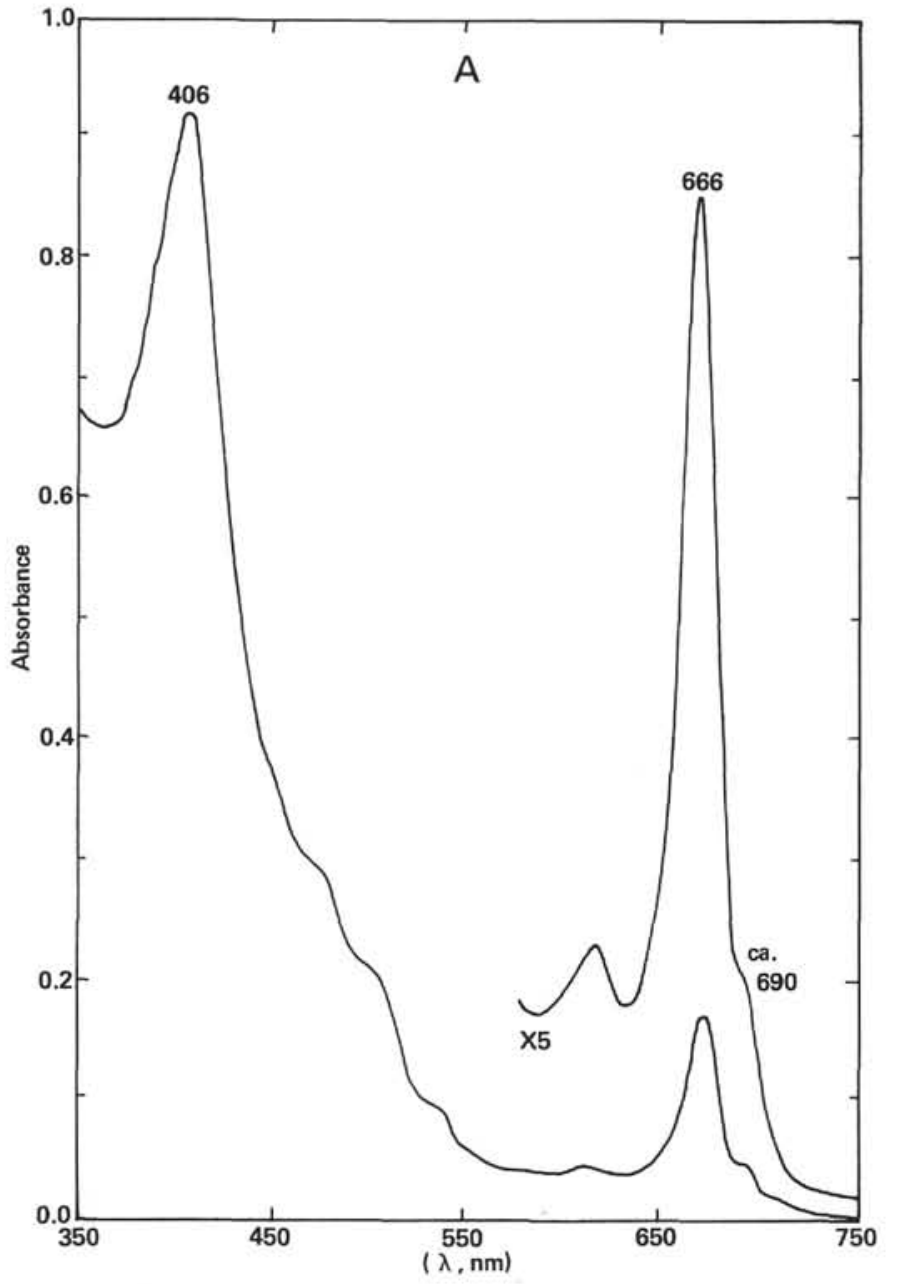

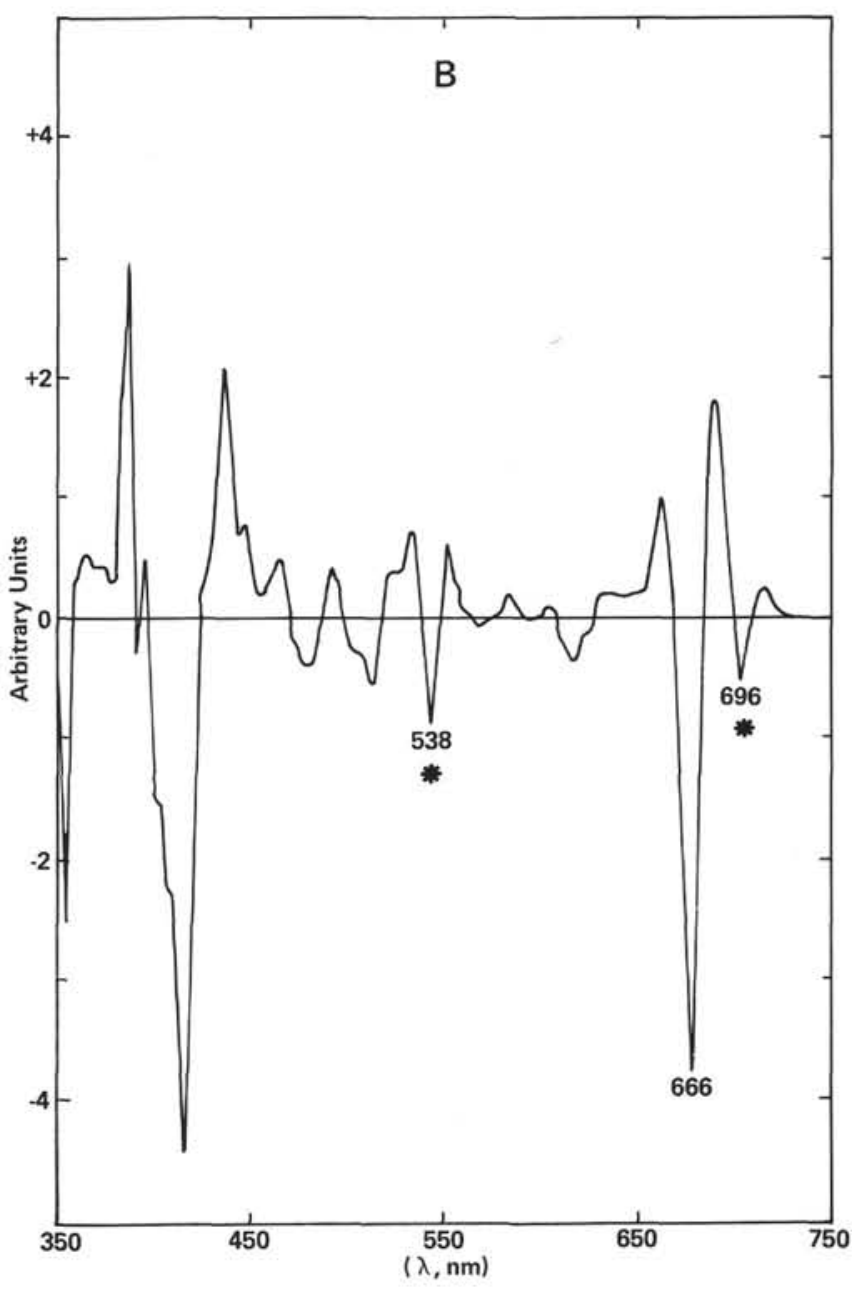

Figure 5. Electronic spectral characteristics of mono-carboxylic acid chlorins isolated from Section 471-3-2. A. Electronic absorption spectrum. B. Second derivative function (* indicates maxima characteristic of purpurin-18; see text). (Solvent: ethyl ether.) 
primarily oxidized, were present in high enough concentrations to ensure survival of a portion of chlorophyllderived phorbide structure until sediment stabilization and establishment of anoxic conditions occurred. This sample, a diatomaceous ooze recovered from a sub-bottom depth of 72 meters, yielded traces of pheophytin-a, a mix of monoacids similar to the pheophorbide-a/purpurin-18 isolate of Section 471-3-2 (cf., Fig. 5), an array of defunctionalized pigments reminiscent of the 9-ketophorbides isolated from Japan Trench diatomaceous sediments (see Baker and Louda, 1980), and the two sets of chlorins (viz., "636" and " $676 / 658 / 646$ "), which we shall now discuss.

Chlorin-"636," a highly defunctionalized chlorin isolated from Section 471-8-5, exhibited the unique electronic spectrum presented in Figure 6. Previously (Baker and Louda, 1980) we isolated a very similar chlorin from a Pleistocene section of the deep-sea terrace off northern Honshu that contained much older material resedimented from upslope (Site 438, Leg 57-Baker and Louda, 1980). The coincidence of chlorin-"636," free-base porphyrins, and a history of reworking lead to the postulate that chlorin-" 636 " may represent a secondarily oxidized derivative of free-base porphyrins. Chlorin-"636," in this study, differs little from the Japan

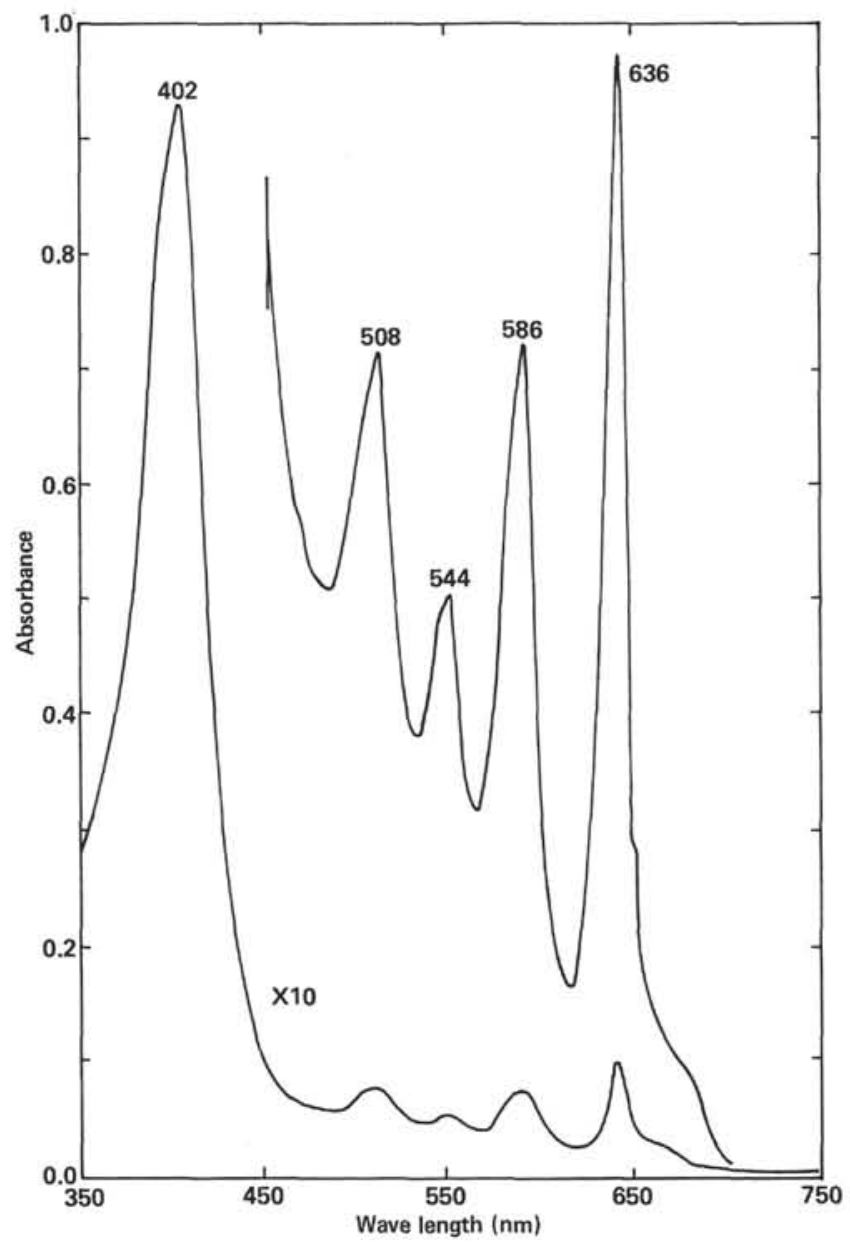

Figure 6. Electronic spectrum of "chlorin-636" isolated from Section 471-8-4 (solvent: ethyl ether).
Trench pigment except in an enhancement of band II. Respectively, chlorin-" 636 " isolated from Leg 57 or 63 samples yielded band orders of I $>$ IV $>$ III $>$ II or I $>$ II $>$ IV $>$ III. Both isolates yielded Soret-to-band-I ratios of about 9:1, well above that found for true chlorins and phorbides (i.e., S/I $\sim 2-4: 1$ ). In the previous report (Baker and Louda, 1980), a comparison between chlorin-"636" and known oxidized porphyrin derivatives was made. The examination of chlorin" 636 " isolated during the present study neither negates nor reinforces the previous supposition that this pigment may be a di-oxy or ether derivative of geochemically reworked porphyrins. Repeated attempts to obtain mass spectra of this pigment failed.

Chlorins-" $676 / 658 / 646$," thought to be interrelated by successive reduction or loss of functional groups (viz., carbonyl), were isolated from the recently described Section 471-8-4. Chlorin-"676" exhibited an electronic spectrum with a bifurcated Soret $(357<407$ $\mathrm{nm}$ ) and band I maxima at $676 \mathrm{~nm}$. Upon treatment with sodium borohydride in $1 \%$ ethanolic ethyl ether, the Soret band became a single peak at $398 \mathrm{~nm}$ and the band-I maximum underwent successive hypsochromic shifts to 658 and finally to $646 \mathrm{~nm}$. Chlorin-" 658 ," upon borohydride reduction, exhibited a single hypsochromic shift in the position of band I from 658 to 646 $\mathrm{nm}$, while the Soret remained fixed at $398 \mathrm{~nm}$. Though the exact nature of these chlorins (purpurins?) remains to be solved, it is not at all unlikely that they are purpurin-18 derivatives geochemically altered by devinylation, or reduction to ethyl at the number 2 carbon, and were isolated in varying stages of the reduction of ketone functional groups. All these possibilities are feasible for chlorophyll derivatives initially oxidized, then subjected to the action of anaerobic bacterial action or strict reductive geochemistry. Structures of various phorbides, chlorins, and purpurins have been reported previously (Louda et al., 1980; cf., Seely, 1966).

The diagenetic alteration of phorbides and chlorins to free-base porphyrins (viz., aromatization) was observed to have occurred with the sediment sample suite from the San Miguel Gap, and to have only started in the Baja California borderland sediments recovered above a porcellanite section. The aromatization reaction appears to have been approximately half completed at sediment depths of between 70 and 116 meters (viz., Sections 467-8-5 and 467-13-4), corresponding to projected in situ temperatures of ca. $10^{\circ} \mathrm{C}$ (see Site 467 report, this volume) for Site 467. Previously, aromatization of phorbides, yielding DPEP-series free-base porphyrins, has been observed to occur within Black Sea sediments (Baker et al., 1978a) at in situ temperatures between $22^{\circ} \mathrm{C}$ and $40^{\circ} \mathrm{C}$. Only trace production of freebase porphyrins was found to have occurred in the highly compacted Japan Trench sediments with present temperatures ca. $10^{\circ} \mathrm{C}$ to $12^{\circ} \mathrm{C}$ (Baker and Louda, 1980). A 0.6-m.y. unconformity is reported for Site 467 at about 70 meters sub-bottom depth (Site 467 report, this volume); the amount of missing sediment overburden and the effect upon present thermal profiles are thus unknown. Overall, examination of Table 2 does 
show that the alteration of phorbides/chlorins to freebase porphyrins has been essentially completed at ca. 350 meters sub-bottom depth (cf., Sections 467-36-2, 467-41-4).

Chlorin-“641"' (or “643"), reported in Table 2, was separated from the remaining chlorin isolates due to an apparent correlation with free-base porphyrins. Chlorin-"641" yields electronic spectra with a Soret maximum of $396 \mathrm{~nm}$ and a band I maximum at 641 $\mathrm{nm}$, which is extremely narrow in band width (i.e., spikelike). A broad band IV maximum also occurs at $500 \mathrm{~nm}$, but little to no fine structure is observed between bands I and IV (i.e., 640-500 nm). Spectra such as this are reminiscent of, yet by no means identical to, that elicited by the deoxomesopyropheophorbide-a chromophore (viz., 390, 500, $638 \mathrm{~nm}$ : cf., Baker and Louda, 1980). At present, chlorin-" 641 "' is thought to be either the precursor to free-base DPEP-series porphyrins, a secondary chlorin (cf., Blumer and Omenn, 1961) produced from previously generated free-base porphyrins, or to represent one side of a steady-state transformation between the dihydroporphyrin and porphyrin, and the reverse, stages of diagenesis.

\section{Free-Base Porphyrins}

Sediments from the San Miguel Gap recovered between 70 and 800 meters sub-bottom depth (Sections 467-8-5 to 467-85-4, inclusive) yielded large quantities of free-base porphyrins, at times exceeding $1 \mathrm{mg}$ from an initial $100 \mathrm{~g}$ aliquot of wet-weighted sediment (e.g., Sections 467-63-2 and 467-74-1).

A typical initial isolate of free-base porphyrins exhibited the electronic spectrum given as Figure 7 and identified by the dashed trace (i.e., Section 467-74-1). For comparison a 1:1 weight to weight $(w / w)$ synthetic mixture of deoxophylloerythrin and deoxomesopyropheophorbide-a was prepared and its electronic spectrum is shown as the solid trace in Figure 7. Attention is drawn to the remarkable similarity between the spectrum of the impure isolate and that of the synthetic porphyrin/phorbide mix. Further acid extraction $(1.5 \%$ $\mathrm{HCl} ; \mathrm{w} / \mathrm{v}$ ) and chromatographic purification resulted in separation of free-base porphyrins from the chlorin" $641 / 643$ " component recently discussed. The purified free-base isolate from Section 467-74-1 produced the electronic spectrum shown in Figure 8. All free-base porphyrins from Site 467 sediment samples were purified in like manner and to similar degrees of spectral clarity.

Eleven samples of San Miguel Gap sediments yielded sufficient quantities of free-base porphyrins to be carried through the purification scheme and characterized mass spectrometrically. Table 3 summarizes the normalized average $14 \mathrm{eV}$ mass spectra of the free-base porphyrins isolated from Site 467 sediment sections. Unique to the present case is the finding of a small but measurable ETIO-porphyrin component in these free-base porphyrin assemblages. The overall DPEP to ETIO ratio from the pigment arrays reported in Table 3 is $78: 1$, the overwhelming abundance of DPEP probably accounts for the previous reports that only the DPEP-series is

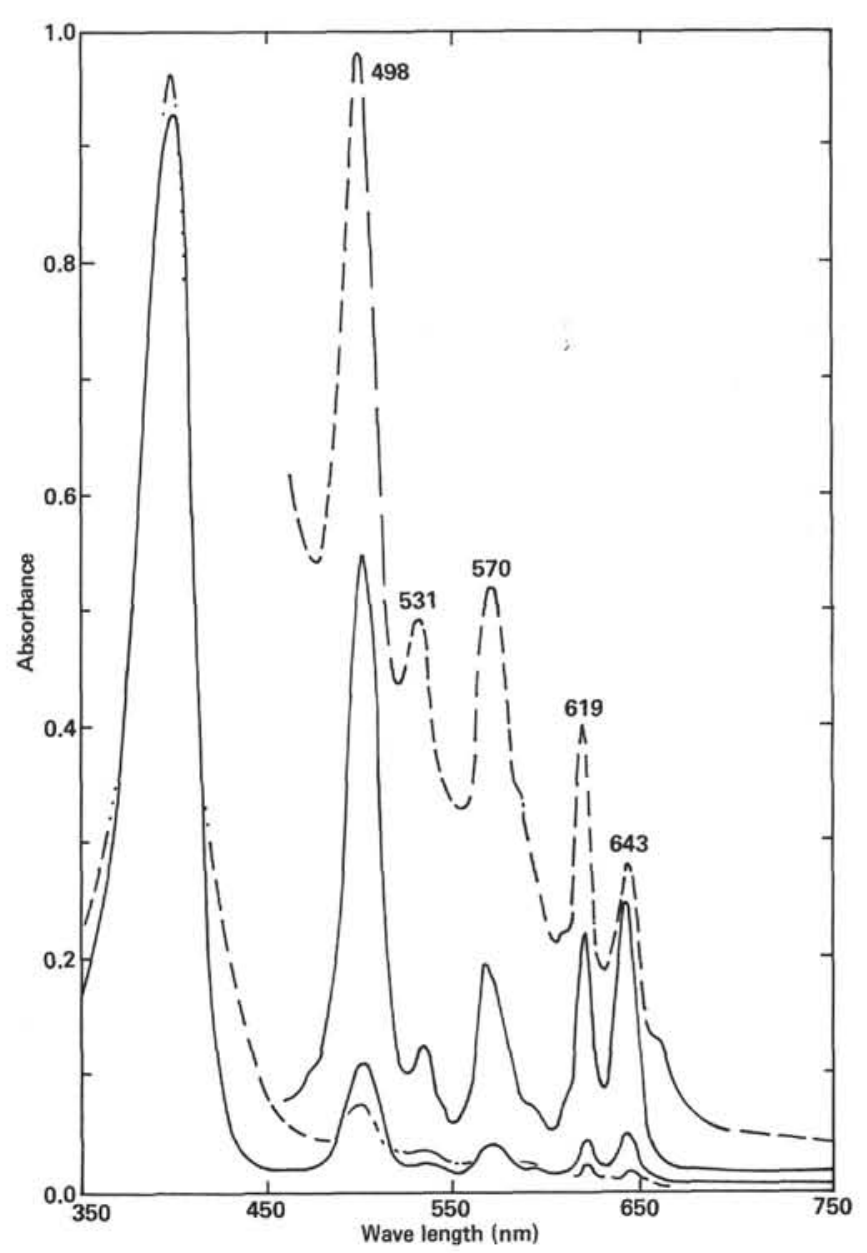

Figure 7. Electronic spectra of a synthetic mixture $(1: 1, w / w)$ of deoxophylloerythrin and deoxomesopyropheophorbide-a (solid trace) compared to that of a partially purified free-base porphyrin/chlorin isolate from Section 467-74-1 (dashed trace) (solvent $=$ ethyl ether $)$.

present in geologic free-base porphyrins (cf., Baker et al., 1978a). However, the implications of even trace ETIO-porphyrin generation/retention prior to chelation are profound and will be discussed later.

Because of the abundance of free-base porphyrins in Site 467 sediment samples, repeated purification was possible, and exceedingly clear mass spectra were obtained. Careful volatilization of the sample in the mass spectrometer enabled any trace lower-molecular-weight contaminants to be distilled prior to appearance of freebase porphyrin ions. Only in the early portion of the volatility profile of free-base porphyrins were ETIOseries ions observed. Figure 9 is a comparison of two uncorrected spectra obtained from the free-base isolate of Section 467-18-5. During volatilization of this isolate a total of 52 scans were taken, of which only the first onethird (ca. 18) contained detectable ETIO-porphyrin ions. The latter two-thirds of the total scans recorded exhibited essentially similar negatively skewed envelopes of DPEP-series molecular ions (e.g., C-28 to C-32).

The presence of minor amounts of chlorin-" 641 ", with initial free-base porphyrin isolate may suggest that the ETIO-porphyrins reported are actually chlorins, be- 


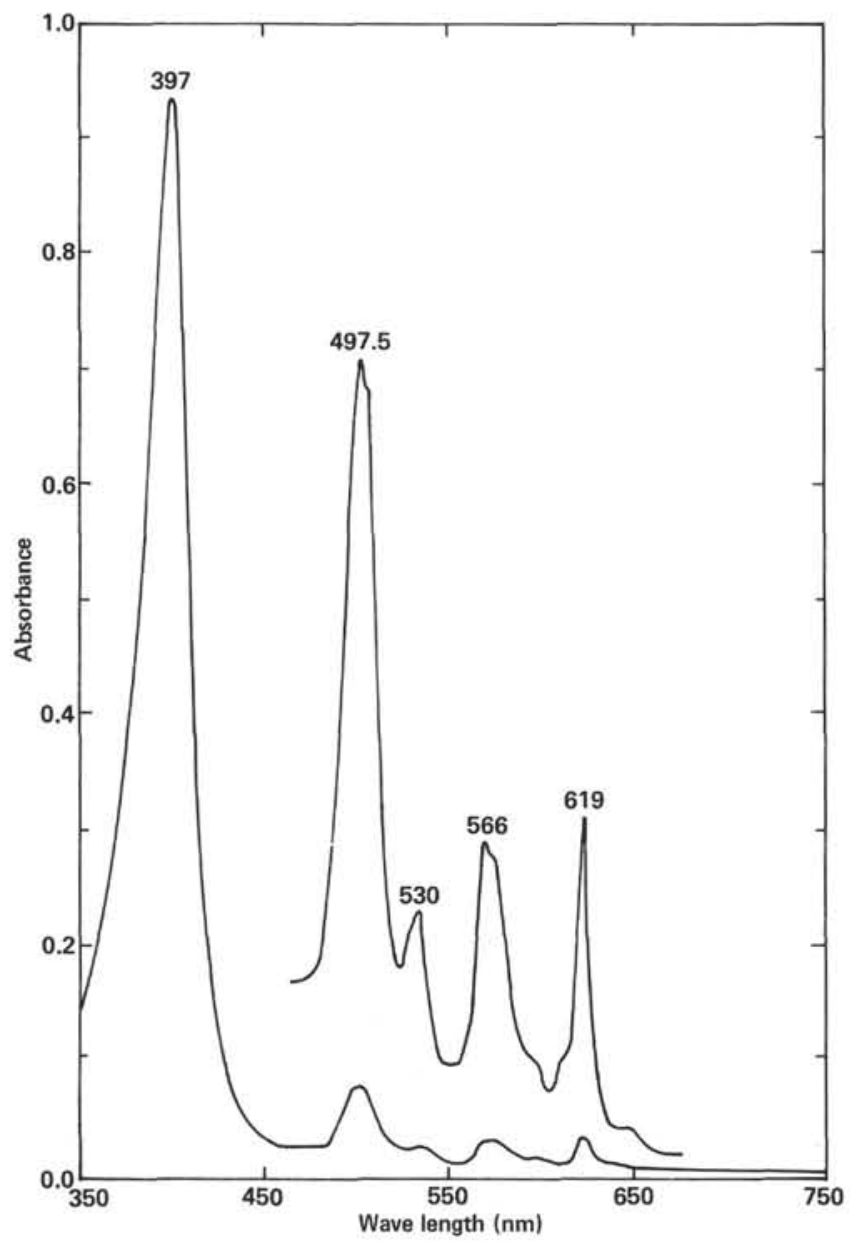

Figure 8. Electronic spectrum of purified free-base porphyrins isolated from Section 467-74-1 (solvent: ethyl ether).

cause one can derive a DPEP +2 ion from DPEP by reduction to the corresponding phorbide or by opening of the isocyclic ring yielding an ETIO homologue. However, two facts argue that the observed series at $m / z 380$ $+14 n$ (where $n=0,1, \ldots 7$ ) are, in fact, ETIO-porphyrins. First, the isolates employed in mass spectrometry were purified until chlorin-" 641 "' was removed, as determined via electronic spectroscopy (cf., Figs. 7 and 8). Secondly, the known volatility of tetrapyrrole pigments in the mass spectrometer is ETIO > DPEP $\gg$ CHLORIN $\geq$ PHORBIDE (cf., Baker and Louda, unpublished data; Budzikiewicz, 1978).

A unique and unwanted derivatization of two freebase porphyrin isolates (viz., 467-41-4 and 467-48-2) occurred during separation of these pigments. Following neutralization of the acid-extracted pigments with sodium carbonate and transfer to fresh ethyl ether, the isolate from Section 467-41-4 was found to exist completely as a zinc porphyrin and that from Section 467$48-2$ to be about $50 \%$ artifact and $50 \%$ original freebase. Reaction appears to have taken place between a zinc salt, present as a component of the trace "metal impurities" portion of reagent grade sodium carbonate, and free-base porphyrin during short exposure to basic conditions. That is, only with these two isolates, while in the aqueous phase (cf., Fig. 1), was the neutrality point missed during titration with carbonate and were $p \mathrm{H}$ values greater than 8 obtained. Neutrality was reestablished by the dropwise addition of $1.5 \% \mathrm{HCl}$ $(w / v)$. Local acidification during this latter phase, in the presence of zinc salts, is the most likely impetus for the observed reaction.

Figure 10 is the uncorrected mass spectrum of the zinc porphyrin artifact obtained from the free-base porphyrins of Section 467-41-4. The DPEP and ETIOseries distributions, originally present as the free-base form, were calculated following correction for the known abundances of the three major zinc isotopes (i.e., $\mathrm{Zn}^{64}, \mathrm{Zn}^{66}, \mathrm{Zn}^{68}$; cf., Table 3 and the section on Materials and Methods).

Comparisons of the corrected normalized mass spectra obtained for the free-base isolate from Section $467-48-2$, in both the native free-base and artifactual zinc-chelate forms, proved that selective chelation on the basis of zinc isotope, porphyrin series (viz. DPEP versus ETIO), or homologue (e.g., C-26 . . C-32) had not occurred. The mass spectrum reported for Section 467-48-2 is thus only for the native (i.e., unreacted) freebase porphyrin isolate.

Free-base porphyrin acids, present in Sections $467-$ $8-5$ to $467-74-1$ inclusively, have been isolated, and studies are continuing. Electronic spectra indicate that these acids are of the deoxophylloerythrin type, and quantitation of these compounds has been included in the data presented (e.g., Table 1 and 2).

\section{Metalloporphyrins}

The sediment sample suites studied from Leg 63 Sites 467 and 471 have yielded perhaps the most complete overall view of metalloporphyrins in marine sediments to date. Information has been attained regarding source (i.e., allochthonous versus autochthonous), in situ diagenesis (viz., chelation, alkylation-dealkylation, decarboxylation, etc.), and the release of vanadyl porphyrins from (?) kerogen; and it was possible to relate all aspects to present in situ thermal gradients.

Three main assemblages of metalloporphyrins were isolated from the sediments recovered during Leg 63 operations at the San Miguel Gap and Baja California borderland sites. These, represented by electronic spectra, are: (1) complex mixtures of highly dealkylated (i.e., C-23 to C-30) $\mathrm{Cu}$ and $\mathrm{Ni}$ ETIO-porphyrins, together with Ni DPEP-homologues (Fig. 11, A: Section 467-32-2), isolated from the upper Miocene to upper Pliocene clays and claystones of both Sites 467 and 471; (2) the more common marine assemblages of Ni DPEP and ETIO-porphyrins, present as higher carbon number (i.e., C-29 to C-32) homologies (Fig. 11, B: Section 467-91-2) isolated from the middle to upper Miocene silty claystones and nanno-chalks of both sites; and (3) an extended alkyl homology (i.e., C-23 to C-34) of vanadyl DPEP and ETIO porphyrins isolated from the most deeply buried middle Miocene silty claystone studied from the San Miguel Gap suite (Fig. 11, C: Section 
Table 3. Normalized average $14 \mathrm{eV}$ mass spectra of free-base porphyrins isolated from DSDP/IPOD Leg 63 Site 467 sections.

\begin{tabular}{|c|c|c|c|c|c|c|c|c|c|c|c|c|}
\hline \multirow[b]{2}{*}{ Section $^{\mathrm{a}}$} & \multirow[b]{2}{*}{ Series } & \multicolumn{8}{|c|}{$\begin{array}{c}\text { Carbon Number }{ }^{\mathrm{c}} \\
{[(m / z \text { DPEP }) /(m / z \text { ETIO })]}\end{array}$} & \multirow[b]{2}{*}{$\overline{\bar{x}} \bar{d}$} & \multirow[b]{2}{*}{$\begin{array}{l}\bar{X}_{D}^{e} \\
\bar{x}_{E}\end{array}$} & \multirow[b]{2}{*}{$\frac{\text { DPEP }^{f}}{\text { ETIO }}$} \\
\hline & & $\begin{array}{c}\text { C-25 } \\
(378 / 380)\end{array}$ & $\begin{array}{c}\text { C-26 } \\
(392 / 394)\end{array}$ & $\begin{array}{c}C-27 \\
(406 / 408)\end{array}$ & $\begin{array}{c}C-28 \\
(420 / 422)\end{array}$ & $\begin{array}{c}\text { C- } 29 \\
(434 / 436)\end{array}$ & $\begin{array}{c}\text { C- } 30 \\
(448 / 450)\end{array}$ & $\begin{array}{c}\text { C-31 } \\
(462 / 464)\end{array}$ & $\begin{array}{c}\text { C-32 } \\
(476 / 478)\end{array}$ & & & \\
\hline $467-8-5$ & DPEP & 0.9 & 3.9 & 13.7 & 33.6 & 49.8 & 78.2 & 92.7 & 100.0 & 448.8 & 452.3 & 6.9 \\
\hline$(\mathrm{N}=23)$ & ETIO & 1.4 & 5.5 & 10.0 & 15.8 & 10.5 & 7.6 & 3.1 & & & 424.5 & \\
\hline $467-13-4$ & DPEP & & 0.7 & 7.2 & 23.6 & 38.2 & 66.1 & 68.5 & 100.0 & 450.3 & 455.7 & 4.0 \\
\hline$(\mathrm{N}=64)$ & ETIO & 1.1 & 4.2 & 10.8 & 21.4 & 21.4 & 17.1 & 0.5 & & & 428.8 & \\
\hline $467-18-5$ & DPEP & & 0.3 & 9.0 & 22.5 & 41.5 & 65.2 & 78.3 & 100.0 & 450.2 & 455.2 & 4.0 \\
\hline$(\mathrm{N}=52)$ & ETIO & 0.8 & 2.7 & 8.5 & 16.6 & 39.4 & 11.2 & & & & 430.0 & \\
\hline $467-25-6$ & DPEP & & 1.0 & 14.6 & 34.0 & 70.8 & 86.1 & 100.0 & 49.7 & 447.6 & 448.5 & 20.5 \\
\hline$(\mathrm{N}=21)$ & ETIO & & 1.8 & 3.5 & 4.0 & 3.6 & 2.6 & 1.9 & & & 427.9 & \\
\hline $467-32-2$ & DPEP & & & 6.0 & 28.6 & 57.1 & 100.0 & 79.8 & 38.8 & 449.0 & 449.1 & 182.5 \\
\hline$(\mathrm{N}=19)$ & ETIO & & & & 0.9 & 0.8 & & & & & 428.6 & \\
\hline $467-36-2$ & DPEP & & 0.3 & 8.9 & 32.6 & 60.5 & 100.0 & 80.8 & 35.1 & 447.2 & 477.9 & 36.2 \\
\hline$(\mathrm{N}=26)$ & ETIO & & 0.3 & 2.2 & 3.6 & 2.7 & & & & & 421.8 & \\
\hline $467-41-4 b$ & DPEP & & 0.9 & 15.5 & 29.7 & 59.0 & 70.1 & 100.0 & 44.2 & 448.0 & 448.9 & 31.3 \\
\hline$(\mathrm{N}=6)$ & ETIO & & 0.3 & 3.1 & 3.1 & 3.7 & & & & & 422.0 & \\
\hline $467-48-2$ & DPEP & & & 6.0 & 20.8 & 53.7 & 75.4 & 100.0 & 52.7 & 452.0 & 454.2 & 237.4 \\
\hline$(\mathrm{N}=64)$ & ETIO & & & 0.5 & 0.7 & 0.1 & & & & & 417.6 & \\
\hline $467-58-3$ & DPEP & & & 5.3 & 35.2 & 85.5 & 100.0 & 98.4 & 18.7 & 446.4 & 446.5 & 318.5 \\
\hline$(\mathrm{N}=34)$ & ETIO & & & 0.5 & 0.5 & & & & & & 415.0 & \\
\hline $467-63-2$ & DPEP & & 3.9 & 4.2 & 18.7 & 44.2 & 100.0 & 97.1 & 53.7 & 450.9 & 452.1 & 11.5 \\
\hline$(\mathrm{N}=6)$ & ETIO & & 1.5 & 3.9 & 5.8 & 5.5 & 6.0 & 2.8 & 2.4 & & 436.4 & \\
\hline $467-74-1$ & DPEP & & & 5.8 & 18.3 & 43.1 & 82.7 & 100.0 & 98.8 & 454.8 & 456.0 & 4.7 \\
\hline$(\mathrm{N}=36)$ & ETIO & & & 3.0 & 8.6 & 16.5 & 21.5 & 12.0 & 12.9 & & 449.1 & \\
\hline
\end{tabular}

${ }^{\mathrm{a}} \mathrm{N}=$ number of scans employed in reconstitution of normalized average spectrum covering entire volatility range throughout which porphyrin molecular ions were observed.

${ }^{b}$ Free-base distribution of Section 467-41-4 calculated from corresponding peaks of zinc chelate (artifact). $\mathrm{Zn} 64 / \mathrm{Zn}^{66} / \mathrm{Zn}^{68}=48.9 / 27.8 / 18.6$. Isotopic correction was therefore made for ETIO-series determination (i.e., $\mathrm{E}_{\mathrm{corr}}=\mathrm{E}-[0.568 \times \mathrm{D}]$ ); see text.

c Normalized spectra, highest ion abundance taken as 100.0 , determined at $14 \mathrm{eV}$.

$\mathrm{d} \overline{\overline{\mathrm{X}}}$ : total weighted average mass, including both DPEP and ETIO series;

$$
\overline{\mathrm{X}}=\frac{\Sigma \mathrm{IMD}+\Sigma \mathrm{IME}}{\Sigma \mathrm{ID}+\Sigma \mathrm{IE}} \text { (see Baker and Palmer, 1978). }
$$

${ }^{e} \bar{X}_{D}, \bar{X}_{E}$ : weighted average mass of DPEP and ETIO series separately (see footnote d).

${ }^{f}$ DPEP/ETIO: Ratio of ion intensities of each series $\left(\Sigma \mathrm{I}_{\mathrm{D}} / \Sigma \mathrm{I}_{\mathrm{E}}\right)$.

467-110-3). Each of the major, and minor, metalloporphyrin arrays are now discussed with source and diagenetic considerations presented later.

\section{Copper and Nickel Dealkylated ETIO-Porphyrins Coincident with Nickel Porphyrins of the DPEP-Series}

Only recently has the presence of natural copper porphyrins in deep-ocean sediments been shown (see Palmer and Baker, 1978). In that report copper ETIO-porphyrins were noted to comprise from $10 \%$ to $80 \%$ of those metalloporphyrin mixtures and a correlation between these unique pigments and terrestrially derived organic matter drawn. In the present case, Sections 46725-6 to 467-58-3, inclusive, and Section 471-8-4 were found to contain highly dealkylated copper and nickel ETIO-porphyrins exhibiting identical carbon number homologies (cf., Tables 2, 4, and 5). The occurrence of the $\mathrm{Cu}$ and Ni ETIO-porphyrins in the San Miguel Gap sediment sequence was found to correlate exactly with a region of low tetrapyrrole pigment yield, on a total organic carbon basis (i.e., low PYI, see Fig. 4), and with strata deposited at high sedimentation rates, due to large influxes of terrestrial detritus (see Site 467 report, this volume).

Copper porphyrins, co-isolated with nickel chelates, were first recognized in the extracts and isolates of Leg
63 samples by the bathochromically shifted absorption maxima in electronic spectra (e.g., Fig. 11, A versus Fig. 11, B). Table 4 summarizes the electronic spectral characteristics, postulated source derivation (i.e., terrigenous versus marine), and the metal species present in the various metalloporphyrin assemblages isolated during the present study. Though strict characterization of metalloporphyrins hinges upon mass spectrometric analyses, several differences between the nickel and the copper-nickel porphyrin arrays are evident from examination of the data presented in Table 4. First, the positions of absorption maxima (i.e., Soret, $\alpha, \beta$ ) for the nickel porphyrins are found to be $390.5,513,549.5 \mathrm{~nm}$ for $\mathrm{Ni}$ chelates with DPEP-to-ETIO ratios between unity and 4:1 (cf., Tables 4 and 5). This contrasts with maximal absorption at ca. 393, 520, and $554 \mathrm{~nm}$ for metalloporphyrin arrays with up to about a 5:1 ratio of $\mathrm{Cu}$ to $\mathrm{Ni}$ chelates (e.g., Sections 467-36-3 and 467-41-4; Table 4). Concurrent with the bathochromism of band position, due to the presence of the copper chelates, is a marked decrease in the $\alpha$ - to $\beta$-band ratio of these arrays (Table 4). The lowering of $\alpha$ to $\beta$ ratios, in this case, appears more directly related to the presence of the highly dealkylated porphyrins as well as the nature of the chelated metal species. Thus assessment of alterations of nickel porphyrins (e.g., DPEP to ETIO), employing 


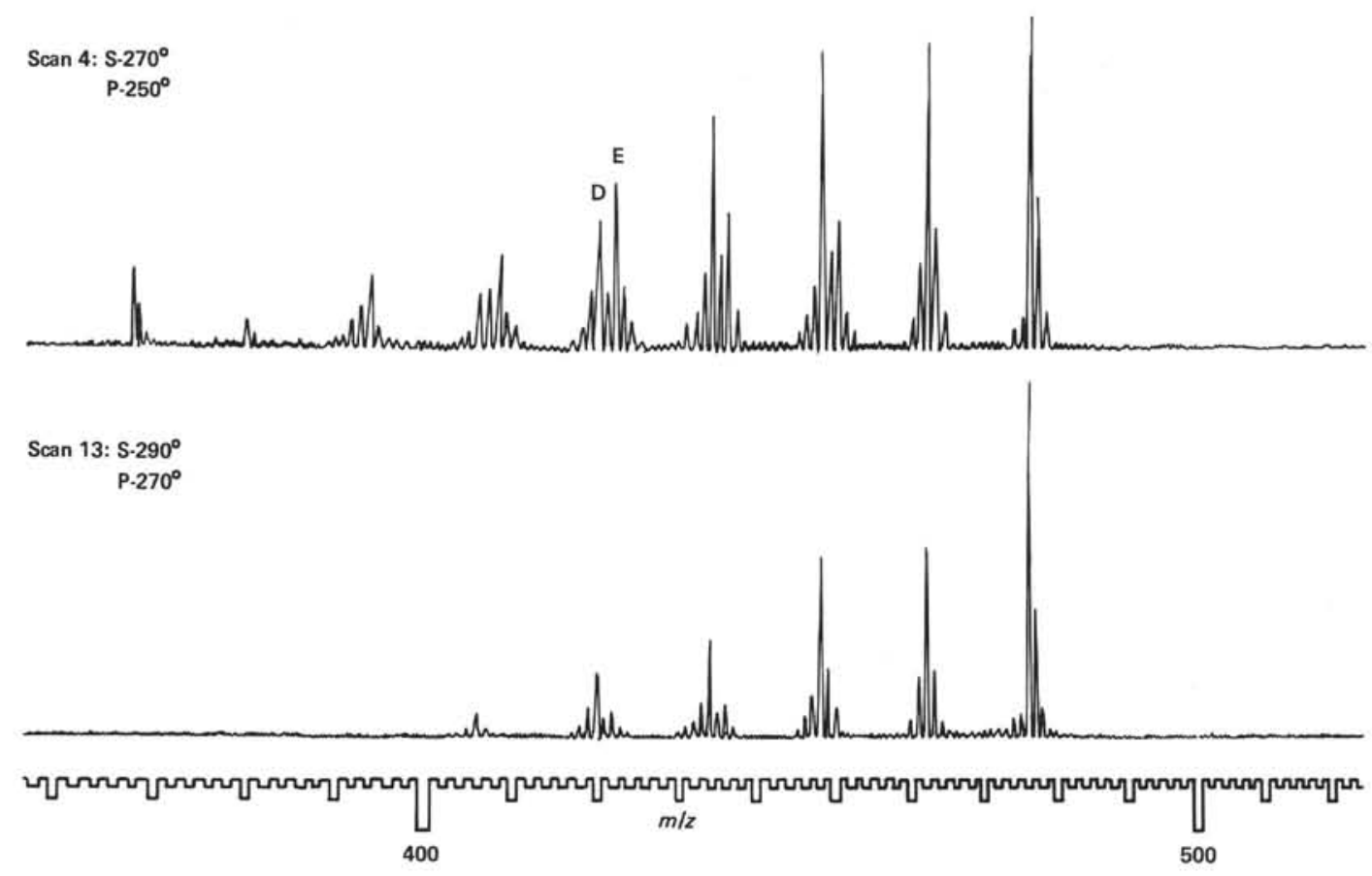

Figure 9. Uncorrected real-time $14 \mathrm{eV}$ mass spectra of free-base porphyrins isolated from Section 467-18-5. (The upper portion of the figure is Scan 4, and the lower portion is Scan 13 of a total number of 52 scans covering the entire volatilization of this isolate; $\mathrm{S}$ and $\mathrm{P}$ refer to the temperature in degrees Celsius of the Source and Probe, respectively. D and E refer to DPEP and ETIO series, respectively.)

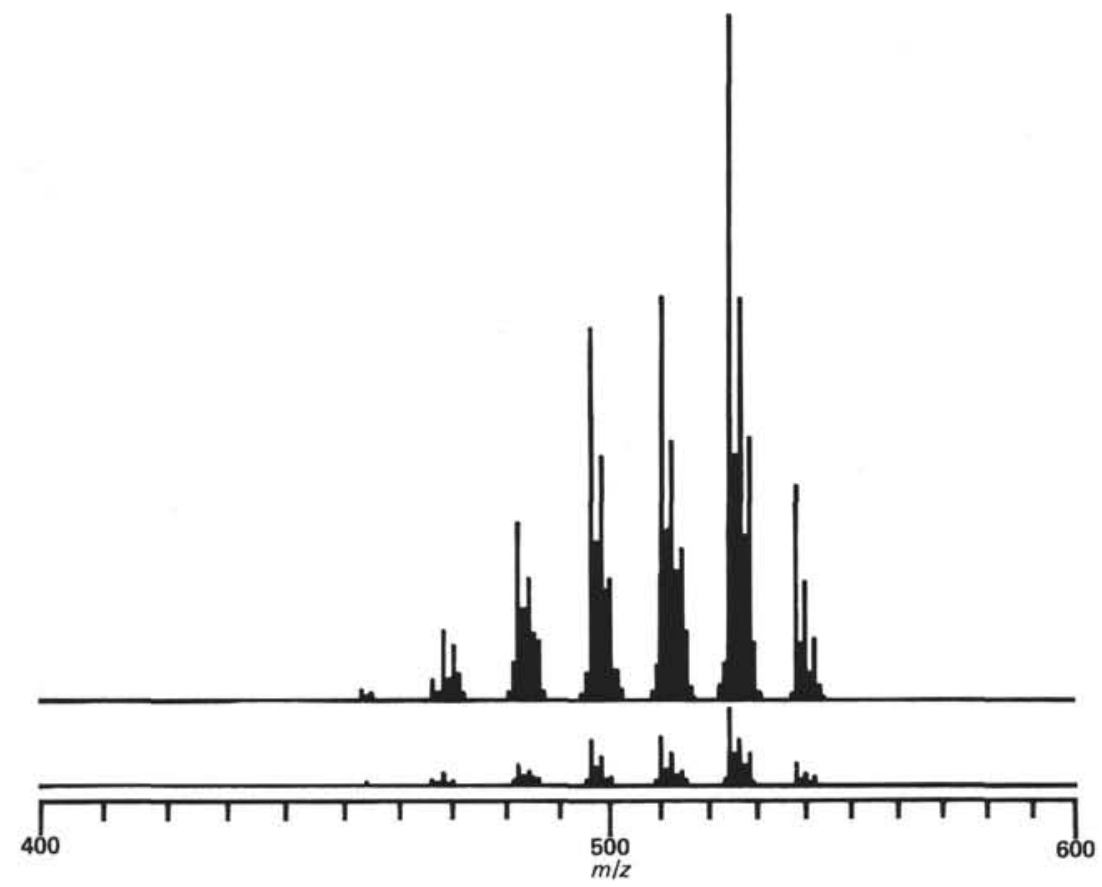

Figure 10. Partial, uncorrected, $14 \mathrm{eV}$ mass spectrum of zinc porphyrin artifacts formed during isolation of free-base porphyrins from Section 467-41-4 (see text for details and explanation). 

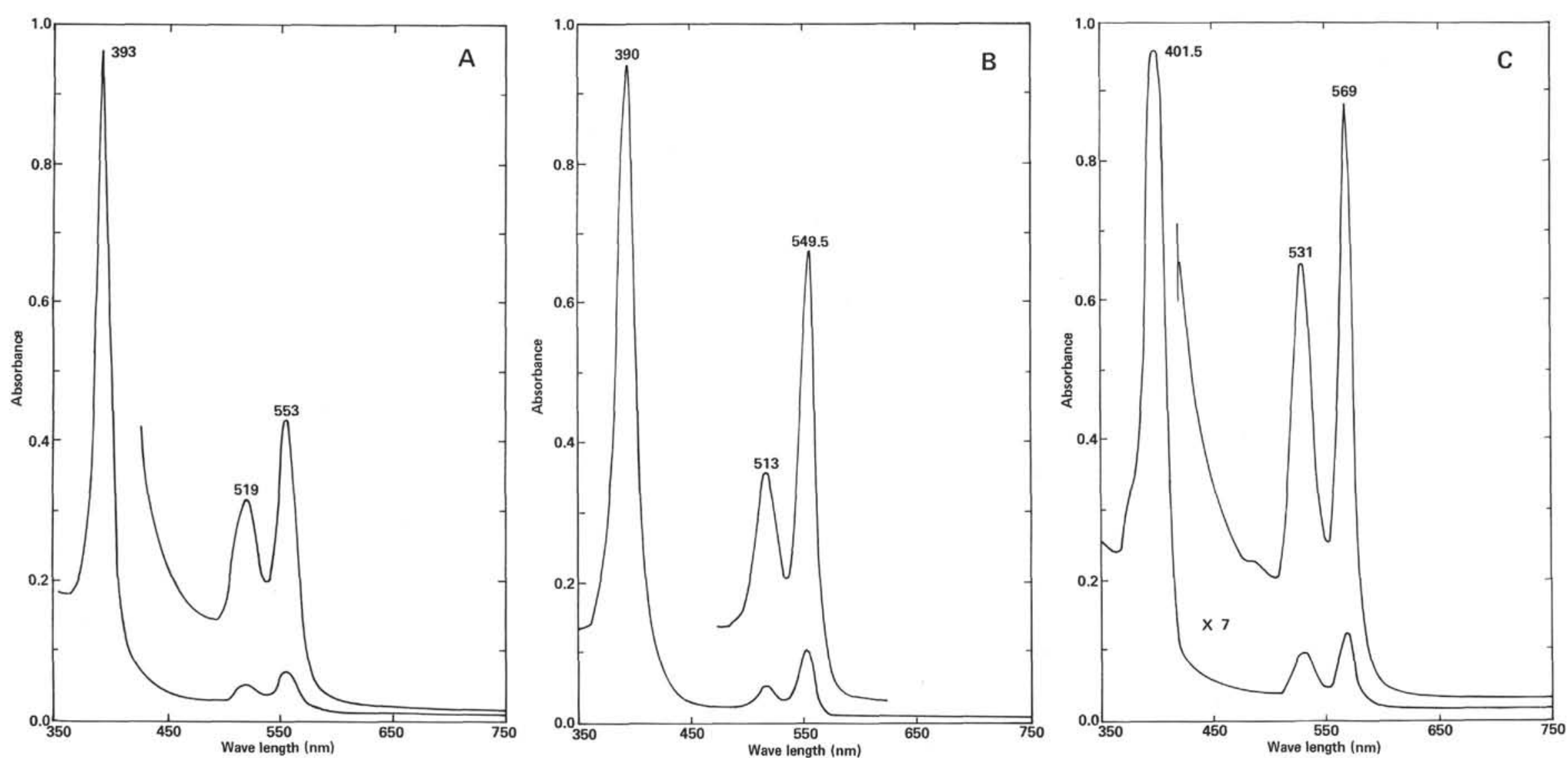

Figure 11. A. Electronic spectrum of metalloporphyrins isolated from Section 467-32-2 (solvent: ethyl ether). B. Electronic spectrum of nickel porphyrins isolated from Section 467-91-2 (solvent: ethyl ether). C. Electronic spectrum of vanadyl porphyrins isolated from Section 467-110-3, San Miguel Gap (solvent: ethyl ether). 
Table 4. Electronic spectral characteristics, source derivation, and metal species of metalloporphyrins isolated from DSDP/IPOD Leg 63 sections.

\begin{tabular}{|c|c|c|c|c|c|c|c|}
\hline \multirow[b]{2}{*}{ Section } & \multicolumn{3}{|c|}{ Maxima, (nm) } & \multirow[b]{2}{*}{$\alpha / \beta$} & \multirow{2}{*}{$\begin{array}{l}\text { Per Cent } \\
\text { Terrigenous }^{\mathrm{b}}\end{array}$} & \multirow{2}{*}{$\begin{array}{c}\mathrm{Ni} / \mathrm{Cu} \\
\text { (ETIO component) }\end{array}$} & \multirow{2}{*}{$\begin{array}{l}\text { Metalloporphyrin } \\
\text { Class }\end{array}$} \\
\hline & Soret & $\beta$ & $\alpha$ & & & & \\
\hline $467-25-6$ & 393 & (ca. 520) & 553 & - & $(100.0)$ & $?$ & $\mathrm{Ni}-\mathrm{Cu}$ \\
\hline $467-32-2$ & 393 & 519 & 553 & 1.18 & 92.0 & 0.27 & $\mathrm{Ni}-\mathrm{Cu}$ \\
\hline $467-36-3$ & 393 & 520 & 554 & 1.61 & 82.8 & 0.21 & $\mathrm{Ni}-\mathrm{Cu}$ \\
\hline $467-41-4$ & 392 & 519 & 553 & 1.57 & 100.0 & 0.18 & $\mathrm{Ni}-\mathrm{Cu}$ \\
\hline $467-48-2^{\mathrm{a}}$ & 392.5 & 518.5 & 551.5 & 1.76 & 80.3 & 0.45 & $\mathrm{Ni}-\mathrm{Cu}$ \\
\hline $467-58-3$ & 392 & 514.5 & 550 & 2.06 & 66.6 & 1.92 & $\mathrm{Ni}-\mathrm{Cu}$ \\
\hline $467-63-2$ & 392 & 514 & 550 & 2.22 & 0.0 & - & $\mathrm{Ni}$ \\
\hline $467-74-1$ & 391 & 513 & 550 & 2.38 & 0.0 & - & $\mathrm{Ni}$ \\
\hline $467-85-4$ & 391 & 513 & 550 & 2.24 & 0.0 & - & $\mathrm{Ni}$ \\
\hline $467-91-2$ & 390.5 & 513 & 549.5 & 2.22 & 0.0 & - & $\mathrm{Ni}$ \\
\hline $467-97-2$ & 390.5 & 513 & 549.5 & 2.31 & 0.0 & - & $\mathrm{Ni}$ \\
\hline $467-110-3$ & 390.5 & 513 & 549.5 & 2.48 & 0.0 & - & $\mathrm{Ni}$ \\
\hline $467-110-3$ & 401.5 & 531 & 569 & - & - & - & $\mathrm{V}=\mathrm{O}$ \\
\hline $471-34-2$ & 393.5 & 517 & 553 & 2.10 & 47.7 & 1.026 & $\mathrm{Ni}-\mathrm{Cu}$ \\
\hline $471-34-2$ & 391 & 513 & 550.5 & 2.25 & - & - & $\begin{array}{l}\text { Ni Deoxophyllo- } \\
\text { erythrin }\end{array}$ \\
\hline $471-34-2$ & 394 & 551 & 582.5 & 3.02 & - & - & $\mathrm{Ni}$ Phylloerythrin \\
\hline $471-50-2$ & 390.5 & 513 & 550 & 2.26 & 0.0 & - & $\mathrm{Ni}$ \\
\hline $471-69-3$ & 390.5 & 513 & 550 & 2.45 & 0.0 & - & $\mathrm{Ni}$ \\
\hline
\end{tabular}

${ }^{a}$ Reported total from LPLC fractionation (cf., Fig. 13).

b Percent terrigenous equals the $\mathrm{Cu}-\mathrm{Ni}$ ETIO component (see text).

only the alteration of $\alpha / \beta$ ratios (cf., Palmer and Baker, 1979), should be made with caution when mass spectometric data are lacking.

The complexity of the mass spectra of copper-nickel porphyrin arrays is exemplified in Figure 12. The mass spectrum presented represents scan number 11 , of a total of 26 scans, and is presented uncorrected to illustrate the deconvolution techniques involved. This mixture, isolated from Section 467-48-2, contains $\mathrm{Ni}$ DPEP, Ni ETIO, and Cu ETIO-porphyrins. As part of
Figure 12 the $\mathrm{Cu}$ ETIO-series is delineated by the solid line in the $\times 100$ galvometer trace and the Ni DPEPhomology by asterisks in the $\times 1,000$ recording. In this case neither the Ni DPEP nor $\mathrm{Cu}$ ETIO-series require correction. Examining the $\times 1,000$ trace of Figure 12, the Ni ETIO-homology, prior to correction, is seen to consist not only of $\mathrm{Ni}^{58} \mathrm{ETIO}$, at each carbon number. but also of $\mathrm{Ni}^{60}$ DPEP. Correction for this overlapping isotopic contribution, plus the more minor $\mathrm{M}+2$ peak of the corresponding DPEP-homologue (cf., Table 5,
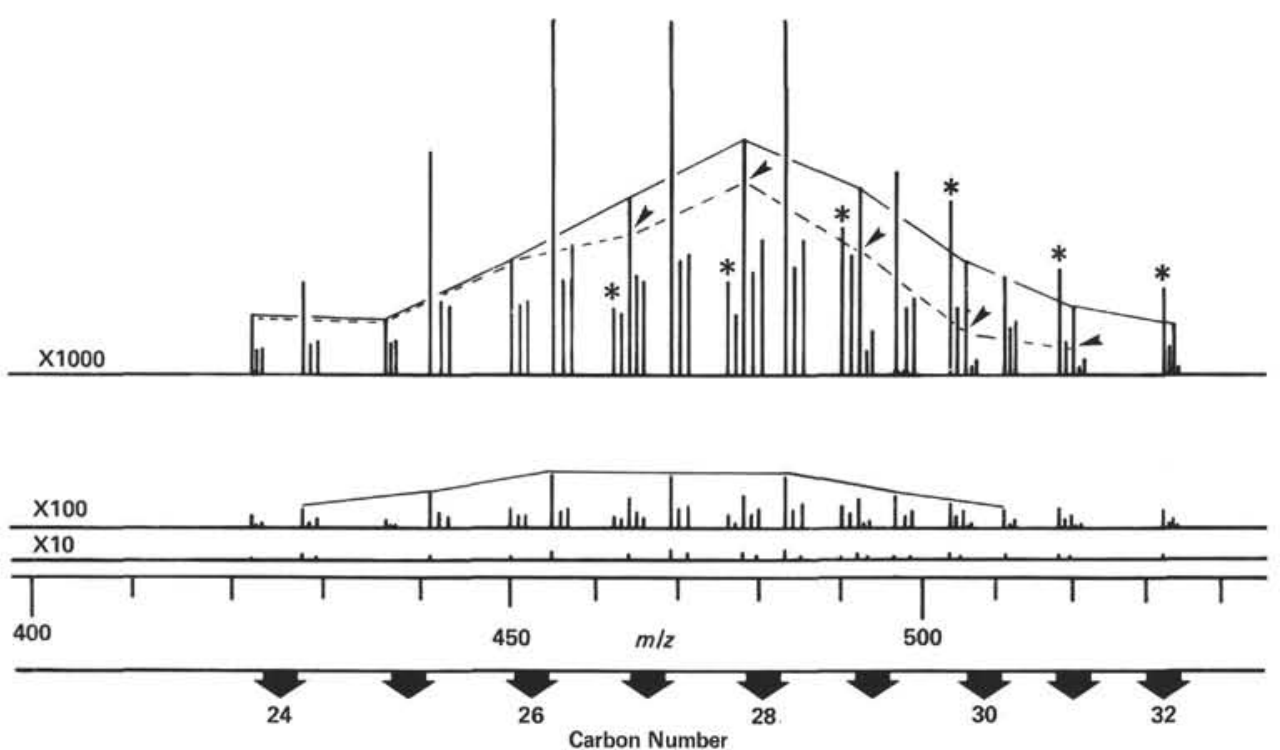

Figure 12. Partial $14 \mathrm{eV}$ mass spectrum of metalloporphyrin mixture isolated from Section 467-48-2 and composed of copper ETIO-porphyrins plus an array of nickel DPEP and ETIO-porphyrins. (Copper [63] ETIO-homology delineated in the $\times 100$ trace. Nickel [58] DPEP homologues indicated by asterisks in the $\times 1000$ trace. Nickel [58] ETIO-series prior to correction for Ni[60] DPEP overlapping contribution is delineated by the solid line, and the corrected [i.e., $\mathrm{NI}^{58} \mathrm{E}^{\prime}=\mathrm{Ni}^{58} \mathrm{E}-(0.386) \mathrm{Ni}^{58} \mathrm{D}$ ] homology by a dashed line and arrows in the $\times 1000$ trace. Scan number 11 of 26.) 
footnote b), then results in the corrected Ni ETIOhomology delineated by the dashed trace and arrows in the $\times 1,000$ spectrum of Figure 12 .

Obtaining the precise normalized weighted average mass spectrum of geologic copper-nickel porphyrin arrays is often a struggle against the analytical selection of series and/or homology. Figure 13 is the low-pressure liquid chromatogram (LPLC) obtained during the purification of metalloporphyrins isolated from Section 467-48-2. Following elution of an unidentified hydrocarbon fraction and perylene, an extremely broadened zone of metalloporphyrins moved down and off the column. Arbitrary fraction "cuts" were made of this band (i.e., \#1-\#3, Fig. 13), including a "tail" cut (i.e., \#4, Fig. 13) that was collected rapidly by increasing the developing solvent polarity. On the basis of electronic spectral characteristics (see insets, Fig. 13), it was found that Ni DPEP porphyrins appeared concentrated in the earlier eluates whereas the tailing portions contained the majority of $\mathrm{Cu}$ ETIO components (i.e., note absorption maxima and $\alpha / \beta$ ratios; Fig. 13). The cuts labelled \#1 to \#3 were repooled prior to mass spectrometry, whereas \#4, the "tail,"' was analyzed separately.

Figure 14 is the isotopically corrected $14 \mathrm{eV}$ mass spectra of the metalloporphyrin isolate of Section 46748-2 just described. The total reconstituted average mass spectrum (i.e., LPLC cuts \#1-\#4; Fig. 13) is shown in Figure 14, B. Prior to reconstitution, on a weighted basis, the "tail" of the LPLC purification (i.e., cut \#4, Fig. 13), representing $7 \%$ of the total mixture, yielded the corrected mass spectrum presented in Figure 14, C. Thus the conclusion that copper ETIO-porphyrins exhibit higher chromatographic polarity than the coincident $\mathrm{Ni}$ chelates was borne out; this conclusion was arrived at before on the basis of electronic spectral characteristics. Further, by conventional liquid chromatography, utilizing visual or hand-held ultraviolet light (i.e., fluorescence) detection, the often-used practice of "heart-cut" fraction collection might lead to elimination of the more polar components that were found to tail in considerable amounts.

"Dissection" of the totally reconstituted mass spectrum into ETIO and DPEP-series has been found to be a valuable technique for assessing the similarities between the copper and nickel components. Normalization of each of the copper and nickel ETIO-porphyrin homologies unto itself and co-plotting the resultant spectra by carbon numbers, rather than $\mathrm{m} / \mathrm{z}$ values, provide the required comparison. Figure 14, A illustrates the result of this process for the $\mathrm{Cu}$ and $\mathrm{Ni}$ ETIO-porphyrin isolated from Section 467-48-2. The striking overlap of these ETIO-porphyrin homologies is immediately apparent and strongly suggests a similar source for these ETIO-series chelates. In line with the previous postulate that dealkylated copper ETIO-porphyrins are derived from, and markers for, oxidized ter-
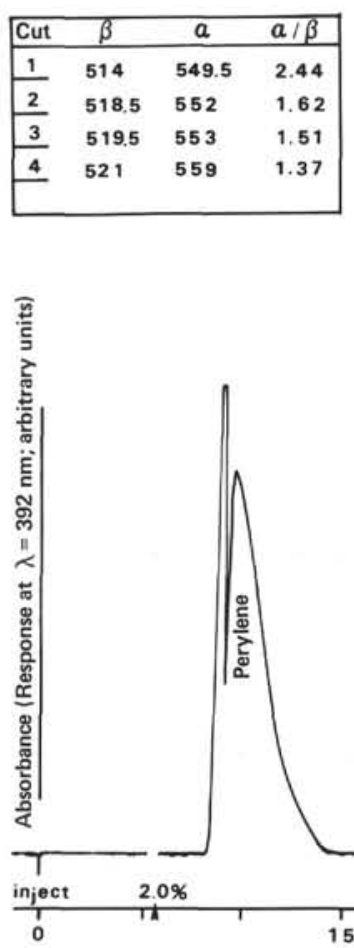

Figure 13. Low-pressure liquid chromatogram of metalloporphyrins isolated from Section 467-48-2. (Column: $8 \times 250 \mathrm{~mm}$. Packing: aluminum oxide, neutral 175-200 $\mu$. Solvent: stepwise gradient, beginning at $1.5 \%$, of acetone [percentages indicated by arrows] in petroleum ether $\left[30^{\circ}-60^{\circ}\right]$ delivered at $12 \mathrm{ml} \mathrm{min}^{-1}, 150 \mathrm{psig}$. Electronic absorption spectra of nickel and copper porphyrin cuts recorded in ethyl ether. Percentages each "cut" represents of the total metalloporphyrin assemblage are: $1=34.3 \% ; 2=50.9 \% ; 3=8.0 \% ; 4=6.8 \%$, using $\Sigma \mathrm{m} M=34.82$ for nickel DPEP at $550 \mathrm{~nm}$.) 

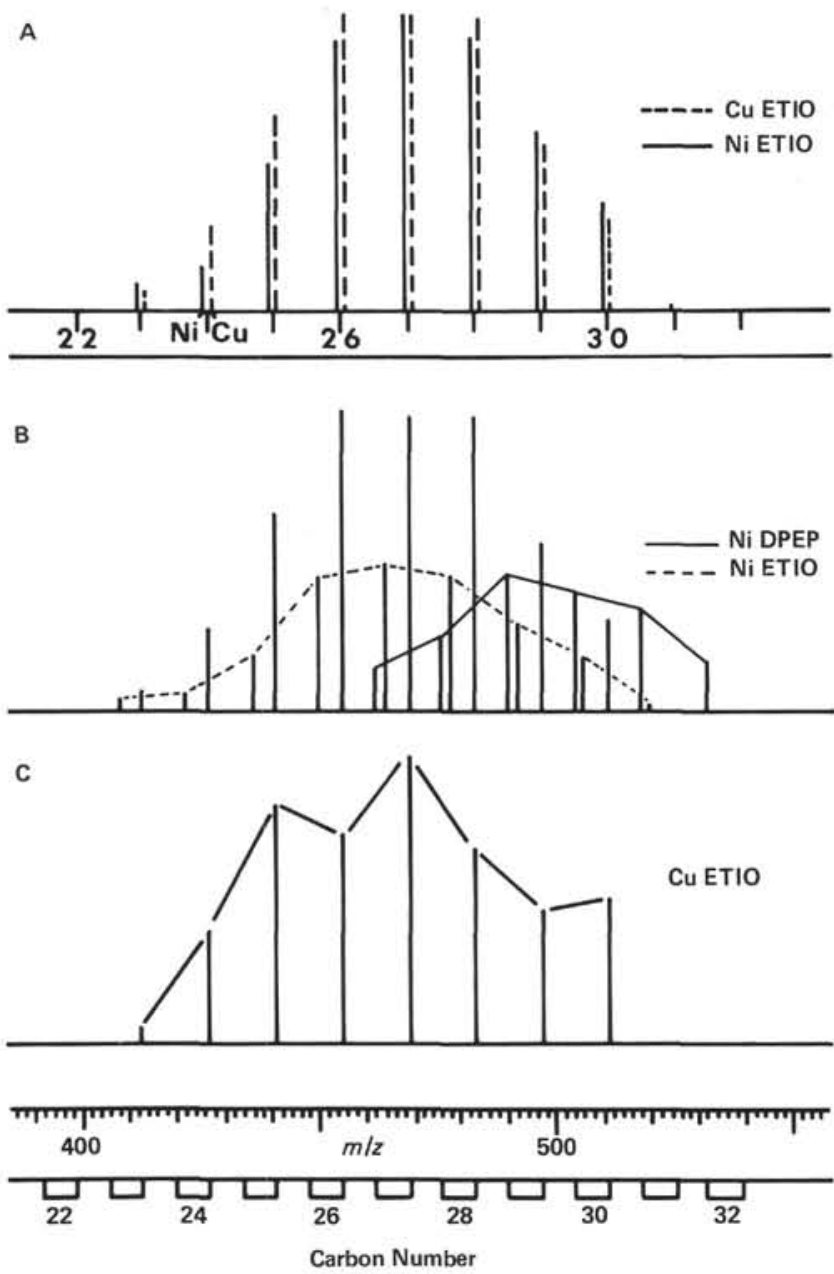

Figure 14. Isotopically corrected $14 \mathrm{eV}$ mass spectra of metalloporphyrins isolated from Section 467-48-2. A. Ni and Cu ETIOporphyrins, each series normalized individually and co-plotted by carbon number. B. Main fractions of LPLC (cf., Fig. 13, Cuts 1, 2, and 3). C. "Tail" fraction from low-pressure liquid chromatography (cf., Fig. 13, Cut 4) consisting only of copper ETIOporphyrins. (See text for details.)

restrial organic matter in marine sediments (Palmer and Baker, 1978), we now see that a coincident nickel component is present. Only the copper chelates, however, afford the required "handle" by which to recognize this contribution.

As an outcome of the above analyses, resultant data, conclusions, and assumptions, the normalized average $14 \mathrm{eV}$ mass spectra of the metalloporphyrin arrays isolated from Leg 63 sediments that contain copper ETIOporphyrins (Table 5) were manipulated in like manner and the percentage of copper and nickel ETIO-porphyrins calculated. The values obtained were then directly equated to a "Per-Cent Terrigenous" contribution to the metalloporphyrins found in Sections 467-32-2 to 467-58-3, inclusive, and Section 471-34-2 as reported in Table 4. Section 467-25-6 is reported (Table 4) as containing $100 \%$ terrigenous metalloporphyrins solely on the basis of electronic spectra (due to a lack of an adequately purified final isolate for mass spectrometry). The resultant values reported as the "Per-Cent Terrig- enous" metalloporphyrin contribution, and applying only to metalloporphyrins (i.e., not total organic matter), are further discussed later during considerations of the in situ diagenesis of autochthonous chlorophyll derivatives.

As part of Table 4, the nickel to copper ratio of the ETIO-porphyrin components of each mixed isolate is reported. These values were calculated in an effort to find any relationship between the relative abundance of nickel or copper and potential sources of these metals or the environments in which chelation took place. No direct relationship is obvious, as yet. On a purely speculative basis, one might propose that the decrease in the ratio of $\mathrm{Ni}$ to $\mathrm{Cu}$, progressing from Sections 467-58-3 to 467-32-2, is due to an increase in the oxidizing nature of depositional environments from the upper Miocene to lower Pliocene at the San Miguel Gap locale. This would then stem from two interrelated facts regarding nickel and copper. First, the solubilities of nickel and copper salts (e.g., oxides, sulfates, and hydrates of same) expected in oxidizing waters are not that much different, when compared to the increased solubility that nickel sulfide exhibits in relation to that exhibited by the corresponding copper compound in anoxic environments. Secondly, the known reaction kinetics for the chelation of copper and nickel by porphyrins dictates faster reaction with copper, forming very stable complexes (e.g., see Erdman et al., 1957), and may lead to preferential copper chelation by the terrestrial ETIOporphyrins when deposited into oxic marine sedimentary environments.

Minor amounts of copper DPEP-series porphyrins were identified in the metalloporphyrin isolates from Sections 467-32-2 and 467-36-2 (Table 5). The homologies of these porphyrins matched neither the coincident $\mathrm{Ni}$ DPEP-series nor the $\mathrm{Cu}$ and Ni ETIO-porphyrin distributions. At present, the source of Cu DPEP appears enigmatic, though copper chelation by the diagenetically immature products of either autochthonous or allochthonous chlorophylls, if deposition was oxidizing, may be a possibility to explore further.

\section{Nickel Porphyrins}

Middle to upper Miocene sediments, both from the San Miguel Gap and Baja California sites (i.e., Sections 467-63-2 to 467-110-3, inclusive, and Sections 471-50-2, 471-69-3: Tables 4 and 5) yielded metalloporphyrin arrays consisting only of nickel chelates. Section 467-1103 also contained vanadyl porphyrins, as we discuss later.

Electronic (Table 4) and mass spectrometric analyses (Table 5) of the nickel porphyrin isolates show these pigments to be characteristic of marine sedimentary metalloporphyrins, as previously reported from various DSDP site localities (e.g., see Baker et al., 1978, 1979; Palmer and Baker, 1980).

The application of low-pressure liquid chromatography, especially with Soret absorption monitoring (e.g., $392 \mathrm{~nm}$ ), afforded rapid purification of nickel porphyrins with collection of the entire complement of pigment (see the section on Materials and Methods). As discussed earlier, the heterogeneity of porphyrin mix- 
Table 5. Normalized-average $14 \mathrm{eV}$ mass spectra of metalloporphyrin assemblages isolated from DSDP/IPOD Leg 63, Site 467.

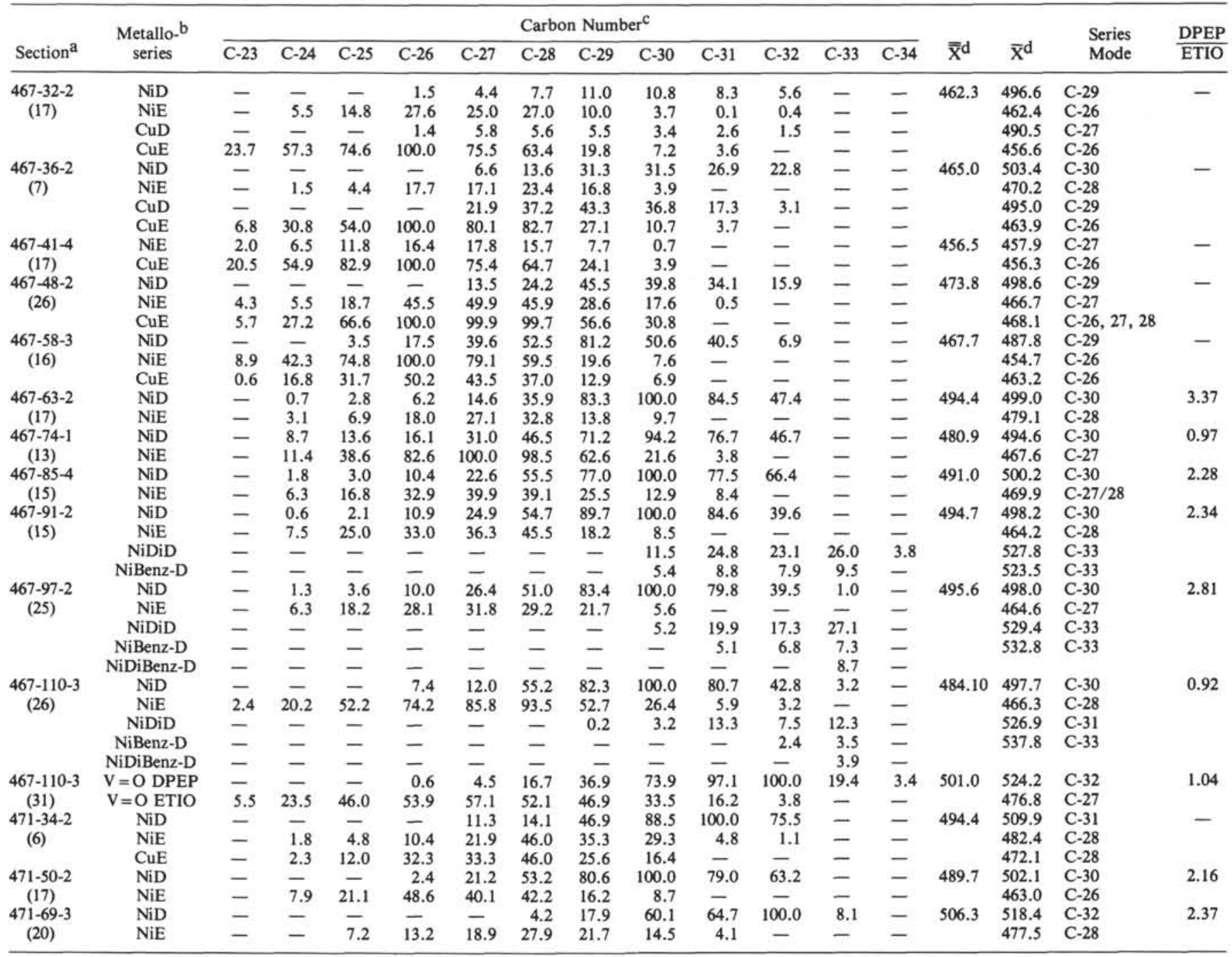

${ }^{a} \mathrm{~N}$ refers to number of spectra employed in averaging processes.

b NiD, CuD refers to nickel or copper chelate of DPEP-series; NiE, CuE refers to nickel or copper chelate of ETIO-series; NiDiD refers to di-DPEP type porphyrin or alternately a dihydro-benz structure; NiBenz-D and NiDiBenz-D refers to porphyrin-nickel complexes with molecular weights equal to calculated benzporphyrin and dibenzporphyrin structure of the DPEP-series (note that NiBenz-D could also be a Ni di-Benz of the ETIO-series). Refer also to text.

c Molecular weights (nominal) and carbon numbers for each series of nickel, copper, and vanadyl chelates given in the Appendix.

$\mathrm{d} \overline{\mathrm{X}}$ is the weighted average mass of the entire metalloporphyrin array for the sample indicated. $\overline{\mathrm{X}}$ refers to a weighted average mass of a specific porphyrin (e.g., $\overline{\mathrm{X}}_{\mathrm{D}}$ of NiDPEP, etc.). Refer to notes $\mathrm{d}$ and $\mathrm{e}$ of Table 3 and cf., Baker and Palmer, 1978.

tures often leads to unwanted series and homology selection during so-called routine analyses. Demonstrating this fact with the nickel porphyrins we present the data given in Figures 15 and 16.

The organic solvent extractable portion of sedimentary organic matter usually contains high molecular weight compounds, which can interfere with subsequent analytical procedures when we are focusing on biomarker pigments. A common preliminary step in the analyses of porphyrins is gel-permeation chromatography (i.e., GPC: cf., Baker and Palmer, 1978). During the initial GPC of the crude extracts from sediments returned by Leg 63, as in previous studies, all eluates from all chromatographies are investigated for tetrapyrrole pigments. A remarkable fraction of nickel porphyrins has been observed during the "mild" technique of GPC. Figure 15, A is the corrected mass spectrum of a minor "tail" fractionation from the GPC of the extract of Section 467-110-3, following subsequent purification via LPLC. Relatively large amounts of C-23 to C-27 Ni ETIO-porphyrins were found to have been retarded during GPC. The main fraction from this separation, and the only one visibly containing pigmented matter, did, on a weighted basis, contain the majority of porphyrin. However, examination of Figures 15, B, the corrected mass spectrum of the main fraction, and $15, \mathrm{C}$, the reconstitution of the mass spectrum of total nickel porphyrins from Section $467-110-3$, shows that the C-23 ETIO chelate (i.e., porphin with alkylation equivalent to 3 methylene units) was entirely excluded from the main nickel porphyrin GPC isolate.

As discussed earlier for free-base and copper-nickel porphyrin isolates, further selection of both series and homologues can occur during volatilization of nickel 

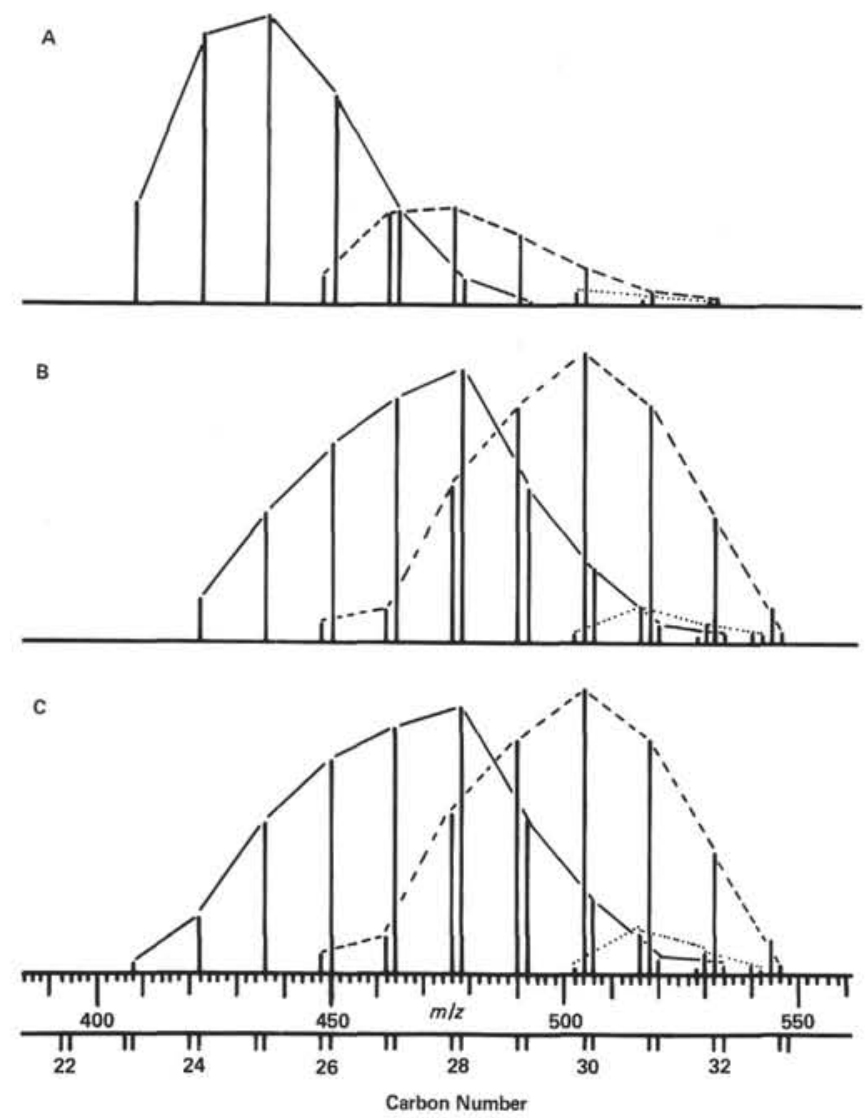

Figure 15 . Isotopically corrected $14 \mathrm{eV}$ mass spectra of nickel porphyrins isolated from Section 467-110-3. A. "Tail" of gel permeation fraction. B. Main, "red," band from gel permeation. C. Total reconstituted mass spectrum (ETIO-series is delineated by solid line, DPEP by dashed line, di-DPEP (alt., dihydrobenz) by dotted line, and Benz-porphyrins (ETIO-6 $\mathrm{m} / \mathrm{z}$ ) are unmarked; see text for details).

porphyrin isolates. Rapid heating of a sample will indeed produce interpretable mass spectra. However, during careful distillation of these isolates one is better able to observe and record the lower homologues (e.g., C-23 to C-25), often obscured by co-isolated contaminants in the range of 350 to 450 daltons. Figure 16 illustrates the observed changes in the uncorrected, real-time, mass spectra of the nickel porphyrin isolate from Section 471-50-2. Not only does the average weighted mass (i.e., $\overline{\mathrm{X}}$; cf., Table V) change during distillation, but also large increases in the ratio of DPEP to ETIO chelates were found. So profound can the selective distillation of porphyrin be that scan 17 , the last spectrum of this analysis yielding porphyrin ions, was found to represent only five Ni DPEP homologues. Further, the total reconstituted and isotopically corrected $14 \mathrm{eV}$ mass spectrum of the nickel porphyrins from this section (i.e., 471-50-2, Table 5) yielded a DPEP-to-ETIO ratio of 2.16 and a weighted average mass of 489.7 . Such a pattern was not represented by any single spectrum obtained.

The nickel porphyrin isolates from the San Miguel Gap samples, taken below the upper Miocene to upper Pliocene claystones containing large amounts of highly

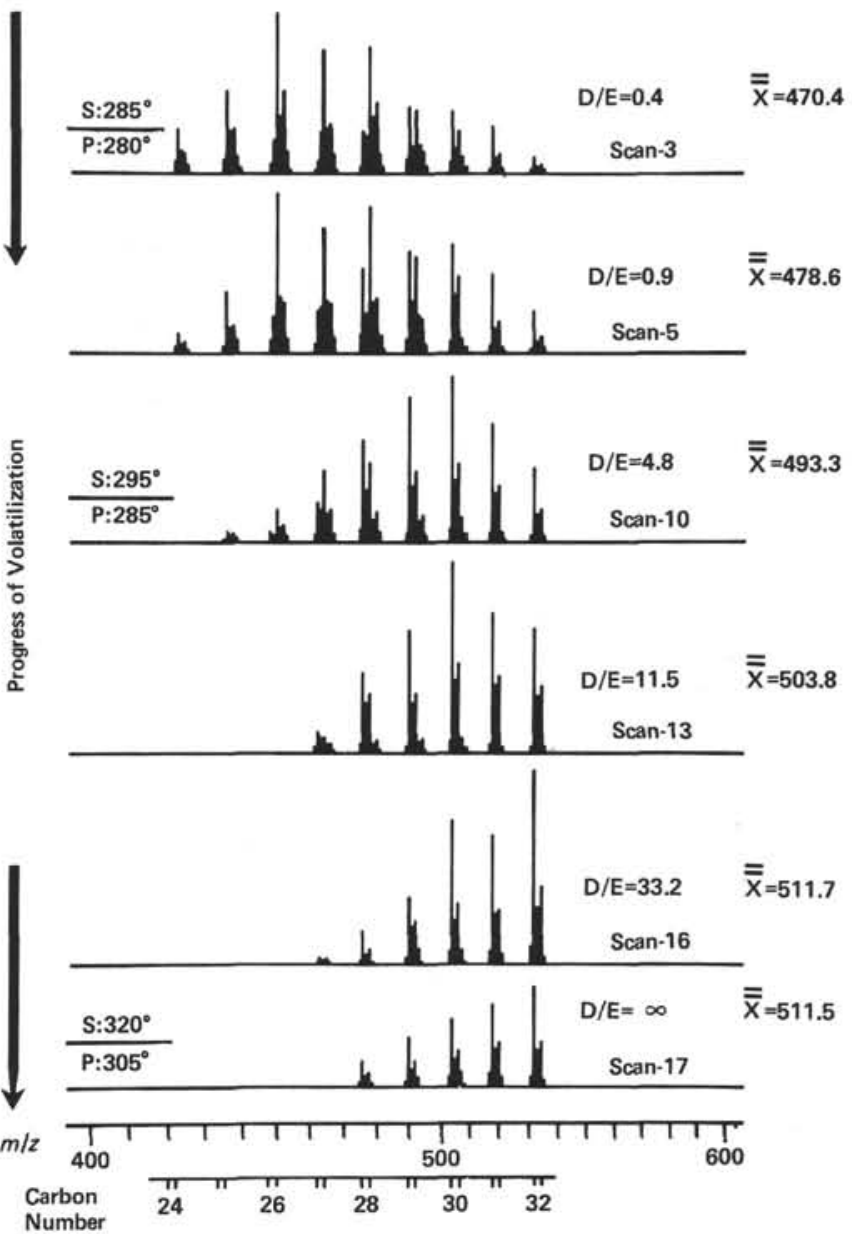

Figure 16. Changes in mass spectra of nickel porphyrins isolated from Section 471-50-2 during volatization of the sample. (Total corrected mass spectrum yielded a DPEP to ETIO ratio [i.e., D/E] of 2.16 and an overall weighted average mass [i.e., X] of 489.7 [c.f., Table 5 and text].)

dealkylated copper and nickel ETIO-porphyrins (viz., terrestrially derived pigments), illustrate well the maturation of marine metalloporphyrins that comes with increased depth of burial (i.e., thermal stress). Examining the mass spectral distributions (Table 5) of nickel porphyrins isolated from Sections 467-63-2 to 467-110-3, inclusive, several overt changes can be found. Except for the anomalously low DPEP-to-ETIO ratio of the nickel porphyrins from Section 467-74-1, an orderly and explainable change in DPEP-to-ETIO ratios was found. Choosing Section 467-63-2 as a starting point for nickel porphyrin thermal maturation, and ignoring for the moment the Section 467-74-1 isolate, we observe an increase in the amount of Ni ETIO in the Section 467-85-7 array. This initial Ni DPEP to Ni ETIO conversion is then followed by a minor increase in the amount of $\mathrm{Ni}$ DPEP (viz., Sections 467-91-2, 467-97-2, Table 5) and finally a large conversion of Ni DPEP to Ni ETIO in the deepest sample (viz., 467-110-3, Table 5). The conversion of metallo-DPEP to metallo-ETIO porphyrins with increased thermal stress applied by retort (Morandi and Jensen, 1966), laboratory experimentation (Didyk et al., 
1975), or observed through the analyses of naturally occurring geologic assemblages (Baker, et al., 1967, 1977, 1978b; Didyk et al., 1975; HajIbrahim and Eglinton, in press) is a well accepted fact, though exact reaction kinetics are lacking. Concurrent with the minor increases in the DPEP-to-ETIO ratio of Ni porphyrins from Sections 467-91-2 and 467-97-2 is the appearance of C-33 Ni DPEP and C-30 to C-33 homologies of Ni Di DPEP (alt., Ni dihydroBENZ-DPEP) and the BENZ-DPEP chelates. Quite recently the proposed BENZ-porphyrin structure (Baker et al., 1967; Yen et al., 1969) has been proven by the isolation of phthalimide and methyl phthalimide from the chromic acid oxidation of the petroporphyrins from Boscan distillates (Barwise and Whitehead, 1980; in press). The appearance of alkyl metallo-DPEP homologues above C-32 and the metalloDi DPEP and BENZ-porphyrin structures in the deeper sections of the San Miguel Gap strata suggests a direct correlation to thermal stress and possible release of these structures from a bound state (e.g., linkage to kerogen, asphaltenes, resins).

Though samples are limited in the Baja California borderland suite studied (i.e., Site 471), the appearance of C-33 Ni DPEP in the isolates from Section 471-69-3 suggests that the thermal maturation of metalloporphyrins in these strata (viz. $650 \mathrm{~m}$ sub-bottom depth) is just beginning. Summaries of thermal profiles and the relation to chlorophyll diagenesis/catagenesis follow in the Discussion.

\section{Nickel Porphyrin Acids and Keto-Acids from Site $\mathbf{4 7 1}$}

A unique and highly complex array of metalloporphyrins was found to be present in an upper middle Miocene silty claystone recovered from the Baja California borderland sequence (viz., Section 471-34-2). Figure 17 illustrates the separation and characterization of the three metalloporphyrin classes isolated from this sediment sample. In a manner identical to that previously described for the isolation of nonfunctionalized nickel and copper-nickel porphyrins, the main component (see Tables 2, 4, and 5) was found to be a mixture of Ni DPEP and $\mathrm{Cu} / \mathrm{Ni}$ ETIO-porphyrin homologues. The distribution of these pigments suggests concurrent input of autochthonous marine chlorophylls, geochemically evolving into the Ni DPEP-series, and an influx of terrestrially derived (allochthonous) dealkylated ETIOporphyrins isolated as nickel and copper chelates. The $\mathrm{Cu}$ and Ni ETIO-porphyrins isolated from Section 471-34-2 presumably have a different source than those found in the San Miguel Gap claystones (viz., Sections 467-32-2 to 467-58-3, inclusive). This postulation stems from the finding that the mode of the $\mathrm{Cu}$ and Ni ETIOporphyrins from Site 467 is vastly predominant at C-26, whereas C-28 dominates both the $\mathrm{Cu}$ and Ni ETIO-porphyrins from Section 471-34-2. Further, the sediments yielding the $\mathrm{Cu}$ and Ni ETIO-porphyrins array from Site 471 are geologically older than those from the more northern Site 467 (cf., Table 1, 4, and 5).

Polar nickel porphyrins also were isolated from Section 471-34-2 (see Fig. 17 and Table 4). These pigments eluted from columns of silica gel only with $20 \%$ to $25 \%$ acetone in cyclohexane and were thus suspected of possessing free carboxylic acid moieties. The electronic absorption spectrum of this mixed isolate exhibited Soret absorption at $392 \mathrm{~nm}$ and three maxima in the visible range at 512,551 , and $583 \mathrm{~nm}$. The $583 \mathrm{~nm}$ absorption has been reported previously as "tetrapyrrole-586," and on the basis of chromatographic behavior and borohydride treatment was tentatively classified as a decarboxylated nickel phylloerythrinlike pigment (Leg 57, Baker and Louda, 1980).

In the present case, the polar nickel porphyrins, isolated from Section 471-34-2, were esterified with diazomethane and rechromatographed over alumina, affording separation into two components. Nickel porphyrin acid methyl esters eluted with $1 \%$ acetone in petroleum ether, whereas the more polar nickel phylloporphyrin acid methyl ester(s) eluted with $15 \%$ acetone in petroleum ether.

The less polar fraction (C-32 to C-29) was tentatively identified as a four-membered homology of nickel deoxophylloerythrin, presumably the carboxylated precursor of the Ni DPEP-series. The $70 \mathrm{eV}$ mass spectrum recorded was obtained only after a third trial, and rapid heating of the probe was required. An odd molecular weight series, corresponding to the composite losses of $59\left(-\mathrm{COOH}_{3}\right), 73\left(-\mathrm{CH}_{2} \mathrm{COOCH}_{3}\right)$, and $87\left(-\mathrm{CH}_{2} \mathrm{CH}_{2}\right.$ $\mathrm{COOH}_{3}$ ), was observed. The $\beta$-cleavage product (M-73) is known to dominate this fragmentation process with the porphyrin-acid methyl esters (Louda and Baker, unpublished data; cf., Budzikiewicz, 1978). The rapid heating of the sample and the presence of large amounts of lower molecular weight contamination (i.e., $\mathrm{m} / \mathrm{z}<$ 400 ) presumably lead to the unusual fragmentation and lack of parent ions found. In any case, the isolation of nickel porphyrins (identified as nickel by isotopic ratios and electronic spectra) containing a carboxylic acid moiety and lacking auxochromes (e.g., vinyl, keto) is noted.

The more polar nickel porphyrin acid methyl ester fraction, believed to be nickel phylloerythrin, exhibited an electronic spectrum (see Fig. 17 and Table 4) with Soret absorption at $394.5 \mathrm{~nm}$ and visible bands at 551 and $583 \mathrm{~nm}$, similar to published spectra for authentic nickel phylloerythrin (Hodgson and Baker, 1967). Studies underway show that the Soret position of this isolate (i.e., $\lambda=394.5 \mathrm{~nm}$ ) is due to the presence of co-eluted $\mathrm{Cu}$ and $\mathrm{Ni}$ porphyrins. The exact position of the $\mathrm{Ni}$ phylloerythrin Soret band is $406.5 \mathrm{~nm}$ (Baker and Louda, in preparation). Suspecting this isolate of being nickel phylloerythrin and knowing from previous reports (Holt, 1959) that the 9-keto porphyrins undergo facile reduction, we performed treatment with sodium borohydride in ethanolic ethyl ether. After an 18-hour exposure to trace borohydride (see Fig. 17), partial conversion to an oxy-deoxo derivative was found. Continued reaction for an additional 18 hours lead to the total disappearance of absorption at $583 \mathrm{~nm}$ and a hypsochromic shift in visible band position to 512 and 552 $\mathrm{nm}$. Concurrently, Soret absorption shifted from 394.5 to $392 \mathrm{~nm}$. All of these changes are consistent with this isolate being nickel phylloerythrin and the product of 

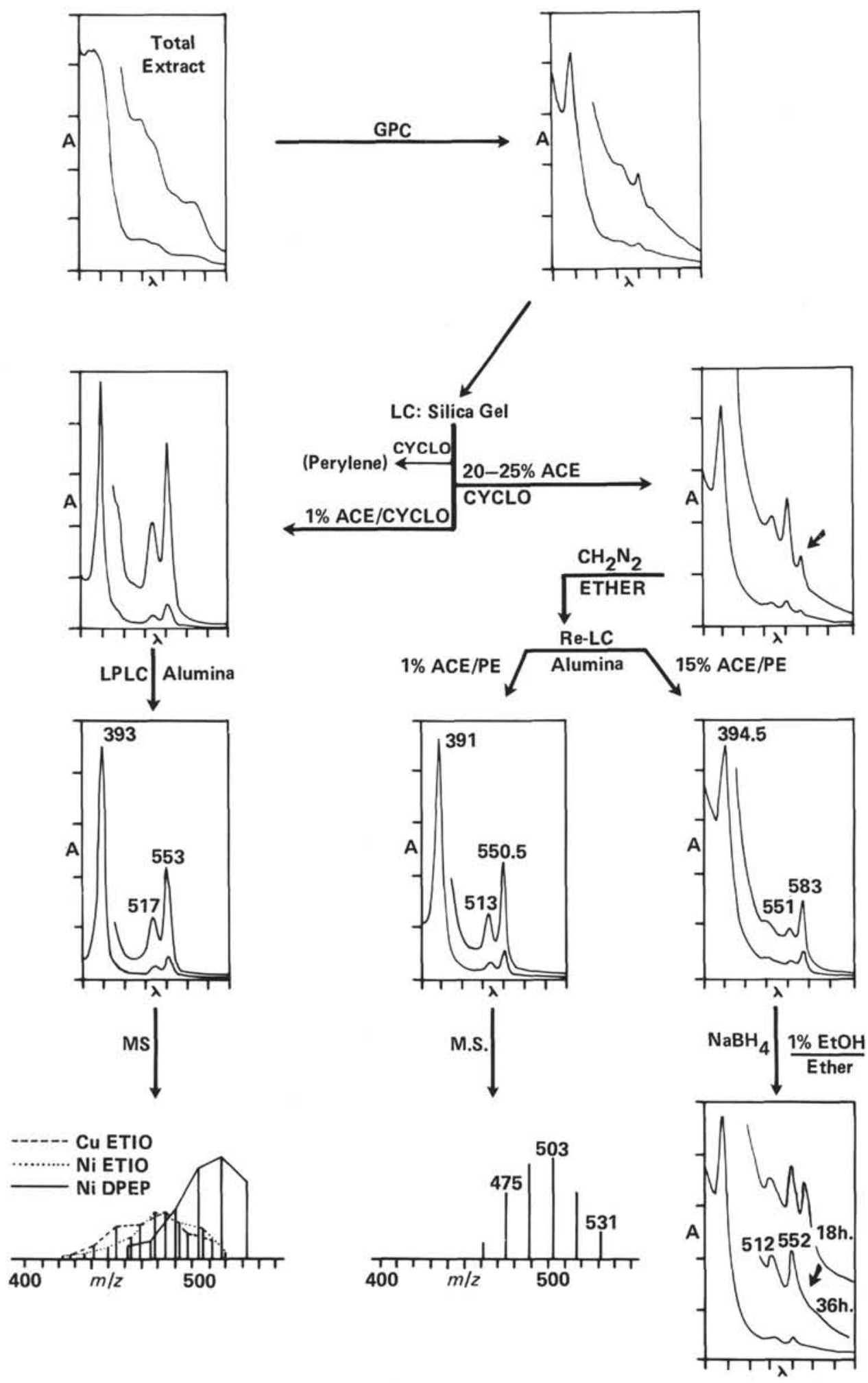

Figure 17. Separation and identification scheme utilized with metalloporphyrins isolated from Section 471-34-2. (Electronic spectra in ethyl ether. Mass spectra shown corrected for isotopic contributions of $\mathrm{Ni}^{60}, \mathrm{Cu}^{65}, \mathrm{C}^{13}$, and $\mathrm{H}^{2}$. Abbreviations: $\mathrm{ACE}=$ acetone; $\mathrm{PE}=$ petroleum ether $\left[30-60^{\circ} \mathrm{C}\right]$; CYCLO = cyclohexane; EtOH = ethanol; Ether = ethyl ether; GPC = gel permeation chromatography [Sephadex LH-20 ; tetrahydrofuran as mobil phase]; LC = liquid [column] chromatography; LPLC $=$ low pressure [high performance], liquid chromatography; $\lambda=$ wavelength, all spectra from $350-700 \mathrm{~nm} ; \mathrm{A}=$ absorbance, all spectra 0-1 AUFS.) 
borohydride reduction being nickel 9-oxy-deoxo-phylloerythrin. As only trace amounts $(<4 \mu \mathrm{g})$ of nickel phylloerythrin were isolated, mass spectrometric analyses were not possible.

Nickel phylloerythrin was also indicated in the San Miguel Gap sediments recovered from 70 to 691 meters sub-bottom depth (see Table 2), but only through the presence of marked absorption maximum at ca. $583 \mathrm{~nm}$ in the electronic spectra of impure isolates.

The sedimentary sequence including Sections 471-342 , 471-50-2, and 471-69-3 illustrates quite well the late diagenesis to early catagenesis of marine nickel porphyrins (cf., Table 2). Section 471-34-2, recently discussed, yielded the nickel complexes of phylloerythrin, deoxophylloerythrin, and a homology of the DPEP series. Section 471-50-2 was found to contain only nickel deoxophylloerythrin and homologies of decarboxylated DPEP and ETIO chelates. The deepest section, 471-69-3, yielded only NI DPEP and ETIO-porphyrins; C-33 Ni DPEP was observed in this section (Table 5).

\section{Vanadyl Porphyrins}

Vanadyl porphyrins were isolated only from the most deeply buried (i.e., 1,035 m sub-bottom depth) sample studied from the San Miguel Gap site (467-110-3). The positions of electronic absorption maxima at 401.5, 531, and $569 \mathrm{~nm}$ (see Fig. 11, C) are shifted slightly to higher energy, compared to spectra recorded in benzene (e.g., $407,533,571-2 \mathrm{~nm}$ ), because we utilized ethyl ether as the standard spectroscopy solvent in our studies.

Vanadyl porphyrins are easily separated from other metalloporphyrins via standard silica gel chromatography. Removal of nonporphyrin nitrogenous bases was accomplished by passing semipurified vanadyl porphyrin isolates over a chromatographic bed of "BP functionalized silica"' (registered U.K. Patent Office \#2030-564, see Barwise and Whitehead, in press). Final purification, prior to mass spectrometric characterization, was performed by rechromatography over standard silica gel.

The total averaged $14 \mathrm{eV}$ mass spectrum of the vanadyl porphyrins isolated from Section 467-110-3 (Fig. 18) exhibits the presence of 9 DPEP-homologues, 10 ETIO-homologues, and covers a carbon number range from C-23 ETIO to C-34 DPEP. The DPEP-toETIO ratio of the Section 467-110-3 vanadyl porphyrins is 1.04 , indicating a point near the half-life of this conversion (i.e., DPEP/ETIO $=1.00$ at $t_{1 / 2}$ ). The vanadyl porphyrins isolated from this San Miguel Gap sediment may be viewed as representing the products first appearing as a result of the thermal or thermocatalytic release of vanadyl porphyrins from maturing organic matter (e.g., asphaltenes, kerogen; cf., Baker et al., 1977; Mackenzie et al., in press). Homologous series of vanadyl porphyrins up to the range of C-38 to C-50 plus are often reported from various petroleum crudes (Baker et al., 1967; Barwise and Whitehead, in press) and their suspected source rocks (Didyk et al., 1975). The vanadyl porphyrins isolated from Section 467-110-3 may therefore represent the initiation of vanadyl por- phyrin release from kerogen, with higher homologue appearance coming only with further thermal treatment. The mass spectral distribution of vanadyl porphyrins isolated from this San Miguel Gap middle Miocene silty claystone is very reminiscent of porphyrin patterns reported for Santiago (Pleistocene?), Belridge (Pliocene), and Wilmington (Miocene) crudes from mainland California (Baker et al., 1967) in that the higher homologues (i.e., > C-34) are absent and also in that they exhibit DPEP-to-ETIO ratios between 0.82 and 2.9.

\section{Nonporphyrin Pigments}

The tetraterpenoid pigments (viz., carotenoids) and the PAH compound perylene were investigated during analyses of Leg 63 sediment samples in order to assess possible correlations between these pigments, the tetrapyrrole pigments, depositional environments, and organic sources.

\section{Carotenoids}

Two samples from the San Miguel Gap suite yielded enough carotenoid pigment for further analyses. Sections 467-8-5 and 467-18-5 yielded carotenoid (viz., $\beta$-carotene; $\mathrm{C}_{40} \mathrm{H}_{56}$ ) concentrations of 53.0 and 80.9 $\mathrm{ng} / \mathrm{g}$ sediment on a dry weight basis. $\beta$-Carotene eluted from columns of microcrystalline cellulose (cf., Fig. 1) with petroleum ether and was purified via chromatography on thin layers $(250 \mu \mathrm{m})$ of silica gel G developed with petroleum ether containing $1 \%$ acetone $(\mathrm{V} / \mathrm{V})$. This also allowed separation of $\beta$-carotene from the more strongly absorbed PAH, perylene if present.

$\beta$-Carotene was entirely epiphasic to partition between n-hexane and $95 \%$ aqueous methanol (see Foppen, 1971; Krinsky, 1963). The electronic absorption spectra of $\beta$-carotene isolated either from Section 467-8-5 (Fig. 19) or Section 467-18-5 exhibited an inflection at 425 or $438 \mathrm{~nm}$ and maxima at 449 or $462 \mathrm{~nm}$ and 478 or $489 \mathrm{~nm}$, depending on the solvent (petroleum ether or benzene, respectively). The bathochromic shift in the position of absorption maxima between petroleum ether and benzene solutions is quite characteristic of these polyene pigments (cf., Vetter et al., 1971). Because of the presence of minor amounts of impurities absorbing in the near ultraviolet, valid spectra could not be obtained below ca. $360 \mathrm{~nm}$; thus the presence of the characteristic cis-peak at $338 \mathrm{~nm}$ in the electronic spectrum of $\beta$-carotene (cf., Vetter et al., 1971; Zechmeister, 1958 ) is unknown.

Mass spectra of $\beta$-carotene isolates and authentic standards (Roth Laboratories, West Germany) were determined both at $70 \mathrm{eV}$ and $12 \mathrm{eV}$ ionization potentials (for details see the section on Materials and Methods). Figure 20 compares the $12 \mathrm{eV}$ spectrum of authentic $\beta$-carotene (Fig. 20, A) with the $70 \mathrm{eV}$ spectrum of the Section $467-8-5$ isolate (Fig. 20, B), and the $12 \mathrm{eV}$ spectrum obtained from $\beta$-carotene $(536 \mathrm{~m} / z)$ in all cases was found to be the base peak $\left(\mathrm{M}^{+}\right)$. Only in $70 \mathrm{eV}$ spectra was a doubly charged ion observed. This peak, 267 $m / z$, is ascribed to formation of a doubly charged species from the $[\mathrm{M}-1]^{+}$peak of $\beta$-carotene. In $12 \mathrm{eV}$ 


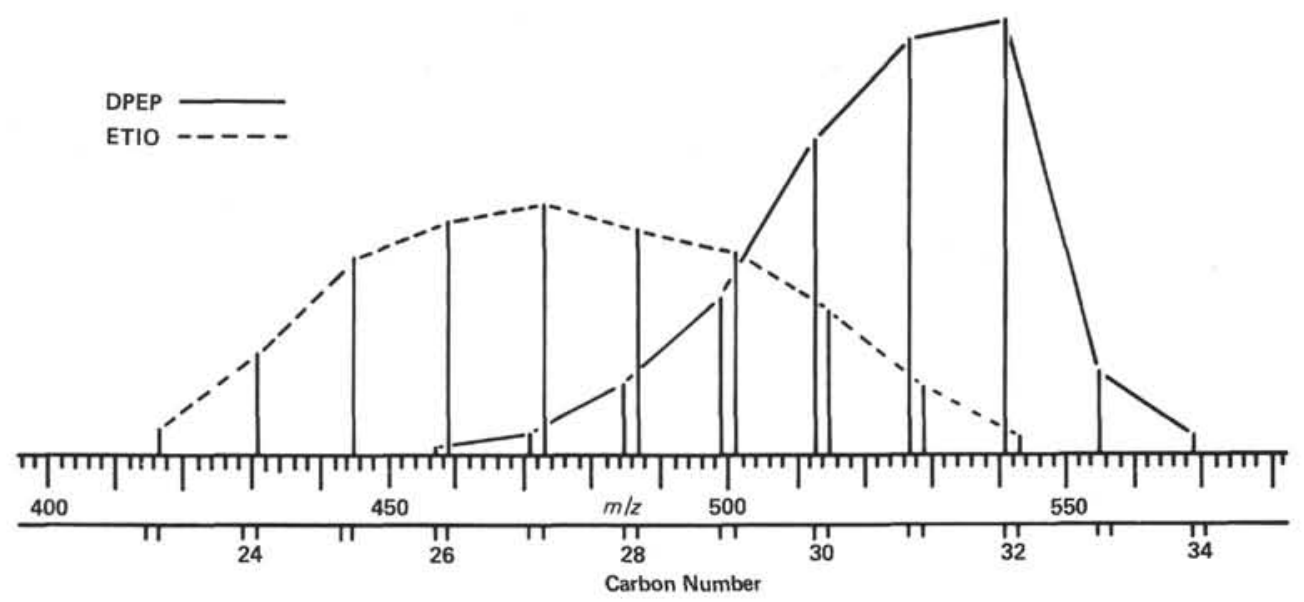

Figure 18. Partial $14 \mathrm{eV}$ mass spectrum of vanadyl porphyrins isolated from Section 467-110-3 (see text for details).

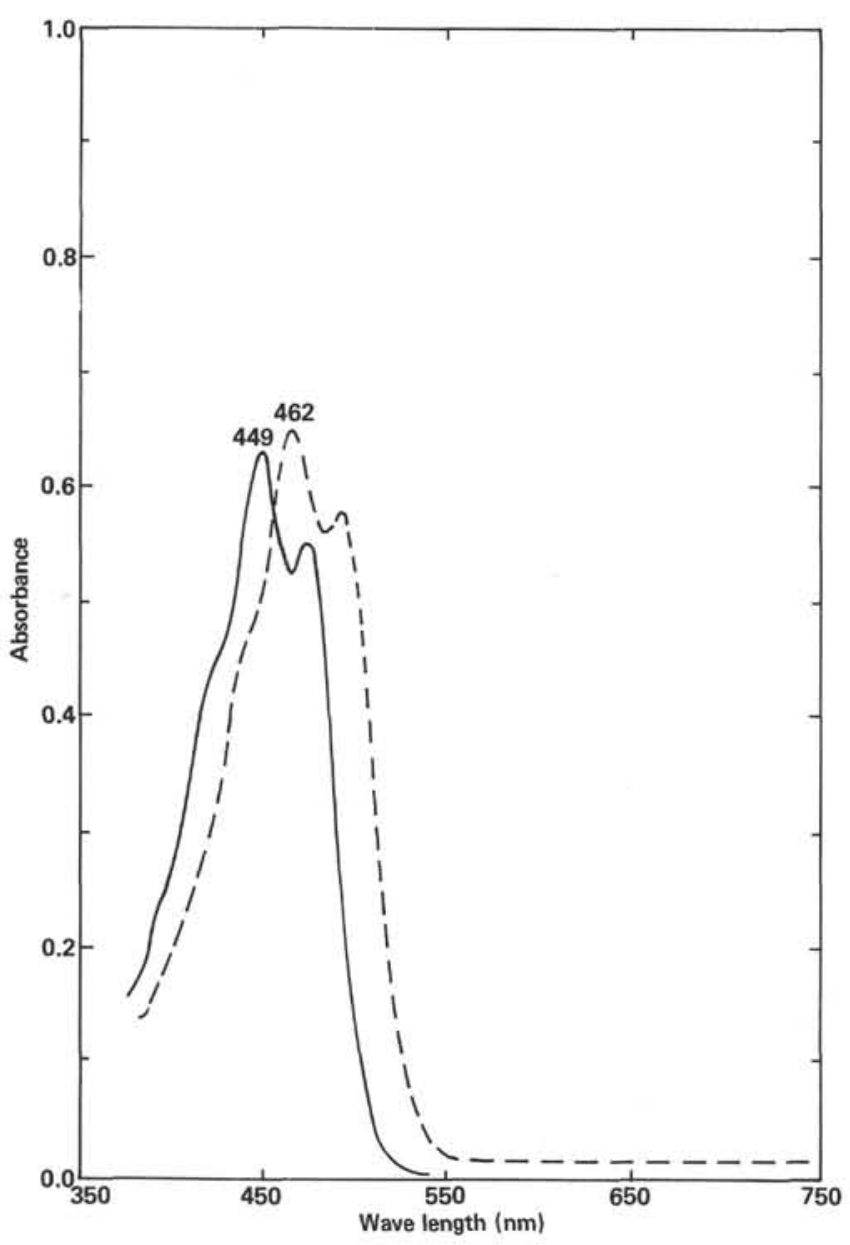

Figure 19. Electronic spectrum of $\beta$-carotene isolated from Section 467-8-5 (solvents: petroleum ether, solid trace; benzene, dashed trace).

spectra of $\beta$-carotene authentic and Site 467 isolates, consistent M-2 ions were observed. In the higher energy $70 \mathrm{eV}$ spectra, M-4 ions appeared. These observations suggest that care be exercised in interpreting high energy mass spectra of geologic carotenoid isolates, if diagenetic dehydrogenation (viz., aromatization) is sus- pected. Major fragment ions from $\beta$-carotene, in either 12 or $70 \mathrm{eV}$ spectra, were found at $444 \mathrm{~m} / z$, M-92, and $378 \mathrm{~m} / z, \mathrm{M}-158$. These losses correspond to the loss of toluene and $\mathrm{C}_{12} \mathrm{H}_{20}$, respectively (Vetter et al., 1971). The loss of xylene, M-106 (i.e., $430 \mathrm{~m} / z$ ), reported by others (Vetter et al., 1971) was not observed in either the $12 \mathrm{eV}$ or $70 \mathrm{eV}$ spectra of $\beta$-carotene isolates or standards.

$\beta$-Carotene and other carotenoids have previously been reported from marine sediments recovered from the California borderland (Fox et al., 1944; Schwendinger and Erdman, 1963), the Japan Trench (DSDP/ IPOD Legs 56, 57, Baker and Louda, in press; Louda et al., in press), and from more deeply buried sediments returned from the Cariaco Trench (DSDP Leg 15, Watts and Maxwell, 1977) and the Blake-Bahama Basin (DSDP Leg 44, Cardoso et al., 1978).

Carotenoids, presumably as nonpigment diagenetic derivatives, may contribute to the generation of certain components of petroleum (e.g., toluene; xylene; 2,6dimethyl-napthalene, ionene, etc.; cf., Day and Erdman, 1963; Hunt, 1979) and conceivably could be precursors to such early diagenetic C-4 to C-7 hydrocarbons as the gem-dimethyl alkanes reported from various sediments recovered by DSDP operations (Legs 42, 2 and 44: Hunt and Whelan, 1978a and b).

Currently, the diagenesis of carotenoids that survive until sediment stabilization and development of anoxic conditions is believed to be via progressive reduction of the polyene skeleton (Watts and Maxwell, 1977) and may well lead to the formation of such fossilized tetraterpenoids as perhydro-carotene ${ }^{2}$ (i.e., carotane, Murphy et al., 1967) and perhydro-lycopene (i.e., lycopane: Kimble et al., 1974) isolated from the Green River and Messel oil shales, respectively.

The isolation of significant amounts of $\beta$-carotene from Sections 467-8-5 and 467-18-5, and an indication of the same in Section 467-13-4, together with the ab-

\footnotetext{
2 In our original article the $\mathrm{C}_{40} \mathrm{H}_{78}$ compound was identified as perhydro- $\beta$-carotene. We have opted to delete the $\beta$-classification, because the positioning of double bonds in the biologic precursors to this geologic product cannot be given.
} 


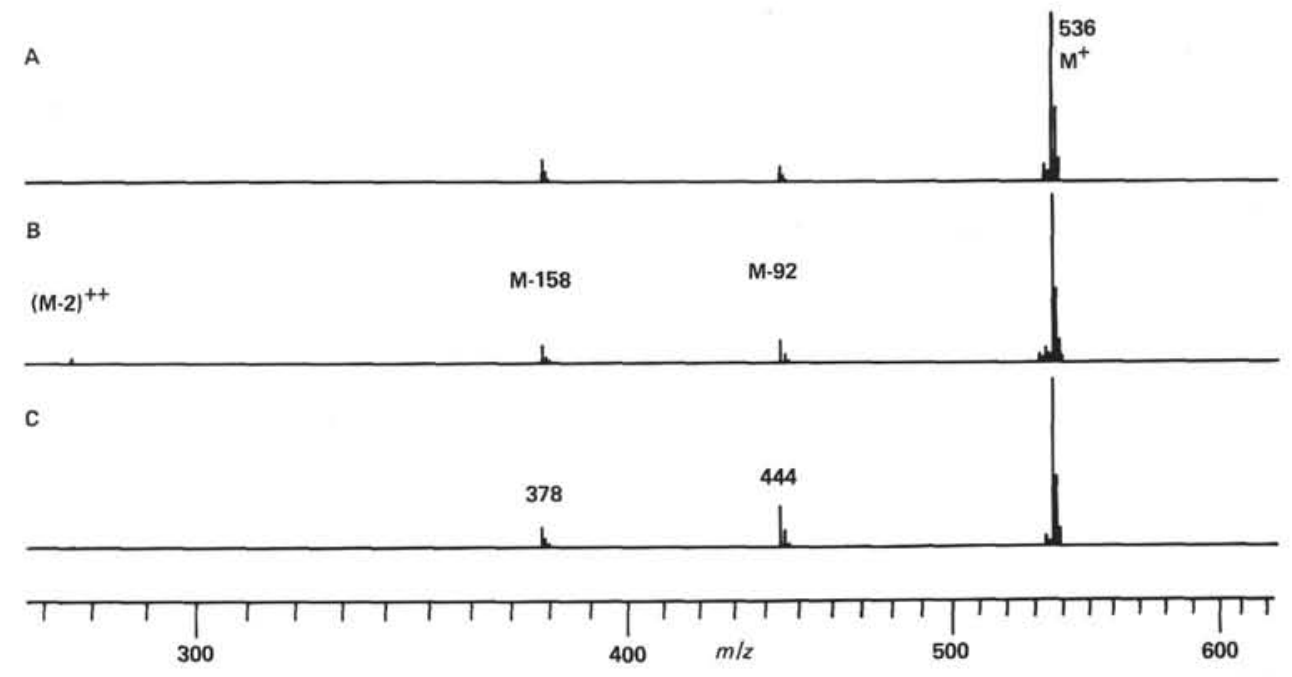

Figure 20. Mass spectra of $\beta$-carotene. A. authentic, 12eV; B. Section 467-8-5, $70 \mathrm{eV}$; C. Section 467-18-5, $12 \mathrm{ev}$; determined via solid probe, direct insertion, with probe temperatures $250^{\circ} \mathrm{C}$ to $270^{\circ} \mathrm{C}$, and source temperatures $270^{\circ} \mathrm{C}$ to $285^{\circ} \mathrm{C}$.

sence of carotenoids above and below these sections, exactly corresponds to an increase in the pigment yield index (PYI) determined from the tetrapyrrole pigments (cf., Fig. 4). Thus it is suggested that the upper Pliocene and lower Quaternary sediments recovered from 70 to 165 meters sub-bottom depth at the San Miguel Gap site were deposited from highly productive overlying waters and underwent rapid establishment of reducing conditions, including the possible presence of anoxic bottom waters.

\section{PAH, Perylene}

Perylene, in sediment samples from Sites 467 and 471 , was investigated in order to elucidate any possible correlation between possible terrrestrial sources of this enigmatic PAH (cf., Aizenshtat, 1973) and the highly dealkylated copper and nickel ETIO-porphyrins, also believed to be terrestrially derived (cf., Palmer and Baker, 1978).

Perylene was routinely isolated as a sub-fraction from the "hydrocarbon impurity" portion of nickel or copper/nickel porphyrins, with which it co-chromatographed during the initial silica gel separations (see Fig. 1). Subsequent LPLC purification of the metalloporphyrins on columns of alumina cleanly separated perylene from the majority of other "hydrocarbon impurities," as well as from the tetrapyrrole chelates (see Figs. 3 and 13). In some cases further purification of perylene was attained via thin-layer chromatography.

The electronic spectrum of perylene isolated from Section 467-48-2, and typical of the isolate purity attained prior to mass spectrometry, is presented in Figure 21.

Compiled data on the relative concentrations and electronic and mass spectra of perylene isolates obtained

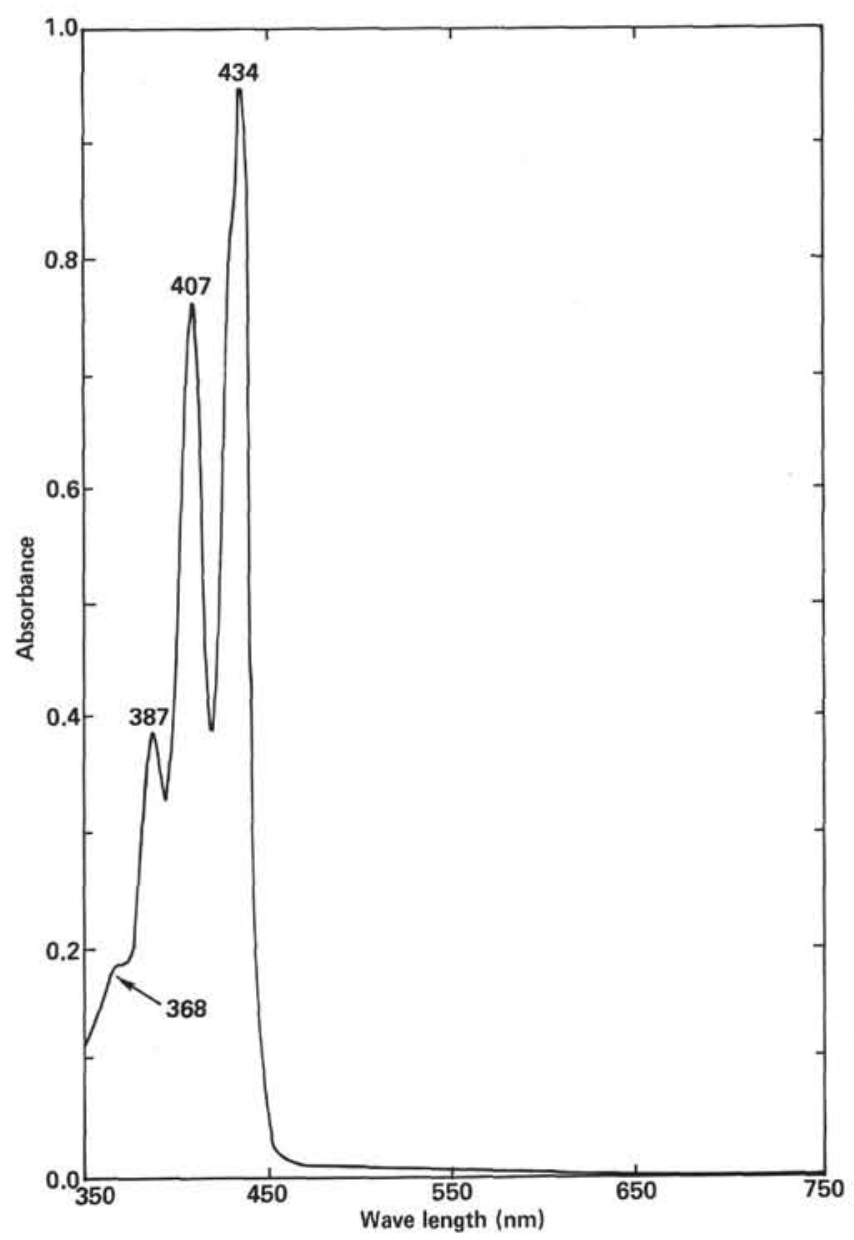

Figure 21. Electronic spectrum of perylene isolated from Section $467-$ 48-2 (solvent: diethyl ether). 
from Leg 63 samples are shown in Table 6. Quantification of perylene, from electronic spectra and using log $\Sigma \mathrm{m} M=4.56$ at $434 \mathrm{~nm}$, is given as a series ranging from "indicated" to a "plus-4" category (i.e., less than 10 to more than $2000 \mathrm{ng} / \mathrm{g}$ sediment dry weight). That the analyses are semi-quantitative rather than truly quantitative came about because first priority for quantitation was assigned to the tetrapyrrole pigments.

Representative $12 \mathrm{eV}$ mass spectra of perylene isolates and an authentic standard (Aldrich Chemical, U.S.), as well as the $70 \mathrm{eV}$ spectrum of the known compound, are given in Figure 22. Normalized mass spectra of the twelve perylene isolates, able to be purified for mass spectrometric analysis, are presented as part of Table 6 .

The $12 \mathrm{eV}$ mass spectrum of perylene (Fig. 22, A-D) is exceedingly simple, with only the molecular ion (252 $\mathrm{m} / \mathrm{z})$ and a very minor M-2 peak $(250 \mathrm{~m} / \mathrm{z})$ appearing. $70 \mathrm{eV}$ mass spectra of perylene, whether authentic (Fig. 22 , E) or isolated from Leg 63 samples, exhibits additional ions at M-28 (i.e., loss of $\mathrm{C}_{2} \mathrm{H}_{4}$ ), enhanced M-2 and M-4 peaks, and doubly charged ions of both the $\mathrm{M} /(\mathrm{M}-2) /(\mathrm{M}-4)$ and $(\mathrm{M}-28) /([\mathrm{M}-2]-28)$ clusters.

No direct correlation between the relative quantity (or even the presence or absence) of perylene (Table 6) and the copper and nickel ETIO-porphyrins reported herein is apparent (see Tables 4 and 5). The analyses of perylene isolated from these samples suites, however, show clearly that alkylation of perylene progresses as sediment depth, or more correctly, in situ temperature (see Discussion), increases. The mass spectra of perylene(s) presented in Table 6 and Fig. 22 clearly reveal the progressive alkylation that was found to begin at 542 meters sub-bottom depth in sediments from the San Miguel Gap site and to continue throughout the lower strata. These catagenetic changes involve the production of $\mathrm{C}_{1}, \mathrm{C}_{3}$, and $\mathrm{C}_{3}$-alkylated homologues of perylene

Table 6. Electronic and mass spectral characterization of perylene isolated from DSDP/IPOD Leg 63 sections.

\begin{tabular}{|c|c|c|c|}
\hline Section & $\begin{array}{l}\text { Relative } \\
\text { Quantity }^{\mathrm{a}}\end{array}$ & $\begin{array}{l}\text { Electronic Spectrum }{ }^{\mathrm{a}} \\
\qquad(\mathrm{nm})\end{array}$ & $\begin{array}{c}\text { Normalized } 12 \mathrm{eV}^{\mathrm{b}} \\
\text { Mass Spectrum }[(\mathrm{m} / \mathrm{z}(\%)]\end{array}$ \\
\hline $467-3-3$ & - & - & - \\
\hline $467-8-5$ & + & $369,391,412,439:$ B & $252(100.0)$ \\
\hline $467-13-4$ & +++ & $369,391,412,439:$ В & $252(100.0)$ \\
\hline $467-18-5$ & + & $369,387,407,434: \mathrm{EE}$ & $252(100.0)$ \\
\hline $467-25-6$ & ++ & $(385), 407,434: \mathrm{EE}$ & - \\
\hline $467-32-2$ & +++ & $369,391,412,439:$ В & $252(100.0)$ \\
\hline $467-36-2$ & ++ & $(370), 391,412,439: \mathrm{B}$ & $252(100.0)$ \\
\hline $467-41-4$ & +++ & $369,391,412,439:$ В & $252(100.0)$ \\
\hline $467-48-2$ & ++ & $368,387,407,434: \mathrm{EE}$ & $252(100.0)$ \\
\hline $467-58-3$ & ++++ & $369,391,412,439:$ В & $252(100.0), 266(14.5), 280(4.7)$ \\
\hline $467-63-2$ & +++ & $368,385,407,434: \mathrm{EE}$ & $252(100.0), 266(5.8), 280(3.6)$ \\
\hline $467-74-1$ & ++ & $369,391,412,439:$ В & $252(100.0), 266(6.8), \begin{array}{l}280(4.2) \\
294(2.5)\end{array}$ \\
\hline $467-85-4$ & - & - & - \\
\hline $467-91-2$ & ++ & $369,391,412,439:$ B & $\begin{array}{r}252(100.0), 266(24.3), 280(15.0) \\
294(5.8)\end{array}$ \\
\hline $467-97-2$ & + & $(390),(410), 439: \mathrm{B}$ & - \\
\hline $467-110-3$ & +++ & $(370), 391,412,439: \mathrm{B}$ & - \\
\hline $471-3-2$ & - & - & - \\
\hline $471-8-4$ & - & - & - \\
\hline $471-34-2$ & ind. & $(390), 412,439: \mathrm{B}$ & - \\
\hline $471-50-2$ & ind. & $(390),(410), 439:$ B & - \\
\hline $471-69-3$ & + & $369,391,412,439: \mathrm{B}$ & $252(100.0), 266(19.6), 280(6.7)$ \\
\hline
\end{tabular}

$\mathrm{a}_{\text {ind. }}=$ indicated; $+=<10 \mathrm{ng} / \mathrm{g} ;++=<100-1000 \mathrm{ng} / \mathrm{g} ;+++=<1000-2000$ $\mathrm{ng} / \mathrm{g} ;++++=>2000 \mathrm{ng} / \mathrm{g}$; all weights as sediment, dry weight. Calculation utilized $\log \Sigma \mathrm{m} M=4.56$ at $434 \mathrm{~nm}$, with molecular weight of 252 amu (see text also). B = benzene, $\mathrm{EE}=$ ethyl ether.

$\mathrm{b}$ Determined by direct solid probe introduction EI-MS with source and probe temperaDetermined by direct solid probe introduction $\mathrm{E}$ tures been $100^{\circ} \mathrm{C}$ and $150^{\circ} \mathrm{C}$, respectively.
tur

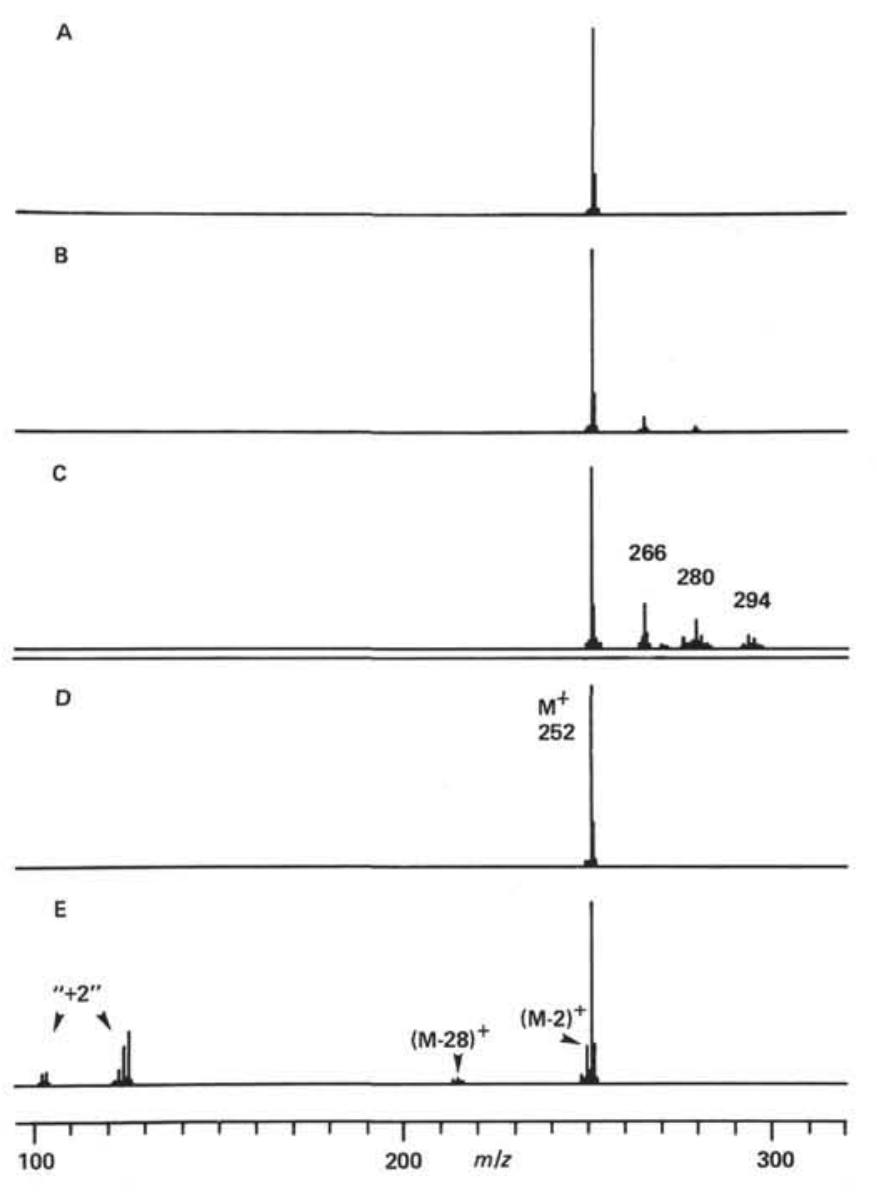

Figure 22. Mass spectra of perylene isolates and knowns A. Section 467-48-2, 12eV. B. Section 467-63-2, 12eV. C. Section 467-91-2, $12 \mathrm{eV}$. D. Authentic perylene, $12 \mathrm{eV}$. E. Authentic perylene, $70 \mathrm{eV}$. (All spectra were recorded via solid probe direct insertion with source and probe temperatures ca. $100^{\circ} \mathrm{C}$ to $150^{\circ} \mathrm{C}$.)

(i.e., $\mathrm{m} / \mathrm{z}$ values of 266,280 , and 294 ). Obviously, the $\mathrm{C}_{1}$-substituted homologue must be methyl perylene and may exist as any one of, or all of, three possible isomers (i.e., 1, 2, or 3 methyl perylene: cf., Aizenshtat, 1973, for structure and numbering). The $\mathrm{C}_{2}$ (di-methyl, or ethyl) and $\mathrm{C}_{3}$ (tri-methyl, methyl-ethyl, or propyl) perylenes present numerous possibilities for the presence of isomeric forms and are beyond the scope of the present work. Two isomeric forms of methyl perylene and three isomers of ethyl (alt. dimethyl) perylene have been reported from capillary CG-MS analyses of sediments recovered from depths of over $1.2 \mathrm{~km}$ in the Moroccan basin (Leg 50, Brassel et al., 1980).

The perylene-alkyl perylene mixed isolate from Section 467-91-2, a middle Miocene clayey nannofossil chalk at 854 meters sub-bottom depth (see Table 1), was subjected to gas chromatography (Fig. 23). The identity of perylene was reconfirmed, on the basis of retention time as compared to the authentic standard, and the presence of the $C_{1}$ and $C_{2}$-alkyl perylenes indicated. Further study would be required prior to the formulation of possible isomeric identification.

Numerous sources for perylene in marine sediments have been proposed. A sampling includes the erythroaphin pigment of insects and terrestrial wood-rotting 


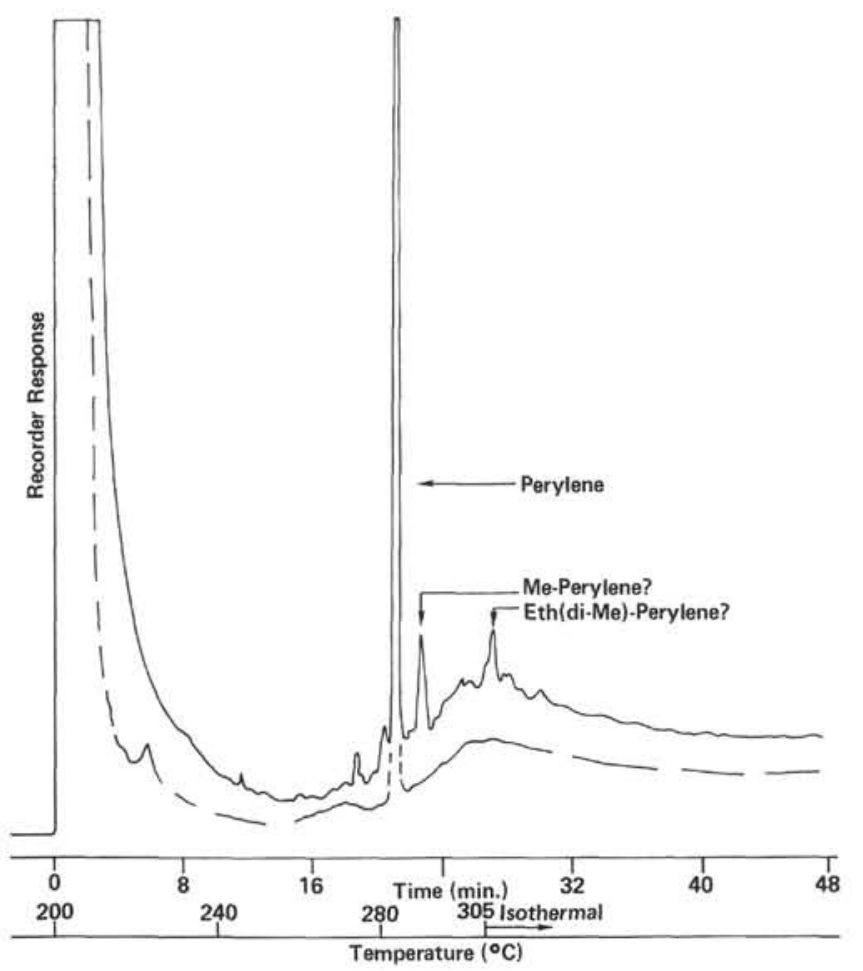

Figure 23. Gas chromatogram of perylene(s) isolated from Section 467-91-2 (upper, solid line) compared with authentic (Aldrich Chem. Co.) perylene (lower, broken line). (Conditions: column $1.5 \mathrm{~m}, 3 \%$ 0V-17 on Gas-Chrom Q; carrier Gas, helium at $30 \mathrm{ml}$ $\min ^{-1}$; detection, FID.)

fungi (Aizenshtat, 1973), marine microbes (Wakeham et al., 1979), diatomaceous organic matter (Hites et al., 1980), syndepositional generation from unspecified precursors (Brassel et al., 1980), and terrestrial lipids deposited via potamic influx (Simoneit, 1978).

A wide variety of in vitro syntheses of perylene and substituted perylenes are reported when using various precursors including: authracene, tetrahydroanthroquinone, napthalene, and dinapthols (Clar, 1964). Further, the decarboxylation of 3,4,9,10-perylene tetracarboxylic acid in alkaline solutions, at pressure, and the oxidation of perylene-3,9-quinone to anthraquinone-1, 5-dicarboxylic acid are known (Clar, 1964). Parallel geochemical transformations, in either direction, may well occur. In addition to the possible direct diagenetic production of the perylenes from closely related biologic progenitors (e.g., erythrophin; cf., Aizenshtat, 1973), derivable from insects and terrestrial fungi (Thomson, 1965), we would then call attention to the presence of anthraquinones in numerous crinoids (Echinodermata; Fox, 1976), and possibly other marine organisms, as sources of perylene. Hydroxy-quinone pigments have been previously suggested as possible precursors to the extended polyaromatic "fringelites" isolated from intact Jurassic crinoids (Blumer, 1965). If possible perylene precursors, such as anthraquinones, are eventually found, then the problematic finding of perylene in the Nambian shelf sediments, thought to contain solely marine organic matter (Wakeham et al., 1979), would be partially solved.
Though the source and generation of perylene, per se, remains uncertain, the findings reported herein on the alkylation of perylene indicate that the state of perylene alkylation may be quite useful as an indicator of geothermal regimes and histories (i.e., onset and degree of catagenesis).

\section{DISCUSSION}

The results reported herein on the tetrapyrrole pigments present in sediments recovered from the San Miguel Gap and Baja California borderland sites (DSDP/IPOD Leg 63, Sites 467 and 471) have afforded the most complete overview of chlorophyll diagenesis in marine sediments to date. Relation of tetrapyrrole pigment yield to the presence or absence of carotenoid pigments in less deeply buried sediments, both herein and previously (Baker and Louda, 1980; Louda et al., in press), has provided a means by which to assess paleodepositional conditions. Attempts to relate the presence or absence and relative quantities of perylene, a suggested terrestrial marker (Aizenshtat, 1973), to the presence or absence of the highly dealkylated copper and nickel ETIO-porphyrin arrays, also thought to be terrestrially derived (Palmer and Baker, 1978), have proved futile, and the source of perylene, quite ubiquitous in sediments from Sites 467 and 471, remains enigmatic.

Prior to discussing the results and geochemical information attained by the present studies on Leg 63 sediment samples, a short review of marine versus terrestrial chlorophyll diagenesis appears warranted in order to provide a proper frame of reference.

The diagenetic pathway of chlorophyll that results in the formation of nickel or vanadyl DPEP porphyrins appears to follow rather closely the "Treibs" scheme, as originally proposed (Treibs, 1936). However, major and minor alterations to this rather straightforward series of reductions, de-esterifications, and decarboxylations have evolved and gained credence during the last 20 years.

In marine, and possibly freshwater, aquatic environments the direct deposition of autochthonous (viz., phytoplankton) chlorophyll, as pheophytin, is known to lead to the presence of pheophytin-a in anoxic sediments. Pheophytin-a then reacts to give a series of as yet unidentified 9-keto-phorbides and phorbides and is eventually aromatized to limited homologies (e.g., C-28 to C-32) of free-base porphyrins of the DPEP-series homologues (cf., Baker and Louda, 1980; Baker et al., 1978a). Following aromatization, often concurrently in strata of sufficient thermal regimes, chelation of nickel occurs (Baker et al., 1978a and b; Palmer et al., 1979). Vanadyl porphyrin formation, found in past studies (Palmer et al., 1979) and those reported herein, appears to occur simultaneously or following complexation of DPEP-series porphyrin with an unidentified component of nonextractable organic matter (e.g., asphaltene, kerogen). Further thermal stress elicits release of vanadyl porphyrins, as identifiable entities (cf., Baker et al., 1977; Mackenzie et al., in press). Continued thermal treatment of nickel and vanadyl DPEP-porphyrins then leads to the catagenic alteration of these pigments. Such 
alteration includes rupture of the isocyclic ring to produce the metallo-ETIO series (cf., Alturki et al., 1972; Baker, 1969; Baker et al., 1977; Palmer et al., 1979), dealkylation of each series (Baker et al., 1977; Palmer et al., 1979; Yen et al., 1969), and the appearance of higher alkyl homologues (viz., $>\mathrm{C}-32$ ) of $\mathrm{Ni}$ and $\mathrm{V}=\mathrm{O}$ DPEP as well as the formation and/or release of metalloporphyrins of the Di-DPEP and the Benz-porphyrins of both the DPEP and ETIO-series (cf., Baker, 1966; Baker et al., 1967; Barwise and Whitehead, in press; Yen et al., 1969). The above synopsis is thus referred to as reductive or anoxic chlorophyll diagenesis and is known primarily in marine sedimentary environments.

Excluding the possible fossilization of freshwater aquatic sediments (including lacustrine, estuarine), interglacial gyttja, and the like, the only other known environment that gives rise to geologic porphyrins is that of terrestrial peats and coals. Because sapropelic coals are reported to yield primarily DPEP-type porphyrins (Treibs, 1935a and b) reminiscent of anoxic sedimentary diagenesis, and because of a lack of studies on this class of coals, discussion here is limited to humic-type coals. Humic coals, from lignite to HVA in rank, have been reported to yield only ETIO-porphyrins (Palmer, 1979; Palmer et al., 1980; Treibs, 1935a and b), though trace amounts of the DPEP-series can be shown in isolates from certain sub-bituminous ranked samples via highpressure liquid chromatographic techniques (S. E. Palmer, personal communication). Current studies by the authors on the diagenesis of the chlorophylls in the peat-forming environments of South Florida (Louda and Baker, 1980) are beginning to reveal that the early oxidative cleavage of the isocyclic ring-in a manner directly analogous to that suggested as being active in oxic marine depositional environments (Baker and Louda, 1980; Louda and Baker, 1980; Louda et al., 1980)-may lead to the ETIO-porphyrin assemblages of the more mature humic coals. Pigments directly derived from higher plant chlorophylls (viz., a and b) appear to be the most labile in the peat-forming process, due to early oxic depositional phases, whereas bacteriochlorophylls, produced by the in situ growth of Thiorhodaceae and Athiorhodaceae, seem to be preferentially preserved. This phenomenon most likely relates directly to lower oxygen tension in the surface to near-surface accumulations where life conditions exist for the purple bacteria (Louda and Baker, 1980). Thus the initial biogenic primer to humic-coal porphyrins may in large part be bacterial with subsequent oxic phases in the history of coal-generating chlorins (viz., dihydroporphyrins and tetrahydroporphyrins lacking the isocyclic ring) and ETIO-series porphyrins. The only study, to date, on the metalloporphyrins in humic coals reports the presence of gallium (viz., $[\mathrm{Ga}-\mathrm{OH}]^{++}$) ETIO-porphyrins in a British bituminous coal (Bonnett and Czechowski, 1980).

In the present study relatively large quantities of highly dealkylated $\mathrm{Cu}$ and Ni ETIO-porphyrins, exhibiting homologous series primarily from $\mathrm{C}-23$ to C-30, were isolated from San Miguel Gap sediments recovered between 233 and 542 meters sub-bottom depth
(Site 467) and from the Baja California borderland site at 316 meters sub-bottom depth (Site 471; cf., Tables 1, 2, 4, and 5). The ETIO-porphyrins (as $\mathrm{Cu}$ and $\mathrm{Ni}$ chelates) in the San Miguel Gap samples must certainly derive from the same source, because the homological distribution of each chelate is identical (cf., Fig. 14, Table 5). Intersite comparisons further reveal that the $\mathrm{Cu}$ and Ni ETIO-porphyrins isolated from the San Miguel Gap sediments (Site 467) and the Baja California borderland sample (471-34-2) most likely derive from different sources. That is, the mode of the $\mathrm{Cu}$ and $\mathrm{Ni}$ ETIO-porphyrins from Site 467 is C-26 versus a mode of C-28 for the isolate from Site 471. According to the only known mass spectrometric comparison of porphyrins in the various ranks of coal (Palmer, 1979; Palmer et al., 1980), the Site $467 \mathrm{Cu}$ and Ni ETIO-porphyrins probably derive from reworked terrestrial (viz., coal washouts, etc.) organic matter at a stage of initial maturity greater than HVA (see Hunt, 1979; Tissot and Welte, 1978 for organic maturity comparisons); on the other hand, the single isolate from Site 471 probably was originally derived from organic matter no more mature than an "early" HVA ranked coal. Correlation of these highly dealkylated $\mathrm{Cu}$ and Ni ETIO-porphyrins with a terrestrially derived source rests not only upon comparison of porphyrin quality (i.e., all ETIO and highly dealkylated) but also upon quantity (i.e., pigment yield per organic carbon content of sediments; see Fig. 4). The concentration of ETIO-porphyrins in 30 samples of U.S. humic coals, those yielding detectable pigments from a total of 50 samples, were found to range from ca. 0.005 to $4.03 \mu \mathrm{g} / \mathrm{g}$, with only two cases above $1 \mu \mathrm{g} / \mathrm{g}$ (Palmer et al., 1980). This is in striking contrast to the concentrations of porphyrins in organic rich marine sediments $(10-30 \mu \mathrm{g} / \mathrm{g})$, petroleum asphaltenes (10-3, $100 \mu \mathrm{g} / \mathrm{g}$; cf., Baker et al., 1967), or petroleum crudes (10-1600 $\mu \mathrm{g} / \mathrm{g}$; cf., Hodgson et al., 1967). Thus the presence of DPEP-porphyrins at high concentrations indicates an anoxic history for marine sedimentary and petroleum porphyrins and is in sharp contrast to the ETIO-porphyrins present in humic coals at near trace quantities. These ETIO-porphyrins are believed to be primarily the result of a history of oxidation in initial "post-peat" coal-forming situations.

Reexamination of Figure 4, which is a plot of pigment yield (cf., PYI in Table 1) versus sub-bottom depth, illustrates that the highly dealkylated $\mathrm{Cu}$ and $\mathrm{Ni}$ ETIO-porphyrins isolated from samples recovered between 233 and 542 meters from the San Miguel Gap site (cf., Tables 4, 5) indeed coincide with depressed pigment preservation in these strata. Further, the coincidence of free-base DPEP-porphyrins and phorbides/ chlorins, actually constituting the majority of tetrapyrrole yield (see Table 2), indicates that a mixed source of both autochthonous (viz., marine, DPEP from plankton pheophytin-a) and allochthonous (viz., terrestrial, $\mathrm{Cu}$ and Ni ETIO) components constituted the original organic matter deposited in these upper Miocene to upper Pliocene claystones (viz., Sections 467-25-6 to 46758-3, inclusive; cf., Tables 1 and 2). 
On the basis of this discussion, which strengthens the previous report that the highly dealkylated $\mathrm{Cu}$ ETIOporphyrins in marine sediments are derived from terrestrial sources (Palmer and Baker, 1978) and proves coincidence of the Ni component, we consider these pigments allochthonous; they therefore do not represent products of the in situ diagenetic-catagenetic progress of tetrapyrrole pigments in these strata. Data reported herein (see Table 4) is presented on this basis and includes calculation of that percentage of metalloporphyrin isolates represented by the unique $\mathrm{Cu}$ and $\mathrm{Ni}$ ETIO-porphyrins. Determination of this "terrestrial component" becomes paramount in the examination of the in situ diagenesis of autochthonous chlorophyll derivatives, as will now be discussed.

In the course of studying such well-sampled sedimentary sequences as those from Site 467 , trends in the diagenetic-catagenetic progress of tetrapyrrole pigments are often amenable to detailed examination. In the past, observation of the chelation reaction was possible in DSDP/IPOD samples from only three Legs (Leg 42, 2; Baker et al., 1978a; Leg 44; Baker et al., 1978b; Leg 47A, Baker and Palmer, 1979). In each case, either because of sample spacing, lack of in situ temperature measurements, or extreme lithologic breaks related to the rifting of the Atlantic, only part of the chelation reaction progress was unraveled. Data obtained from the present study of Leg 63, Site 467 sediments have provided the most complete view of the chelation reaction yet.

Chelation, the diagenetic transformation of free-base porphyrins to metalloporphyrins (viz., nickel, vanadyl), is most easily examined by plotting the percent freebase, alternately percent metalloporphyrin, versus subbottom depth and/or in situ temperature. The plot obtained for the tetrapyrrole pigments from Site 467 is presented as Figure 24. Figure 24, $\mathrm{A}$ is the trend revealed by utilizing only uncorrected metalloporphyrin yield data. The apparent bi-modality of the reaction has now been found not to represent the in situ diagenesis of autochthonous chlorophyll derivatives; rather, it is a further expression of the existence of the terrestrially derived dealkylated $\mathrm{Cu}$ and Ni ETIO-porphyrins discussed before. Employing the data presented previously (Tables 2-5), subtraction of the "terrestrial component" then allowed the actual in situ transformation of free-base to nickel porphyrins to be followed (Fig. 24, B). The corrected plot then shows that in situ formation of nickel porphyrins from free-base porphyrins, in turn derived from autochthonous chlorophyll, occurred between 542 and 911 meters sub-bottom depth. Employing in situ temperature measurements taken on board the Challenger, ${ }^{3}$ we then find that chelation, from initiation to completion, occurred through a present temperature regime of about $40^{\circ} \mathrm{C}$ to $60^{\circ} \mathrm{C}$. Reaction kinetics dictate that both time and temperature must be considered the present results of chelation occurring in upper to middle Miocene sediments at temperatures of $40^{\circ} \mathrm{C}$ to $60^{\circ} \mathrm{C}$;

\footnotetext{
${ }^{3}$ Bottom water, $4.5^{\circ} \mathrm{C} ; 304$ meters sub-bottom depth, $23.5^{\circ} \mathrm{C}$; minimum thermal gradient, $63^{\circ} \mathrm{C} / \mathrm{km}$ (Site 467 report, this volume).
}

this idea corresponds quite well to results from studies on Tarfaya Basin sediments (DSDP/IPOD Leg 47A), in which chelation was found to occur between present temperatures of $25^{\circ} \mathrm{C}$ to $50^{\circ} \mathrm{C}$ for lower Miocene to Cretaceous calcareous muds (cf., Baker and Palmer, 1979; von Rad, Ryan, et al., 1979).

The correlation of various stages in the diagenesis/catagenesis of tetrapyrrole pigments and perylene with sub-bottom depth and present in situ thermal profiles for both the San Miguel Gap and Baja California borderland sites ( $467 \& 471$, respectively) is presented in Figure 25. Present in situ temperatures were calculated from simple (viz., linear) thermal gradients utilizing onboard measurements (Sites 467 and 471 Reports, this volume).

Aromatization, the change from dihydroporphyrin to porphyrin chromophores, occurred at Site 467 between sub-bottom depths of 70 and 542 meters, but was essentially completed at about $\mathbf{3 4 0 . 5}$ meters (cf., Table 2 ). Thus aromatization appears to have been most vigorous between ca. $20^{\circ} \mathrm{C}$ to $35^{\circ} \mathrm{C}$. The aromatization reaction within sediments recovered from Site 471 can only be inferred, due to sample spacing and the occurrence of porcellanites, to have occurred between Section 471-8-4, from which only trace free-base porphyrin was isolated, and Section 471-34-2, which contains only metalloporphyrins (cf., Table 2). Thus in situ paleodepths of between 100 and 300 meters and temperatures of $10^{\circ} \mathrm{C}$ to $25^{\circ} \mathrm{C}$ probably have yielded the free-base porphyrin precursors to the metalloporphyrins isolated from the deeper strata of Site 471 (Fig. 25). Aromatization of phorbides/chlorins within Site 471 sediments would then have taken place upon burial for a late Miocene to Present period versus that of the early to late Pliocene to Present span required for the same reaction to have occurred at Site 467 . Overall aromatization of geologic phorbides and chlorins appears to occur at temperatures of ca. $20^{\circ} \mathrm{C}$ to $35^{\circ} \mathrm{C}$ when exposed for periods of 5 to $15 \mathrm{~m} . \mathrm{y}$. Initiation of the aromatization reaction most likely occurs at sediment temperatures of ca. $15^{\circ} \mathrm{C}$ and overlaps quite well with the defunctionalization of phorbides prior to aromatization, reported from studies of Japan Trench sediments presently at $8^{\circ} \mathrm{C}$ to $11^{\circ} \mathrm{C}$ (Baker and Louda, 1980).

Chlorin(s)-641 (Table 2) was not included in the above consideration of the aromatization reaction, because this compound(s) appears to be involved in an ambiguous steady-state or equilibrium with free-base porphyrins. That is, a direct correlation between the presence of free-base porphyrins and chlorin(s)-641 does exist but the meaning of this relationship is, at present, vague. The electronic spectra of chlorin 641 isolates, with Soret absorption at ca. 396 to $398 \mathrm{~nm}$ and a band I maximum of $641 \mathrm{~nm}$ (ethyl ether solvent), precludes a metallo-chlorin identity. That is, while band I maxima of metallochlorins are hypsochromically shifted in relation to that of corresponding free-base chlorins, the Soret position is shifted bathochromically and does not occur below about $420 \mathrm{~nm}$ (see Hodgson and Baker, 1967; Jones et al., 1968). Further, the most conclusive evidence for chlorin(s) 641 not being metallo-chlorins is 


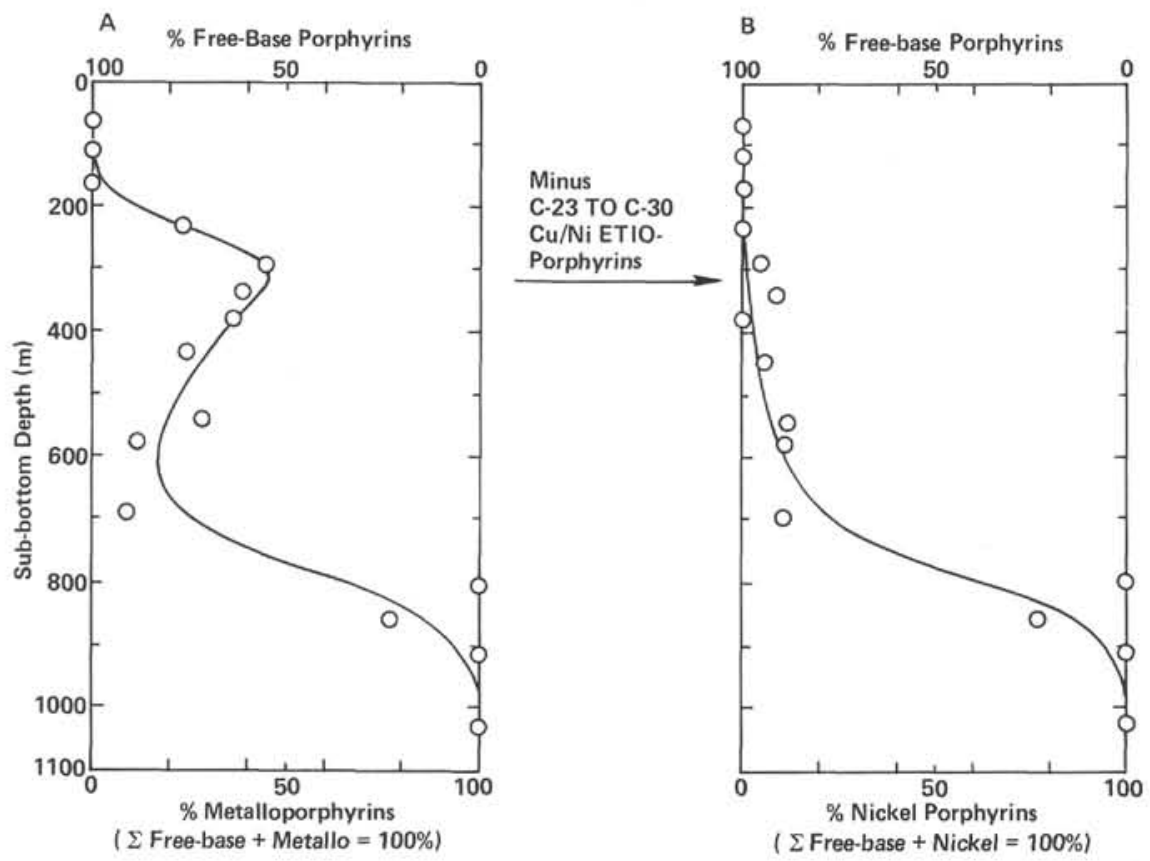

Figure 24. Chelation during in situ diagenesis of autochthonous chlorophyll derivatives within San Miguel Gap sediments (Site 467). A. Plot of free-base porphyrins/total metalloporphyrins versus sub-bottom depth. B. Curved plot of free-base porphyrins/nickel porphyrins versus sub-bottom depth following subtraction of allochthonous dealkylated $\mathrm{Cu}$ and $\mathrm{Ni}$ ETIO-porphyrins. (The sum of metallo-[alt. nickel] porphyrins plus free-base porphyrins is taken as $100 \%$.)

that this compound(s) extracts into aqueous $\mathrm{HCl}$ (ca. $10 \% \mathrm{~W} / \mathrm{V}$ ) from ethereal solution and metallochlorins do not. The possibilities that chlorin-641 is either involved in a steady-state existence (viz., chlorin $\leftrightharpoons$ freebase), as mentioned earlier, or that it is a "secondary chlorin" (cf., Blumer and Omenn, 1961) (viz., phorbide precursor $\rightarrow$ free-base $\rightarrow$ chlorin-641) appear likely explanations for this ambiguous compound(s).

More deeply buried sediments recovered from both Sites 467 and 471 yielded metalloporphyrin arrays (viz., $\mathrm{Ni}, \mathrm{V}=\mathrm{O}$ ) in various stages of early catagenesis, that is, thermal alteration.

The most deeply buried sediments studied from the Baja California borderland Site 471 (Cores 34, 50, 69) were found to contain nickel porphyrin arrays that exhibited loss of the 9-keto and 7-proprionic acid carboxyl moieties, in that order, with depth. The 9-keto nickel porphyrin acid was tentatively identified as Ni-phylloerythrin and the metalloporphyrin acid as Ni-deoxophylloerythrin (cf., Table 2, Fig. 17). The thermal regimes in which these compounds resided (Fig. 25) indicate that chelation does, in some cases, precede decarboxylation of Ni-porphyrins and that over about $50^{\circ} \mathrm{C}$, on the geologic time scale, thermal decarboxylation of porphyrins is probably completed. Decarboxylation of metalloporphyrins was not observed within the sediments from Site 467 . The overwhelming abundance of free-base and nickel porphyrin isolates as decarboxylated species noted in the present, and past (e.g., see Baker et al., 1978a and b; Baker and Palmer, 1979), studies of DSDP and IPOD samples appear to indicate a high degree of low-temperature decarboxylation acting upon these pigments. The most obvious means to explain low-temperature (e.g., $<15^{\circ} \mathrm{C}$ ) decarboxylation is to invoke microbial processes, though little data on microbial activity on organic acids of such size exists.

The mass spectrometric characterization of nickel porphyrins, isolated from both Site 467 and Site 471 samples (Table 5), reveals that several overlapping catagenetic processes are occurring within these more deeply buried strata at each site. Prior to consideration of these changes, especially the DPEP-to-ETIO ratio, it must be recalled that the results presented herein prove, for the first time, the existence of geologic free-base ETIO-porphyrins (cf., Table 3). Though we believe free-base porphyrins of the ETIO-series to be generated during early oxidative diagenesis, the existence of porphyrins lacking intact isocyclic-ring structure prior to chelation requires a reformulation of thought regarding overall tetrapyrrole geochemistry. That is, we now must view the DPEP-to-ETIO ratio of geologic metalloporphyrins (especially nickel chelates) not only as an expression of the thermal history of the precursor metallo-DPEPseries but also as representing inherited ETIO-compounds. Because nickel and vanadyl porphyrins appear to form via different routes, the existence of free-base ETIO-porphyrins, even in minor amounts, may account for the fact that no Ni-porphyrin assemblage has been isolated from marine sediments as only the DPEP series. Quite regularly, including the present case, the DPEP-to-ETIO ratio of Ni-porphyrins isolated from marine sediments believed to be thermally immature and/or within the period of initial chelation are of the order of 2-8 to 1 (cf., Baker and Palmer, 1979; Baker et 


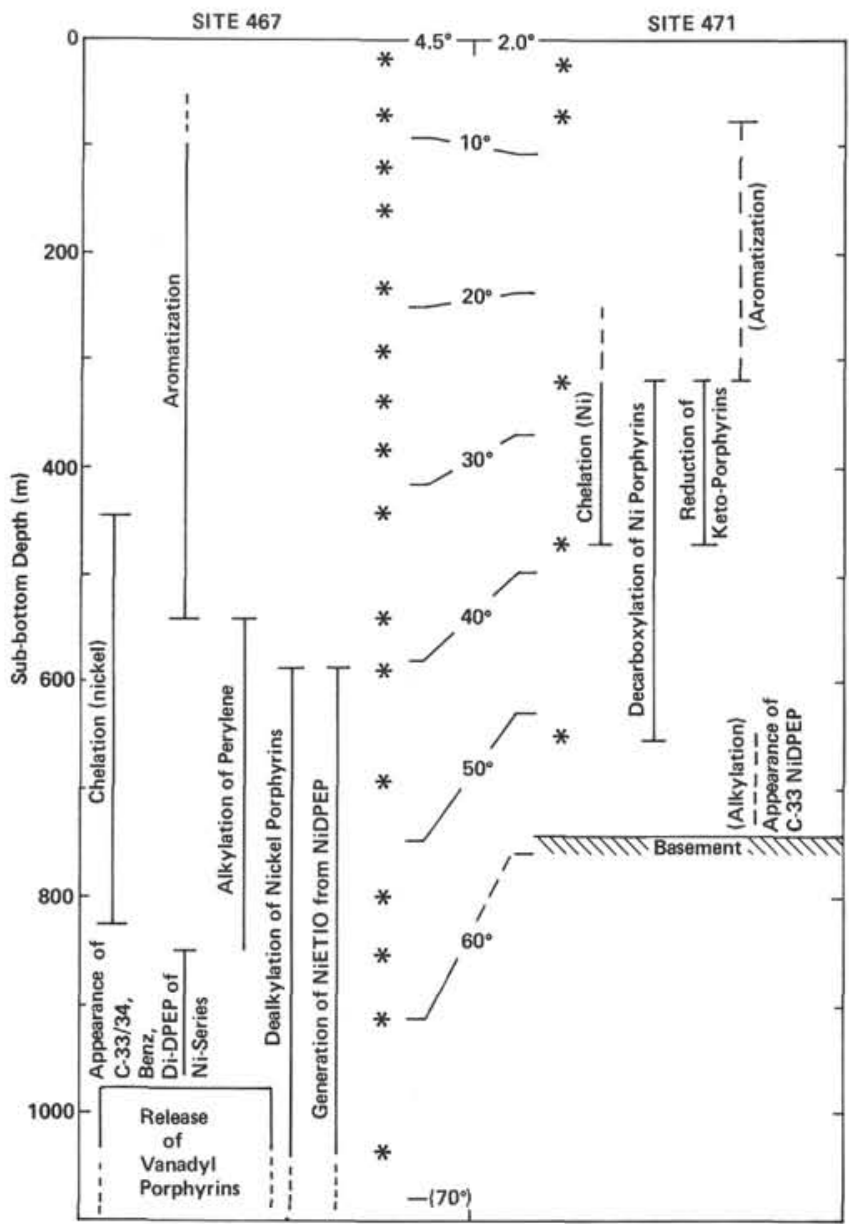

Figure 25. Correlation of events during the diagenesis of tetrapyrrole pigments and perylene to the minimum in situ thermal profiles of DSDP/IPOD Sites 467 and 471 . (Thermal profiles were determined from site reports, this volume. ${ }^{*}$ denotes samples studied. Open-ended bars indicate either a reaction that was not observed to go to completion [lower-end] or one in which the beginning is vague because of sample spacing [upper-end].)

al., 1977; Palmer and Baker, 1979). This may also explain discrepancies in the DPEP-to-ETIO ratios of such Ni-porphyrin isolates as those from the Cape and Angola Basin studies (DSDP Leg 40), which appeared to increase or fluctuate with increased depth of burial (Baker et al., 1978b). Thus valid application of the DPEP-to-ETIO ratio of nickel porphyrins, except during in vitro experimentation with known primers, probably is only possible as the half-point of the reaction is approached and passed (e.g., DPEP/ETIO $=2.0 \rightarrow 1.0$ $-<1.0)$. Further complicating an otherwise direct consideration of the DPEP-to-ETIO ratio is the thermal generation of higher homologues of the DPEP-series and the formation of alternate series (i.e., Di-DPEP and Benz-porphyrins). The data obtained in the present study does, however, indicate that these processes can be disentangled and may, in fact, offer more valid assessment of geothermal histories than the DPEP-toETIO ratio of metalloporphyrins alone.

Data presented on the mass spectrometric analyses of metalloporphyrin isolates from Leg 63 sediment samples (Table 5) do not include determination of the DPEP-to-ETIO ratio for those samples containing dealkylated arrays of NI and Cu ETIO-porphyrins. This was not done because it was (is) impossible to calculate exactly what percentage, if any, of the higher Ni-ETIO homologues (i.e., C-28 to C-31) were the result of in situ diagenesis of autochthonous chlorophyll versus that derived from the source of coincident $\mathrm{Cu}$ ETIO-porphyrins. Because of the close match between homologies of the Ni and $\mathrm{Cu}$ ETIO-porphyrins in these strata (i.e., Sections, 467-32-2 to 467-58-3, inclusive; and Section 471-34-2; see Table 5) all of the Ni ETIO component was assigned to the allochthonous (i.e., terrestrial) category with the Cu-ETIO species.

Aside from the anomalously low DPEP-to-ETIO ratio obtained for the isolate from Section 467-74-1 (i.e., 0.97: Table 5), the DPEP-to-ETIO ratios of nickel porphyrins isolated from samples recovered from 588 meters sub-bottom depth (and below) at Site 467 and 468 meters sub-bottom depth (and below) at Site 471 exhibit alterations directly related to catagenetic reactions. According to current thought (see e.g., Baker, 1969; Baker and Palmer, 1978; Didyk et al., 1975; MacKenzie et al., in press), thermal maturation of metallo-DPEP porphyrins leads to eventual generation of the metalloETIO series. The only alteration to this line of thinking presented herein is that the original DPEP-to-ETIO ratio of metalloporphyrins (viz., Ni) is most likely not infinity but rather some value (e.g., 2-5) considerably less than infinity. Therefore, with the assumption that the DPEP-to-ETIO ratios of nickel porphyrins isolated from the lower strata of both Sites 467 and 471 originated at a value of between 5 to 10 , the catagenesis of these more deeply buried pigments is amenable to interpretation. DPEP-to-ETIO ratios (i.e., D/E) were calculated using only these series, per se, and omitting the DiDPEP and Benz-porphyrins.

Thus when we examine the data in Table 5, we can directly relate the downhole increases in D/E for the nickel porphyrins to the appearance of C-33 NiDPEP. Only in the deepest sample from the San Miguel Gap suite (i.e., Section 467-110-3, $1035 \mathrm{~m}$ sub-bottom depth; see Table 5) does D/E fall below unity, in direct correlation to increasing ETIO-series generation via thermal/ thermocatalytic scission of the isocyclic ring.

Concurrent with the above changes in the nickel porphyrin series is a coincident overall dealkylation. This reaction(s), for the porphyrins, is observed through changes in the overall weighted average mass (i.e., $\overline{\mathrm{X}}$; Table 5) of each isolate, and the weighted average mass of each series individually (i.e., $\overline{\mathrm{X}}_{\mathrm{D}}, \overline{\mathrm{X}}_{\mathrm{E}}$ : Table 5). Thus for isolates for the San Miguel Gap sections, $\overline{\mathrm{X}}$ was observed to decrease initially from 494.4 for Section 467-63-2 to 491.0 for Section 467-85-4, increase slightly during generation of the higher Ni DPEP homologues discussed earlier, and decrease rapidly to 484.10 in the deepest section. Dealkylation of the Ni ETIO-series perhaps best exemplifies this reaction within the San Miguel Gap strata. The weighted average mass of the $\mathrm{Ni}$ ETIO-series $\left(\overline{\mathrm{X}}_{\mathrm{E}}\right.$ : Table 5) was found to decrease more directly with increased depth (alt. temperature) than did 
the corresponding Ni DPEP-series. Hindsight allows this phenomenon to be explained. Because higher homologues of Ni DPEP are being formed or released from a nonextractable or bound state, dealkylation of the DPEP-series should not become dominant until alkylation of same is completed.

The catagenetic alterations of nickel porphyrins observed from these studies are positioned in the depththermal regime plot given as Figure 25. Dealkylation of nickel porphyrins was found to be initiated and is presently occurring in San Miguel Gap sediments at about $40^{\circ} \mathrm{C}$ to $60^{\circ} \mathrm{C}$, with the end member (i.e., C-20 ETIO, or complete destruction) unknown. Appearance of the higher homologues of Ni DPEP (viz., C-33) was found to have occurred in Sections 467-97-2, 467-110-3, and 471-69-3, all of which are presently at calculated in situ temperatures of about $52^{\circ} \mathrm{C}$ to $55^{\circ} \mathrm{C}$ or higher. The appearance of the nickel chelates of the DiDPEP and Benz-porphyrins series, with limited homologies (C-29 to C-34), was found to be initiated at only slightly lower thermal stress (i.e., Section 467-91-2 vs. Section 46797-2: Table 5) than the formation of C-33 NiDPEP.

Vanadyl porphyrins appeared as identifiable entities only in the most deeply buried sample from the San Miguel Gap suite. It was calculated (cf., Fig. 25) that this section (467-110-3) was recovered from strata presently at about $69^{\circ} \mathrm{C}$. This release or formation of vanadyl porphyrins therefore appears to require residency at about $60^{\circ} \mathrm{C}$ (i.e., temperature of the nearest sample lacking significant quantities of vanadyl porphyrins) for periods equivalent to the middle Miocene to present. This of course precludes short-term high-temperature geochemistry near igneous intrusions (cf., Baker et al., 1977) and similar phenomena. The vanadyl porphyrins isolated from the San Miguel Gap sediments recovered from 1,035 meters sub-bottom depth exhibit homologies of the DPEP and ETIO-series from C-23 to C-34 (D/E $=1.04$; see Table 5 ) and is quite reminiscent of the porphyrins reported from Santiago, Belridge, and Wilmington crudes recovered from sedimentary basins on the mainland of California (cf., Baker et al., 1967).

Traces of vanadyl and nickel porphyrins were found in Section 467-3-3, a Quaternary diatomaceous silty clay recovered from 19.5 meters sub-bottom depth at the San Miguel Gap site. These trace isolates, unable to be completely characterized, are attributed to the probable input of more mature organic matter (viz., natural oil seepage, tar) from nearby structural highs such as the Channel Island platform or the mainland near Point Conception to Ventura, California. Numerous oil seeps have been reported in this region including one on the shelf west of San Miguel Island (Emery, 1960), the prolific Coal Oil Point seep from the western extension of the Ventura Basin (Hunt, 1979), and the asphalt mounds distributed along east-west trending faulted anticlines in the Santa Barbara Channel (Hunt, 1979).

The vanadyl porphyrin array isolated from Section 467-110-3, together with an apparent lack of the vanadyl species in less deeply buried, more thermally immature sediments from both Sites 467 and 471 , indicates either formation or release (viz., from a nonextractable state) of these pigments. Vanadyl porphyrins have previously been isolated from DSDP samples recovered from the calcite of the Challenger Knoll (Leg 1, Baker, 1971), the shales and sandstones of both the Cape and the Angola Basins (Leg 40, Baker et al., 1978b), in proximity to an igneous sill in the Cape Verde Rise (Leg 41, Baker et al., 1977), and the reworked (mixed) Pleistocene layers of the Vøring Plateau escarpment and Kipnovich Ridge in the Norwegian-Greenland Sea (Leg 38, Baker et al., 1976).

In the past, attempts have been made to explain the predominance of nickel porphyrins in various bituminous accumulations versus the vanadyl species in others. For example, the association of each has been linked to their general source environment. That is, shales of marine origin are enriched in $\mathrm{Ni}$ and $\mathrm{V}$ versus a concentration of $\mathrm{Cu}, \mathrm{Pb}, \mathrm{Zn}$, and $\mathrm{Sn}$ in fresh-water shales (Degens, 1957). This does indeed aid our linkage of the $\mathrm{Cu}$-porphyrins to a terrestrial source, in the broadest sense, but does little to explain the origin of $\mathrm{Ni}$ versus $\mathrm{V}=\mathrm{O}$ porphyrins. Suggestions have been made, and data given, which draw correlations between nickel porphyrins and low sulfur sediments, asphalts, and crudes, with the vanadyl species being linked to high sulfur (Aizenshtat et al., 1979; Dunning and Moore, 1957; HajIbrahim and Eglinton, in press; Hodgson et al., 1967) and/or high asphaltene contents (Alturki et al., 1972; Quirke et al., 1979; Sugihara and McGee, 1957). It has been suggested that the association between vanadium (viz., vanadyl porphyrins) and sulfur in the asphaltenes of numerous crudes and bitumens is due to sulfur, possibly as benzothiophenes, forming one leg of a tetradentate (i.e., $3 \mathrm{~N}-1 \mathrm{~S}$ ) ligand to vanadyl with three of the four porphyrin nitrogens as the remaining legs (Yen et al., 1969). Such a complexation may then explain why in some cases immature vanadyl porphyrins (i.e., C-28 to C-32 DPEP) are present (Baker et al., 1978b). In most cases, however, including the present study, vanadyl porphyrins appear to be released only after sufficient thermal stress (cracking?) has occurred (Baker et al., 1977; Mackenzie et al., in press). In both of these reports the correlation between vanadyl porphyrins with increased alkylation patterns (viz., carbon numbers $>\mathrm{C}$-32) and a thermal release mechanism (cracking?) has been drawn. Thus, it seems quite probable that vanadyl chelation results from sulfur and/or asphaltene mediated orientation of vanadyl and porphyrin with subsequent alkyl linkages forming between porphyrin and, as yet unidentified organics (asphaltene?). This would then further explain the apparent absence of vanadyl porphyrins in some strata (e.g., Section 467-97-2) and their presence in more deeply buried sediments (e.g., Section 467-110-3). Overall, in immature sediments nickel porphyrins appear to be "free" (i.e., extractable), while the vanadyl species are most likely "bound" (i.e., nonextractable, complexed) and are only released via increased geothermal stress. The transmetallation of Ni-porphyrin to $\mathrm{V}=\mathrm{O}$ porphyrins has been shown in vitro, but evidence in the same report also states that this does not occur geochemically (Mackenzie et al., in press). 
During the present study attempts were made to elucidate any correlations between three pigment classes: tetrapyrroles, carotenoids, and the $\mathrm{PAH}$, perylene.

The carotenoid pigment $\beta$-carotene $\left(\mathrm{C}_{40} \mathrm{H}_{56} ; 536\right.$ $\mathrm{m} / \mathrm{z}$ ) was found to be present only in Quaternary and upper Pliocene diatomaceous silty clays (i.e., Sections 467-8-5 and 467-8-5) from the San Miguel Gap. The presence of $\beta$-carotene exactly coincided with enhanced preservation of tetrapyrrole pigments in these strata (see Fig. 4). Carotenoids have previously been reported in deep sea sediments recovered by DSDP and IPOD Leg 15 (Watts and Maxwell, 1977), Leg 44 (Cardoso et al., 1978), and Legs 56, 57 (Baker and Louda, 1980; Louda et al., 1980). Cariaco Trench sediments, ranging in age from 5 to 340 thousands of years, yielded not only $\beta$-carotene but the dioxy-carotenoid zeaxanthin and the dioxo-carotenoid canthaxanthin (Watts and Maxwell, 1977). Reductive diagenesis of these dioxy and dioxopigments was found to occur and is believed to be progressive (Watts and Maxwell, 1977). The geochemical reduction of carotenoids well explains the findings of perhydro-tetraterpenoids such as carotane (Murphy et al., 1967) and lycopane (Kimble et al., 1974) in certain shales. Enhanced degradation of the oxygenated carotenoids ("xanthophylls," antiquated nomenclature), reported previously (Fox et al., 1944; Schwendinger and Erdman, 1963) and possibly due to auto-oxidation (Vallentyne, 1956), appears responsible for the predominance of the hydrocarbon carotenoids (viz., carotene, esp. $\beta$ ) in the Quaternary and upper Pliocene sediments from the San Miguel Gap site. If we assume a diatom source, mixed with various other planktonic marine algae, for the autochthonous organic matter in these strata, then originally large amounts of fucoxanthin, diatoxanthin, diadinoxanthin, and peridinin must have been present in the original detritus, as these oxycarotenoids are more abundant than the carotenes in marine phytoplankton (e.g., see, Liaaen-Jensen, 1978).

The correlation of the presence of $\beta$-carotene with enhanced preservation of chlorophyll derivatives in the upper Pliocene and Quaternary diatomaceous and siliceous silty clays from Site 467 , together with the absence of the highly dealkylated $\mathrm{Cu}$ and Ni ETIO-porphyrins believed to be of terrestrial origin, indicate that the depositional environment during this time span was one of high marine productivity, quite likely invoked by upwelling, with probable anoxia in the surface sediments and even the bottom waters.

The enigmatic PAH perylene was found to be quite ubiquitous within the sediments from both Sites 467 and 471. Because perylene has been suggested as a biomarker for terrestrial organic matter in marine sediments (Aizenshtat, 1973), attempts were made to correlate its presence or absence and relative quantity in sediment samples from Leg 63 to possible terrestrial influxes. No trend was observed. Perylene did not correlate to the presence or absence of the dealkylated $\mathrm{Cu}$ and Ni ETIO-porphyrins, also suggested as terrestrially derived (cf., Palmer and Baker, 1978).
Rather than observing any direct correlation between perylene and possible sources of organic matter, we found a straightforward diagenetic trend in the alkylation of perylene. That is, mass spectrometric analyses showed that as depth, and therefore in situ temperature, increased, correspondingly higher amounts of C-1, C-2, and C-3 alkylated perylenes were generated (see Table 6, Fig. 22). Relating the alkylation of perylene to the calculated thermal regimes at Site 467 (Fig. 25), we find that the alkylation of perylene was observed to occur through a temperature range of about $38^{\circ} \mathrm{C}$ to $58^{\circ} \mathrm{C}$. The onset of perylene alkylation also precedes the appearance of the higher alkyl homologues of the Ni-porphyrins (e.g., C-33; Table 5; Fig. 25 ) by ca. $10^{\circ} \mathrm{C}$ to $15^{\circ} \mathrm{C}$ and the release of vanadyl porphyrins by ca. $25^{\circ} \mathrm{C}$ (cf., Fig. 25). Thus correlation of the degree of perylene alkylation, with the catagenic alterations of the metalloporphyrins (e.g., DPEP to ETIO ratio, alkylation-dealkylation, and the appearance of alternate [DiDPEP, Benz] series of nickel chelates and the release of the vanadyl species) and diagenetic transformations (e.g., aromatization, chelation) of porphyrins appear to offer a suite of geochemical indicators covering thermal regimes from ca. $15^{\circ} \mathrm{C}$ to $70^{\circ} \mathrm{C}$, over geologic time.

The results and conclusions presented herein draw heavily upon the postulation that the highly dealkylated $\mathrm{Cu}$ and Ni ETIO-porphyrin arrays isolated from the upper Miocene to Pliocene silty claystones of the San Miguel Gap (Site 467) and the upper Middle Miocene silty claystone of the Baja California borderland (Site 471) were originally derived from a terrestrial source. Earlier discussion provided the required background concerning oxidative chlorophyll diagenesis in peat-coal environments and the fact that humic coals (e.g., lignite to HVA; cf., Palmer et al., 1980) are vastly dominated by low concentrations of the lower molecular weight ETIO-porphyrins. Thus the requisite link between the organic matter of the strata yielding these unique porphyrins and possible terrestrial sources needs to be addressed, keeping in mind our belief that the total organic makeup of these sediments is a mixture of autochthonous (viz., free-base porphyrins and the $\mathrm{Ni}$ DPEP-series) and allochthonous (viz., highly dealkylated $\mathrm{Cu}$ and $\mathrm{Ni}$ ETIO-series) components.

Correlation between the organic rich upper middle Miocene strata of the San Miguel Gap site and the Monterey shales deposited during the high ocean stand and widespread upwelling of the Luisian and Mohnian Stages (see the Site Reports, this volume; Demaison and Moore, 1980; Emery, 1960; Nagle and Parker, 1971) is apparent on both time and productivity bases. Several observations tend to link the geochemical history of the San Miguel Gap most closely with the Santa Barbara Channel and the Ventura Basin rather than with the more distant Los Angeles Basin province, aside from present-day geography. According to paleogeographical reconstructions (Curran et al., 1971; Emery, 1960) and sea-level fluctuations (Vail and Mitchum, as cited in Kerr, in 1980), the late Miocene to Pliocene setting in this region was such that the San Fernando, Ventura, 
and Santa Barbara basins formed a narrow seaway bounded by the Transverse Ranges to the north and the Channel Island platform to the south, with the San Miguel Gap at the ocean end of this embayment. Renewed transgression in the late Pliocene to Pleistocene, during which the deep water "Mud Pit Shales" of the Ventura Basin formed, followed the earlier low ocean stand, mentioned above (Nagle and Parker, 1971). It is then suggested that the retreat of the sea during the late Miocene to Pliocene carried with it large quantities of terrestrial detritus, including the dealkylated ETIO-porphyrins isolated from these strata of the Site 467 sample suite as $\mathrm{Cu}$ and $\mathrm{Ni}$ chelates, and deposited much of this within the San Miguel Gap and its slopes. This postulation is in line with the high sedimentation rates noted for these strata (Site Reports, this volume). Humic coals are reported near Buena Vista, Ione, and Carbondale, California (Hill, 1975). But transport from the Great Valley is unlikely, because the southwest opening of the San Joaquin Valley is reported as being closed by the Bakersfield ArchTransverse Ranges in the late Eocene to Miocene (Callaway, 1971). However, the formation of coals and the speculation that the Great Valley was a shallow lagoon choked with terrestrial vegetation in the Paleocene (Hill, 1975 ) indicates possible similar situations in regions more likely drained into the Santa Barbara Channel region. Thus, the required source of organic matter most likely derived from coals would need to lie to the east. The eastward extension of the Ventura Basin, the Soledad Basin, is reported to have had a Miocene sea incursion that withdrew by the late Pliocene (Norris and Webb, 1971). Further, the presence of Eocene coal beds in the Diablo Range and the late Miocene to Pliocene orogenic-related deposition of alluvium reported for this region (Norris and Webb, 1971) makes transport of originally terrestrial organic matter from this region to the Santa Barbara Channel or seaway likely. Alternate terrestrial sources, which also could have drained via the Soledad-Ventura basins, may include the western central Rockies which lack the Late Cretaceous Mancos shales, sandstones, and coal of the corresponding eastern central region (Spencer, 1962).

Though much of the preceding discussion of possible terrestrial sources for the highly dealkylated copper and nickel ETIO-porphyrins isolated from the upper Miocene through Pliocene strata of the San Miguel Gap sediments (Site 467) is speculation, we feel that such endeavor, and further study, will eventually more properly link these unique porphyrin assemblages and their ultimate sources.

\section{SUMMARY}

Sixteen sediment samples from the San Miguel Gap (Site 467) and 5 sediment samples from the Baja California borderland (Site 471), recovered by DSDP/IPOD Leg 63, were analyzed for tetrapyrrole, carotenoid, and perylene pigments. Relationships among the products of chlorophyll diagenesis-catagenesis, the presence or absence of carotenoids, the alkylation of perylene, in situ thermal regimes, paleoenvironment, and the source, transport, and deposition of organic matter have been forwarded and several salient conclusions listed as follows:

\section{Tetrapyrrole Pigments}

1. Aromatization of phorbides and chlorins, producing free-base porphyrins, was observed to occur throughout a present in situ temperature range of about $15^{\circ} \mathrm{C}$ to $38^{\circ} \mathrm{C}$ (Site 467 ).

2. The first isolation of free-base porphyrins of the ETIO-series, vastly subordinate to the coincident DPEP-series, is reported (Site 467).

3. Chelation, forming nickel porphyrins from freebase precursors, was observed to occur within a temperature range of about $30^{\circ} \mathrm{C}$ to $50^{\circ} \mathrm{C}$ (Sites 467,471 ).

4. Participation of keto-porphyrin acids in the diagenesis of chlorophyll was found (Site 471). That is, with increasing depth of burial and temperature, reduction of the 9-keto group of Ni-phylloerythrin, producing Ni-deoxophylloerythrin, and the subsequent decarboxylation of the latter to form predominately $\mathrm{Ni}$ DPEP-porphyrins is reported as occurring between $25^{\circ} \mathrm{C}$ to $55^{\circ} \mathrm{C}$, using the present thermal profile.

5. The appearance (formation, release?) of higher alkyl homologues of $\mathrm{Ni}$ DPEP and the alternate $\mathrm{Ni}$ DiDPEP and Ni Benz-DPEP series was found in sediments presently at temperatures greater than $50^{\circ} \mathrm{C}$ (Sites $467,471)$.

6. The appearance of vanadyl porphyrins, thought to be related to "cracking" from a bound (asphaltene linked?) state, is reported for only the deepest stratum (Section 467-110-3) from the San Miguel Gap site.

7. Nickel and vanadyl porphyrins, isolated in trace amounts from a shallow Quaternary sediment (Section 467-3-3), were linked to the introduction of reworked material from oil seeps present in the Santa Barbara Channel region.

8. Highly dealkylated copper and nickel ETIO-porphyrins were isolated from both the upper Miocene to Pliocene silty claystones of the San Miguel Gap sample suite (Site 467) and an upper middle Miocene silty claystone from the borderland of Baja California (Site 471). These unique pigments were related to an ultimate terrestrial source, such as coal, on the basis of oxic diagenesis of chlorophyll in peat-coal environments, porphyrin distributions in coals, and decreased pigment preservation within the organic matter of these strata. Speculations were made as to possible terrestrial paleosources for such influx to these marine sediments.

9. Greatly enhanced preservation of tetrapyrrole pigments was found in the Quaternary to upper Pliocene and upper Miocene strata that envelop the upper Miocene to Pliocene section yielding chlorophyll derivatives characteristic of a mixed autochthonous-allochthonous input. These high-yield strata were correlated to the oilproducing shales of mainland basins. On the basis of literature searches and the preservation profile (viz., pigment yield index versus depth-age) obtained for the San Miguel Gap sequence (Site 467), the region of high pigment yield in the upper Miocene appears analogous to the formation of the Luisian-Mohnian Stages of the 
Monterey shales in the Ventura Basin, whereas the uppermost increase in tetrapyrrole fossilization correlates to the upper Pliocene to Pleistocene "Mud-Pit" shales of the same region.

\section{Carotenoid Pigments}

$\beta$-Carotene was isolated only from upper Pliocene to Quaternary diatomaceous silty clays recovered at Site 467 . The presence of carotenoids exactly coincides with enhanced tetrapyrrole pigment preservation in these strata and is taken as indicating anoxic deposition from highly productive waters.

\section{PAH, Perylene}

No specific correlation between perylene and possible terrestrial or other sources was found. The ubiquity of perylene and terrestrial clays in these sediments is noted. However, the straightforward alkylation of perylene, producing $\mathrm{C}-1, \mathrm{C}-2$, and $\mathrm{C}-3$ alkylated perylene homologues, was found to proceed with increased depth of burial for sediments recovered from the San Miguel Gap (Site 467). The temperature regime for the onset and increase of perylene alkylation was calculated as being from about $38^{\circ} \mathrm{C}$ to $58^{\circ} \mathrm{C}$. The alkylation of perylene is suggested as an indicator of geothermal stress to augment the diagenetic-catagenetic alterations of chlorophyll derivatives.

DSDP-IPOD Leg 63 operations provided a suite of sediment samples that has yielded (and will continue to do so) vast amounts of data on the organic geochemistry of tetrapyrrole, carotenoid, and perylene pigments. The extent of these data has only begun to be realized.

\section{ACKNOWLEDGMENTS}

These studies were funded by a grant from the National Science Foundation (\#OCE 7913258) and is gratefully acknowledged. Dr. Mitsugu Nishimura is thanked for the gas chromatographic study of authentic perylene and perylene isolates. The diligent assistance of Ms. Patricia Ottens-Avery during initial sample preparation is sincerely appreciated. Drs. E. H. Man, S. E., Palmer and J. K. Whelan are graciously thanked for their reviews of this manuscript, the size and scope of which was not even imagined when the studies began. We also gratefully acknowledge G. C. Stevens, A. J. Barwise, and E. V. Whitehead of British Petroleum Trading Limited for a research sample of "BP-Silica" and valuable discussion regarding usage of this sample. Last, and foremost, the Deep Sea Drilling Project and associated agencies (JOIDES, JOI, NSF) are to be thanked for obtaining and providing such complete sample suites and accompanying data banks.

\section{REFERENCES}

Aizenshtat, Z., 1973. Perylene and its geochemical significance. Geochim. Cosmochim. Acta, 37:559-567.

Aizenshtat, Z., Dinur, D., and Nissenbaum, A., 1979. Tetrapyrroles and associated compounds in Dead Sea asphalts. Chem. Geo., 24: 161-174.

Alturki, Y. I. A., Eglinton, G., and Pillinger, C. T., 1972. The petroporphyrins of gilsonite. In Gaertner, H. R., and Wehner, H. (Eds.), Advances in Organic Geochemistry-1971: Oxford (Pergamon Press), pp. 135-150.

Baker, E. W., 1966. Mass spectrometric characterization of petroporphyrins. J. Am. Chem. Soc., 88:2311-2315. 1969. "Porphyrins." In Eglinton, G., and Murphy, M. T. J. (Eds.), Organic Geochemistry: Berlin (Springer-Verlag), pp. 464-497.

, 1971. Porphyrins in deep ocean sources. Petroporphyrins from Challenger Knoll oil bearing cores. Chem. Geol., 7:45-49.
Baker, E. W., and Louda, J. W., 1980. Products of Chlorophyll Diagenesis in Japan Trench Sediments. II. DSDP/IPOD Sites 438-439 and 440. In Scientific Party, Init. Repts. DSDP, 56, 57: Washington (U.S. Govt. Printing Office), 1397-1408.

, in preparation. Geochemistry of tetrapyrrole, carotenoid, and perylene pigments in sediments from the Gulf of California, DSDP/IPOD Leg 64.

Baker, E. W., and Palmer, S. E., 1978. Geochemistry of porphyrins. In Dolphin, D. (Ed.), The Porphyrins (Vol. I): New York (Academic Press), pp. 486-552. 1979. Chlorophyll diagenesis in IPOD Leg 47A, Site 397 Core Samples. In von Rad, U., Ryan, W. B. F., et al., Init. Repts. DSDP, 47, Pt. 1: Washington (U.S. Govt. Printing Office), 547-551.

Baker, E. W., Palmer, S. E., and Huang, W. Y., 1977. Intermediate and late diagenetic tetrapyrrole pigments, Leg 41: Cape Verde Rise and Basin. In Lancelot, Y., Seibold, E., et al., Init. Repts. DSDP, 41: Washington (U.S. Govt. Printing Office), 825-837. ,1978a. Early and intermediate chlorophyll diagenesis of Black Sea sediments: Sites 379, 380, and 381. In Ross, D. A., Neprochnov, Y. P., et al., Init. Repts. DSDP, 42, Pt. 2: Washington (U.S. Govt. Printing Office), 707-715.

, 1978b. Chlorin and porphyrin geochemistry of DSDP Leg 40 sediments. In Bolli, H. M., Ryan, W. B. F., et al., Init. Repts. DSDP, 40: Washington (U.S. Govt. Printing Office), 639-647. $1978 \mathrm{c}$. Miocene and Cretaceous tetrapyrrole pigments from Leg 44, Site 391. In Benson, W. E., Sheridan, R. E., et al., Init. Repts. DSDP, 44: Washington (U.S. Govt. Printing Office), 639-643.

Baker, E. W., Palmer, S. E., and Parrish, K. L., 1976. Tetrapyrrole pigments in DSDP Leg 38 sediments. In Talwani, M., Udinstev, G., et al., Init. Repts. DSDP, 38: Washington (U.S. Govt. Printing Office), 785-789.

Baker, E. W., Yen, T. F., Dickie, J. P., et al., 1967. Mass spectrometry of porphyrins. II. Characterization of petroporphyrins. $J$. Am. Chem. Soc., 89:3631-3639.

Barwise, A. J. G., and Whitehead, E. V., 1980. Characterization of vanadium porphyrins in petroleum residues, Am. Chem. Soc. Preprints-Div. Petrol. Chem., 25(2):268-279.

, in press. Separation and Structure of Petroporphyrins. In Maxwell, J. R., and Douglas, A. G. (Eds.), Advances in Organic Geochemistry-1979: Oxford (Pergamon).

Biemann, K., 1962. Mass Spectrometry: New York (McGraw Hill), p. 63.

Blumer, M., 1965. Organic pigments: their long-term fate. Science, 149:722-726.

Blumer, M., and Omenn, G. S., 1961. Fossil porphyrins: uncomplexed chlorins in a Triassic sediment. Geochim. Cosmochim. Acta, 25:81-90.

Bonnett, R., 1978. Nomenclature. In Dolphin, D. (Ed.), The Porphyrins (Vol. I): New York (Academic Press), 2-30.

Bonnett, R., and Czechowski, F., 1980. Gallium porphyrins in bituminous coal. Nature, 283:465-467.

Brassell, S. C., Comet, P. A., Eglinton, G., et al., 1980. Preliminary lipid analysis of Cores 14, 18, and 28 from Hole 416A. In Lancelot, Y., Winterer, E. L., et al., Init. Repts. DSDP, 50: Washington (U.S. Govt. Printing Office), 647-664.

Budzikiewicz, H., 1978. Mass spectra of porphyrins and related compounds. In Dolphin, D. (Ed.), The Porphyrins (Vol. III): New York (Academic Press), 395-461.

Callaway, D. C., 1971. Petroleum potential of San Joaquin Basin, California. In Cram, I. H. (Ed.), Future Petroleum Provinces of the United States-Their Geology and Potential: A.A.P.G. Memoir \#15: Tulsa (Am. Assoc. Petrol. Geol.), pp. 239-253.

Cardoso, J. N., Wardroper, A. M. K., Watts, C. D., et al., 1978. Preliminary organic geochemical analysis, Site 391, Leg 44 of the Deep Sea Drilling Project. In Benson, W. E., Sheridan, R. E., et al., Init. Repts. DSDP, 44: Washington (U.S. Govt. Printing Office), 617-623.

Clar, E., 1964. Polycyclic Hydrocarbons (Vol. 2): London (Academic Press), 24-36.

Curran, J. F., Hall, K. B., and Herron, R. F., 1971. Geology, oil fields, and future petroleum potential of Santa Barbara Channel area, California. In Cram, I. H., (Ed.), Future Petroleum Prov- 
inces of the United States-Their Geology and Potential, A.A.P.G. Memoir \#15: Tulsa (Am. Assoc. Petrol. Geol.), 192211.

Day, W. C., and Erdman, J. G., 1963. Ionene: a thermal degradation product of $\beta$-carotene. Science, 141:808.

Degens, E. T., Williams, E. G., and Keith, M. L., 1957. Environmental studies of carboniferous sediments. Part I: Geochemical criteria for differentiating marine from fresh-water shales. Bull. Am. Assoc. Petrol. Geol., 41:2427-2455.

Demaison, G. J., and Moore, G. T., 1980. Anoxic environments and oil source bed genesis. Am. Assoc. Petrol. Geol. Bull., 64: 1179-1209.

Didyk, B. M., Alturki, Y. I. A., Pillinger, C. T., et al., 1975. Petroporphyrins as indicators of geothermal maturation. Nature, 256 563-565.

Emery, K. O., 1960. The Sea off Southern California: New York (John Wiley and Sons).

Erdman, J. G., Walter, J. W,. and Hanson, W. E., 1957. The stability of the porphyrin metallo complexes. Am. Chem. Soc. Preprints-Div. Petrol. Chem., 2:259-266.

Foppen, D. H., 1971. Tables for the Identification of Carotenoids. Chromatogr. Rev., 14:133-298.

Fox, D. L., 1976. Animal Biochromes and Structural Colours (2nd Ed.): Berkeley (University of California Press).

Fox, D. L., Updegraff, D. M., and Novelli, G. D., 1944. Carotenoid pigments in the ocean floor. Arch. Biochem., 5:1-23.

HajIbrahim, S. K., and Eglinton, G., in press. Petroporphyrin fingerprinting of crude oils: potential application to geochemical problems. In Maxwell, J. R., and Douglas, A. G. (Eds.), Advanced Organic Geochemistry-1979: Oxford (Pergamon).

Hill, M., 1975. Geology of the Sierra Nevada: Berkeley (University of California Press).

Hites, R. A., LaFlamme, R. E., Windsor, J. G., et al., Polycyclic aromatic hydrocarbons in an anoxic sediment core from the Pettaquamscutt River (Rhode Island, U.S.A.). Geochim. Cosmochim. Acta, 44:873-888.

Hodgson, G. W., and Baker, B. L., 1967. Spectra of selected geochemically significant porphyrins and chlorins. Chem. Geol. 2:187-1198.

Hodgson, G. W., Baker, B. L., and Peake, E., 1967. Geochemistry of Porphyrins. In Nagy, B., and Colombo, U. (Eds.), Fundamental Aspects of Petroleum Geochemistry: Amsterdam (Elsevier), pp. $177-260$.

Holt, A. S., 1959. Reduction of chlorophyllides, chlorophylls and chlorophyll derivatives by sodium borohydride. Plant Physiol., 34:310-314

Hunt, J. M., 1979. Petroleum Geochemistry and Geology: San Francisco (W. H. Freeman and Co.).

Hunt, J. M., and Whelan, J. K., 1978a. Dissolved gases in black sea sediments. In Ross, D. A., Neprochnov, Y. P., et al., Init. Repts. DSDP, 42, Pt. 2: Washington (U.S. Govt. Printing Office), 661-665.

, 1978b. Light hydrocarbons in sediments of DSDP Leg 44 Holes. In Benson, W. M., Sheridan, R. E., et al., Init. Repts. $D S D P, 44$ : Washington (U.S. Govt. Printing Office), 651-652.

Jones, I. D., White, R. C., Gibbs, E., et al., 1968. Absorption spectra of copper and zinc complexes of pheophytins and pheophorbides. J. Agric. Food Chem., 16:80-83.

Kerr, R. A., 1980. Changing global sea levels as a geologic index. Science, 209:483-486.

Kimble, B. J., Maxwell, J. R., Philip, R. P., et al., 1974. Tri- and tetra-terpenoid hydrocarbons in Messel Oil Shale. Geochim. Cosmochim. Acta, 38:1165-1181.

Krinsky, N. I., 1963. A relationship between partition coefficients of carotenoids and their functional groups. Anal. Biochem., 6:293302.

Liaaen-Jensen, S., 1978. Marine Carotenoids. In Scheuer, P. J. (Ed.), Marine Natural Products (Vol. II): New York (Academic Press), $1-73$.

Louda, J. W., and Baker, E. W., 1980. Incorporation of the various chlorophylls into marine sediments and terrestrial peats. 179th Na- tional A.C.S. Meeting, Division of Geochemistry, Houston, Texas, March 23-28, 1980. Abstracts.

Louda, J. W., Palmer, S. E., and Baker, E. W., 1980. Products of chlorophyll 435, and 436. In Scientific Party, Init. Repts. DSDP, 56, 57, Pt. 1: Washington (U.S. Govt. Printing Office), 13911396.

MacKenzie, A. S. Quirke, J. M. E., and Maxwell, J. R., in press. Molecular parameters of maturation in the Toarcian Shales, Paris Basin, France. II. Evolution of metalloporphyrins. In Maxwell, J. R., and Douglas, A. G. (Eds.), Advances in Organic Geochemistry-1979: Oxford (Pergamon).

Murphy, M. T. J., McCormick, A., and Eglinton, G., 1967. Perhydro- $\beta$-carotene in the Green River Shale. Science, 157:10401042.

Nagle, H. E., and Parker, E. S., 1971. Future oil and gas potential of onshore Ventura Basin, California. In Cram, I. H. (Ed.), Future Petroleum Provinces of the United States-Their Geology and Potential, A.A.P.G. Memoir \#15: Tulsa (Am. Assoc. Petrol. Geol.), pp. 254-297.

Norris, R. M., and Webb, R. W., 1971. Geology of California: New York (John Wiley and Sons).

Palmer, S. E., 1979. Porphyrins in sub-bituminous and bituminous coals. AAPG-SEPM Annual Meeting, Houston, Texas, April 1-4, 1979. A.A.P.G. Stud. Geol. Bull., 63:507. (Abstract)

Palmer, S. E., and Baker, E. W., 1978. Copper porphyrins in deepsea sediments: a possible indicator of oxidized terrestrial organic matter. Science, 201:49-51.

1979. Tetrapyrrole pigments from IPOD Leg 47B, Hole 398D. In Ryan, W. B. F., Sibuet, J.-C., e al., Init. Repts. DSDP, 47, Pt. 2: Washington (U.S. Govt. Printing Office), 571-575.

1980. Nickel porphyrins from Deep Sea Drilling Project Sites 415 and 416. In Lancelot, Y., Winterer, E. L., et al., Init. Repts. DSDP, 50: Washington (U.S. Govt. Printing Office), 643-645.

Palmer, S. E., Charney, L., and Baker, E. W., 1980. The Porphyrins of United States humic coals. 179th National A.C.S. Meeting, Division of Geochemistry, Houston, Texas, March 23-28, 1980. Abstracts.

Palmer, S. E., Huang, W. Y., and Baker, E. W., 1979. Tetrapyrrole pigments from the Bermuda Rise: DSDP Leg 43. In Tucholke, B. E., Vogt, P. R., et al., Init. Repts. DSDP, 43: Washington (U.S. Govt. Printing Office), 657-661.

Quirke, J. M. E., Eglinton, G., and Maxwell, J. R., 1979. Petroporphyrins. 1. A preliminary characterization of the porphyrins of gilsonite. J. Am. Chem. Soc., 101(26):7693-7697.

Schwendinger, R. B., and Erdman, J. G., 1963. Carotenoids in sediments as a function of environment. Science, 141:808-810.

Seely, G. R., 1966. The structure and chemistry of functional groups. In Vernon, L. P., and Seely, G. R. (Eds.), The Chlorophylls: New York (Academic Press), pp. 67-110.

Simoneit, B. R. T., 1978. Organic geochemistry of terrigenous muds and various shales from the Black Sea, DSDP Leg 42B. In Ross, D. A., Neprochnov, Y. P., et al., Init. Repts. DSDP, 42, Pt. 2: Washington (U.S. Govt. Printing Office), 749-753.

Spencer, E. H., 1962. Basic Concepts of Historical Geology: New York (T. Y. Crowell).

Sugihara, J. M., and McGee, L. R., 1957. Porphyrins in gilsonite. $J$. Org. Chem., 22:795.

Tissot, B. P., and Welte, D. H., 1978. Petroleum Formation and Occurrence: Berlin (Springer-Verlag).

Thomson, R. H., 1965. Quinones: nature, distribution and biosynthesis. In Goodwin, T. W. (Ed.), Chemistry and Biochemistry of Plant Pigments: London (Academic Press), pp. 309-332.

Treibs, A., 1935a. Organic mineral substances. IV. Chlorophyll and hemin derivatives in bituminous rocks, petroleums, coals, and phosphorites. Ann. Chem., 517:172-196.

, 1935b. Porphyrins in coal. Ann. Chem., 520:144-151.

1936. Chlorophyll and hemin derivatives in organic mineral substances. Angew. Chem. 49:682-686.

Vallentyne, J. R., 1956. Epiphasic carotenoids in post-glacial lake sediments. Limnol. Oceanogr. 1:252-262. 
Vetter, W., Englert, G., Rigassi, N., et al., 1971. Spectroscopic Methods. In Isler, O. (Ed.), Carotenoids: Basle (Birkhauser Verlag), 189-266.

von Rad, U., Ryan, W. B. F., et al., 1979. Site 397A. In von Rad, U., Ryan, W. B. F., et al., Init. Repts. DSDP, 47, Pt. 1: Washington (U.S. Govt. Printing Office), 17-218.

Wakeham, S. G., Schaffner, C., Giger, W., et al., 1979. Perylene in sediments from the Nambian Shelf. Geochim. Cosmochim. Acta, 43:1141-1144.
Watts, C. D., and Maxwell, J. R., 1977. Carotenoid diagenesis in a marine sediment. Geochim. Cosmochim. Acta, 41:493-497.

Yen, T. F., Boucher, L. J., and Dickie, J. P., 1969. Vanadium complexes and porphyrins in asphaltenes. J. Inst. Pet. 55:87-99.

Zechmeister, L., 1958. Some in vitro conversions of naturally occurring carotenoids. In Zechmeister, L. (Ed.), Progress in the Chemistry of Organic Natural Products (Vol. 15): New York (Springer), 31-82.

APPENDIX

Calculated Nominal Mass Series of Free-Base and Metalloporphyrins Characteristic of Marine Sediments and Bitumens

\begin{tabular}{|c|c|c|c|c|c|c|c|c|c|}
\hline $\begin{array}{l}\text { Carbon } \\
\text { Number }\end{array}$ & $\begin{array}{c}\text { Free-Base } \\
\text { DPEPa/ETIO }\end{array}$ & $\begin{array}{l}\text { Nickel }(58)^{\mathrm{b}} \\
\text { DPEP/ETIO }\end{array}$ & $\begin{array}{l}\text { Copper }(63)^{\mathrm{c}} \\
\text { DPEP/ETIO }\end{array}$ & $\begin{array}{l}\text { Vanadyl }(67)^{\mathrm{d}} \\
\text { DPEP/ETIO }\end{array}$ & $\begin{array}{l}\text { Di-DI } \\
\text { Nickel }\end{array}$ & $\begin{array}{l}\text { EP } \\
\text { Vanadyl }\end{array}$ & $\begin{array}{c}\text { Nickel }^{\mathrm{f}} \\
\text { Benz-DPEP/ETIO }\end{array}$ & $\begin{array}{c}\text { Vanadyl }^{\mathrm{f}} \\
\text { Benz-DPEP/ETIO }\end{array}$ & $\begin{array}{l}\text { Calculatedg } \\
(\mathrm{M}+2)^{+}\end{array}$ \\
\hline 20 & $-/ 310$ & $-/ 366$ & $-/ 371$ & $-/ 375$ & - & - & - & - & 0.024 \\
\hline 21 & $-/ 324$ & $-/ 380$ & $-/ 385$ & $-/ 389$ & - & - & - & - & 0.027 \\
\hline 22 & $336 / 338$ & $392 / 394$ & $397 / 399$ & $401 / 403$ & - & - & - & - & 0.029 \\
\hline 23 & $350 / 352$ & $406 / 408$ & $411 / 413$ & $415 / 417$ & - & - & - & - & 0.032 \\
\hline 24 & $364 / 366$ & $420 / 422$ & $425 / 427$ & $429 / 431$ & 418 & 427 & $-/ 416$ & $-/ 425$ & 0.035 \\
\hline 25 & $378 / 380$ & $434 / 436$ & $439 / 441$ & $443 / 445$ & 432 & 441 & $-/ 430$ & $-/ 439$ & 0.038 \\
\hline 26 & $392 / 394$ & $448 / 450$ & $453 / 455$ & $457 / 459$ & 446 & 455 & $442 / 442$ & $451 / 453$ & 0.041 \\
\hline 27 & $406 / 408$ & $462 / 464$ & $467 / 469$ & $471 / 473$ & 460 & 469 & $456 / 458$ & $465 / 467$ & 0.044 \\
\hline 28 & $420 / 422$ & $476 / 478$ & $481 / 483$ & $485 / 487$ & 474 & 483 & $470 / 472$ & $479 / 481$ & 0.047 \\
\hline 29 & $434 / 436$ & $490 / 492$ & $495 / 497$ & $499 / 501$ & 488 & 497 & $484 / 486$ & $493 / 495$ & 0.051 \\
\hline 30 & $448 / 450$ & $504 / 506$ & $509 / 511$ & $513 / 515$ & 502 & 511 & $498 / 500$ & $507 / 509$ & 0.054 \\
\hline 31 & $462 / 464$ & $518 / 520$ & $523 / 525$ & $527 / 529$ & 516 & 525 & $512 / 514$ & $521 / 523$ & 0.058 \\
\hline 32 & $476 / 478$ & $532 / 534$ & $537 / 539$ & $541 / 543$ & 530 & 539 & $526 / 528$ & $535 / 537$ & 0.062 \\
\hline 33 & $490 / 492$ & $546 / 548$ & - & $555 / 557$ & 544 & 553 & $540 / 542$ & $549 / 551$ & 0.066 \\
\hline 34 & $504 / 506$ & $560 / 562$ & - & $569 / 571$ & 558 & 567 & $554 / 556$ & $563 / 565$ & 0.070 \\
\hline 35 & - & $574 / 576$ & - & $583 / 585$ & 572 & 581 & $568 / 570$ & $577 / 579$ & 0.074 \\
\hline 36 & - & $588 / 590$ & - & $597 / 599$ & 586 & 595 & $582 / 584$ & $591 / 593$ & 0.078 \\
\hline 37 & - & - & - & $611 / 613$ & - & 609 & - & $605 / 607$ & 0.083 \\
\hline 38 & - & - & - & $625 / 627$ & - & 623 & - & $619 / 621$ & 0.087 \\
\hline 39 & - & - & - & $639 / 641$ & - & 637 & - & $633 / 635$ & 0.092 \\
\hline 40 & - & - & - & $653 / 655$ & - & 651 & - & $647 / 649$ & 0.097 \\
\hline 41 & - & - & - & $667 / 669$ & - & 665 & - & $661 / 663$ & 0.102 \\
\hline 42 & - & - & - & $681 / 683$ & - & 679 & - & $675 / 677$ & 0.107 \\
\hline 43 & - & - & - & $695 / 697$ & - & 693 & - & $689 / 691$ & 0.112 \\
\hline 44 & - & - & - & $709 / 711$ & - & 707 & - & $703 / 705$ & 0.117 \\
\hline 45 & - & - & - & $723 / 725$ & - & 721 & - & $717 / 719$ & 0.123 \\
\hline 46 & - & - & - & $737 / 739$ & - & 735 & - & $731 / 733$ & 0.128 \\
\hline 47 & - & - & - & $751 / 753$ & - & 749 & - & $745 / 747$ & 0.134 \\
\hline 48 & - & - & - & $765 / 767$ & - & 763 & - & $759 / 761$ & 0.139 \\
\hline 49 & - & - & - & $779 / 781$ & - & 777 & - & $773 / 775$ & 0.145 \\
\hline 50 & - & - & - & $739 / 795$ & - & 791 & - & $787 / 789$ & 0.151 \\
\hline
\end{tabular}

Note: Cut off points determined by (1) structural impossibilities and (2) the range, plus two homologues, of observed natural isolates (except vanadyl, upper limit not now known-C-50, C-60, ?).

a Lowest of DPEP series is obviously C-22, because the presence of the $6, \gamma$-cycloethano-bridge is prerequisite for this series. C-20 ETIO equals porphin.

b Molecular weight given is for Ni-58. Nickel exists as a penta-isotopic series (Ni-58, 67.8\%; Ni-60, 26.2\%; Ni-61, 3.6\%; and Ni-64, $1.2 \%)$. Only Ni-58 and

$\mathrm{Ni}-60$ are therefore significant (i.e., Ni-60 $=38.6 \% \mathrm{Ni}-58$ ). Correction of Ni-58 ETIO is thus made by subtraction of $0.386 \times \mathrm{Ni}-58 \mathrm{DPEP}$, if present.

$\mathrm{c}$ Molecular weight given is for $\mathrm{Cu}-63$. Copper exists as a bi-isotopic pair [Cu-63,69.1\%, $\mathrm{Cu}-65,30.9 \%]$, both being significant (i.e., $\mathrm{Cu}-65=44.7 \%$ Cu-63)

Correction of Cu-63 ETIO is thus made by subtraction of $0.447 \times \mathrm{Cu}-63$ DPEP, if present. (Note: copper DPEP is very rare.)

$\mathrm{d}$ Vanadyl, the radical $(\mathrm{V}=\mathrm{O})$, composed of vanadium and oxygen (both essentially monoisotopic), requires no correction for isotopic overlap due to the chelated species.

e Proposed Di-DPEP structure contains two cycloethano groups. Note also that this series is identical in nominal mass to possible dihydro-benzporphyrin series as well as to the corresponding benz-ETIO chelates.

f Benz-porphyrins, of either DPEP or ETIO parent structure, contain a four-carbon moiety fused to $\beta, \beta$-pyrrole carbons with completion of aromaticity in the resultant six-membered ring (cf., Baker et al. 1967; Barwise and Whitehead, in press).

$\mathrm{g}$ Calculated value for theoretical relationship of $(\mathrm{M}+2)^{+}$to $\mathrm{M}^{+}$(i.e., contribution of $2-{ }^{13} \mathrm{C}, 2-{ }^{2} \mathrm{H}$, or $\left.{ }^{13} \mathrm{C}+{ }^{2} \mathrm{H}\right)$, according to the formula: $(\mathrm{M}+2)^{+}=$ $\left(1.10 \times\right.$ number $\mathrm{CH}$ groups) ${ }^{2} \div 200$ (after Biemann, 1962). 